\title{
PLUTONIUM VULNERABILITY MANAGEMENT PLAN
}

for the

\section{ENVIRONMENTAL, SAFETY AND HEALTH \\ VULNERABILITIES ASSOCIATED WITH THE \\ DEPARTMENT'S PLUTONIUM STORAGE}

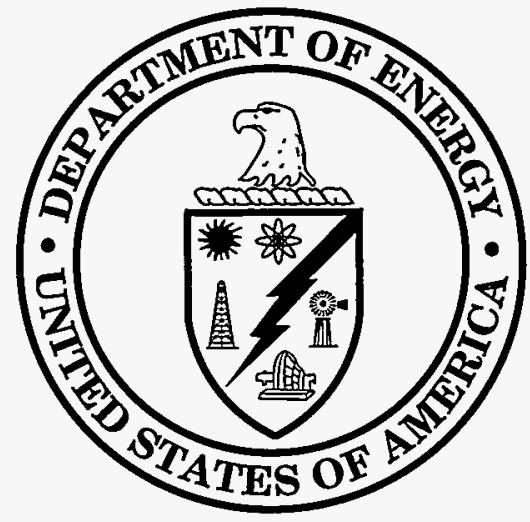

U.S. DEPARTMENT OF ENERGY MARCH 1995 

-

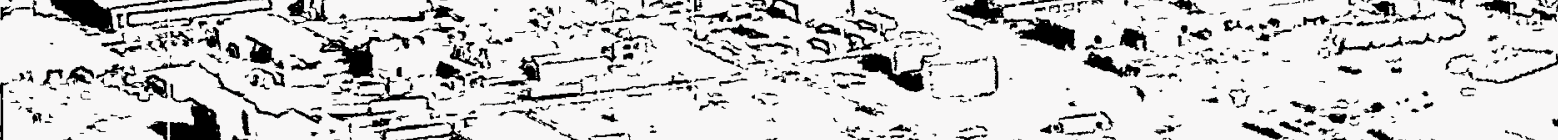

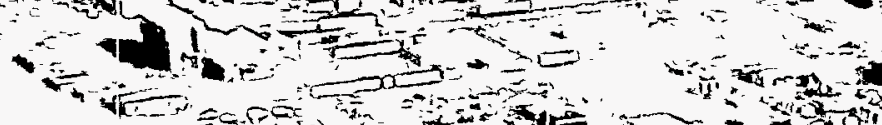

1. In

$\therefore 2$

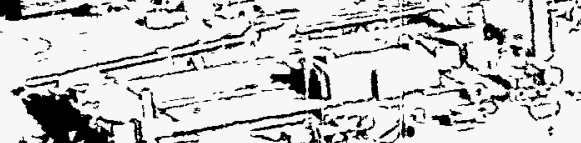
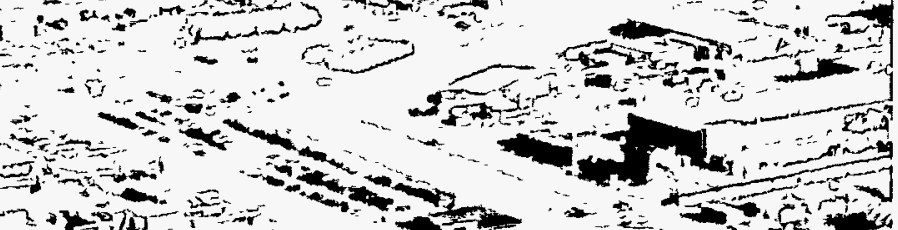


\section{DISCLAIMER}

This report was prepared as an account of work sponsored by an agency of the United States Government. Neither the United States Government nor any agency thereof, nor any of their employees, make any warranty, express or implied, or assumes any legal liability or responsibility for the accuracy, completeness, or usefulness of any information, apparatus, product, or process disclosed, or represents that its use would not infringe privately owned rights. Reference herein to any specific commercial product, process, or service by trade name, trademark, manufacturer, or otherwise does not necessarily constitute or imply its endorsement, recommendation, or favoring by the United States Government or any agency thereof. The views and opinions of authors expressed herein do not necessarily state or reflect those of the United States Government or any agency thereof. 


\section{DISCLAIMER}

Portions of this document may be illegible in electronic image products. Images are produced from the best available original document. 


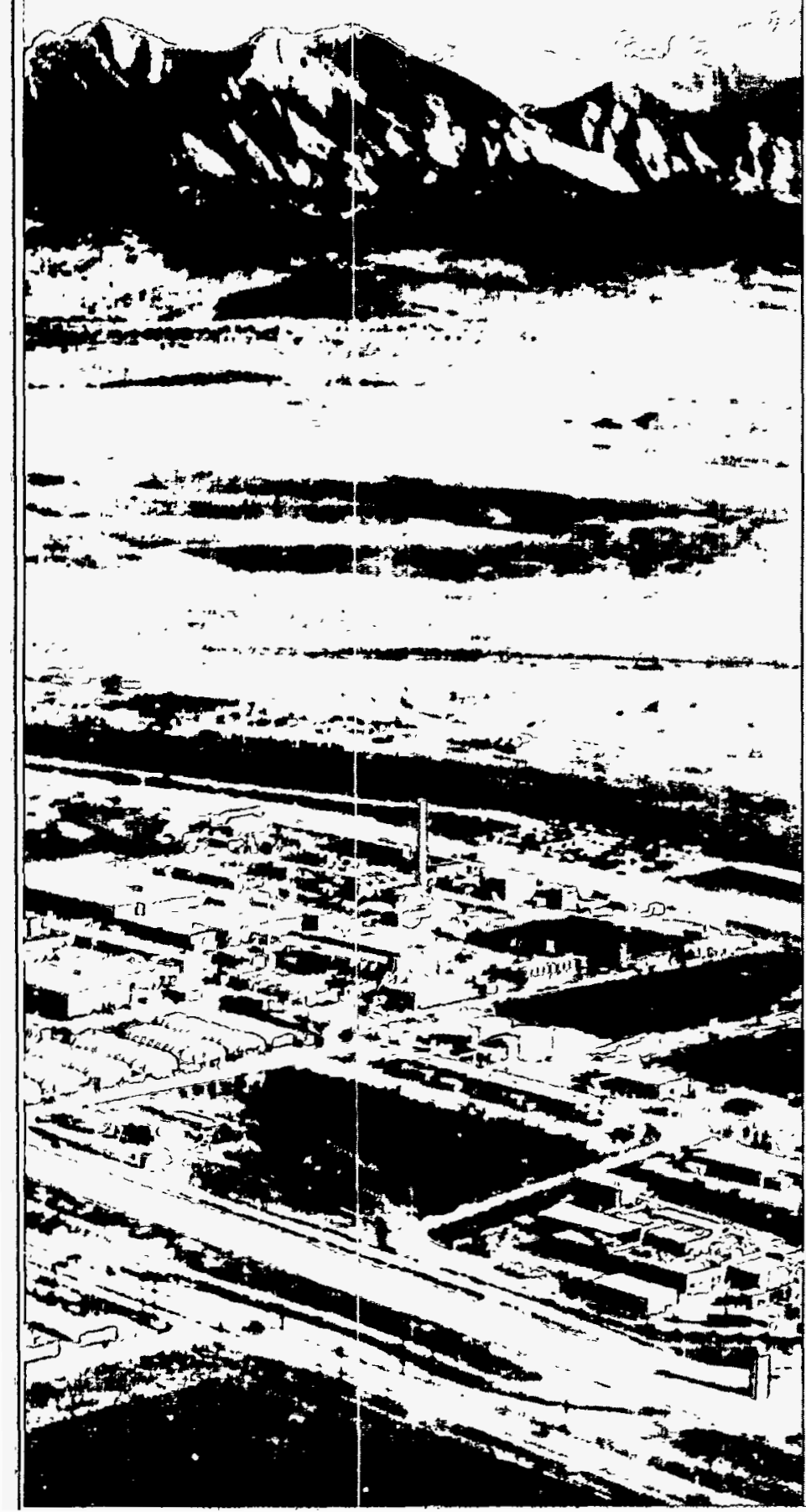

On March 15, 1994, Energy Secretary Hazel O'Leary directed the Office of Environment, Safety and Health to conduct the Plutonium Environment, Safety and Health Vulnerability Assessment. The assessment was performed by a Working Group that included representatives from the Department's program and field offices and from site contractors. Members of the public also participated. This report, the Plutonium Vulnerability Management Plan, describes the Department of Energy's response to the vulnerabilities identified in the Plutonium Working Group Report on Environmental, Safety and Health Vulnerabilities Associated with the Department's Plutonium Storage (Plutonium Working Group Report, DOE/EH-0415).

The Working Group identified 299 vulnerabilities involving the packaging, facility conditions or institutional controls used to protect the 1) workers, 2) public or 3) environment from radiation exposure or contamination from plutonium. This report discusses the corrective actions for the 46 most significant vulnerabilities in each of those three classes and the institutional vulnerabilities.

The Department has not waited for the findings of the Working Group to act on the problems which the Department is facing as a result of the cessation of nuclear weapons production. Nor were most of the Working Group findings unknown to the Department.

The most egregious problems noted in the Plutonium Working Group Report, such as bulging or ruptured containers and leaking pipes, were corrected within a short time of their discovery by onsite personnel.

Work is ongoing to correct the 46 vulnerabilities noted in the Working Group Summary as most significant to the worker, the public or the environment.

Almost 30 percent of the actions listed in this report to correct the 46 significant vulnerabilities have been completed.

Solidification of plutonium liquids has begun at Rocky Flats and at Savannah River. Within three years, we expect that the majority of the plutonium liquids will be solidified. 
Repackaging plutonium metal where it is in contact with plastic, a potential fire hazard, is in progress and will be completed by October 1995 .

The responses contained in this document are part of an overall, coordinated approach to accelerate conversion of all fissile materials, including plutonium, to forms suitable for safe, interim storage. Site Integrated Stabilization Management Plans are being prepared which document the activities for each nuclear material at each site to complete our conversion effort. These Site management plans will include actions necessary to correct all of the 299 vulnerabilities noted in the Plutonium Working Group Report and will be developed in cooperation with interested members of the public. The Department will prepare a summary of the actions in the Site management plans on the 299 plutonium vulnerabilities and issue it in July 1995.

The Plutonium Working Group Report also identifies the 14 most vulnerable facilities and lists them in order of priority. The priority order was based on the nature and extent of the vulnerabilities at a facility, their potential consequences, and the inventory of various forms of plutonium. Following is a description and a table of actions that are being taken relative to those facilities considered "most vulnerable".

Rocky Flats Buildings 771 and 776 were rated as most vulnerable by the Working Group.

Building 771 contains plutonium liquids in bottles and tanks, which poses risk of leakage. Building 776 contains plutonium solids in contact with plastic, which can result in generation of flammable hydrogen gas, and reactive scrap/residues in drums. Plutonium is also contained in smaller quantities in ventilation ducts and gloveboxes which were in use when these buildings were used for nuclear weapons production, and these buildings, as were many throughout the DOE Complex, were built in the 1950 s and do not meet current building codes or standards, including current requirements for resisting high winds and earthquakes.

The Department intends to solve these problems by converting the plutonium liquids into storable solids and moving the solids to new storage vaults being constructed in Building 371. Building 371 is intended for this use because it is the most seismically resistant building on the Rocky Flats site.
Solidification of liquids in Building 771 has been underway for the last year. Several hundred bottles of liquids have been solidified and several tanks have been drained. However, the facility was recently shutdown following serious conduct-of-operations violations and is currently undergoing a rigorous review to ensure that problems are corrected before restart is permitted. The solidification process takes time and considerable effort by experienced people. Deliberate steps are being taken to ensure that the process is done carefully, to proper procedures, to maximize safery for both the worker and the public during draining and solidification. We estimate that the process will be completed within another 3 years.

Buildings 771 and 776 also contain plutonium metal and oxides. Some of it is not packaged properly for long-term storage. By September 1997 and June 1998, respectively, this material will be stabilized and repackaged as necessary and removed to the new storage vaults being constructed in Building 371 .

Several actions have been underway over the past eighteen months to reduce the risk to the workers while preparing to remove the stored materials to Building 371. They include filtered venting of thousands of drums of material so that flammable hydrogen gas cannot accumulate and cause a potential fire or radioactive contamination hazard, and repackaging plutonium metal so that it is not in direct contact with plastic, which will remove this source of hydrogen. Both of these actions will be completed by October 1995 .

These actions will reduce the risk represented by the stored plutonium and eliminate most of the identified vulnerabilities. Some contamination will remain in ventilation ducts and gloveboxes. Complete decontamination will eventually be accomplished, but since the risk is low to both the public and the workers, this has a lower priority.

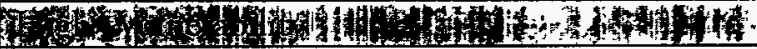

Seven facilities were rated as "high" vulnerability by the Working Group. These included three at Savannah River Site (Building 235-F, FB-Line and Old HB-Line), one at Hanford (Plutonium Finishing Plant) and three at Rocky Flats (Buildings 707, 779 and 371). Concerns were driven by the fact that these facilities contain plutonium in liquids, reactive material in packaging inappropriate for long-term storage, 
holdup in building systems and, at Building 371, plutonium in contact with plastic.

As with much other material left from the weapons program the plutonium at Hanford's Plutonium Finishing Plant is not in a form suitable for long-term storage. Actions are underway now to vent containers to prevent pressure buildup and to repackage the plutonium nitrate liquids to eliminate the problem of storage in potentially embrittled containers. This effort will be completed in 1995. An Environmental Impact Statement (EIS) has been under preparation for 12 months on an expedited basis to evaluate the alternatives for long-term stabilization of the liquids and reactive materials. It will be issued for public comment in August 1995.

Removal of plutonium residue from building systems will not be complete until final decontamination and decommissioning of the facilities, which will take years to complete. In the interim, the potential for release of contamination to the environment is low because the nuclear materials located within these facilities are safely contained and because all exhaust air leaving the facilities is filtered.

As noted above for the "highest" vulnerabilities, all plutonium metal in direct contact with plastic will be repackaged to eliminate this condition by October 1995.

\section{"Moderately High" Vulnerability}

The last group of most vulnerable facilities comprise Savannah River Sites' F- and H-Canyons, Hanford Retired Facilities and two buildings at Los Alamos National Laboratory and Lawrence Livermore National Laboratory. F-Canyon and one of the buildings at Los Alamos (TA-55) recently underwent rigorous operational readiness reviews to identify and correct deficiencies. The Working Group notes that these facilities have fewer significant vulnerabilities than those noted above but that they are included because they store large amounts of plutonium as either liquids or reactive materials or that they contain radioactive contamination in areas with structural and other concerns and where plutonium contamination might be inadvertently released.

The Department is giving high priority to stabilizing plutonium liquids, including those in $\mathrm{F}$ - and $\mathrm{H}$ Canyons, and repackaging reactive materials into forms suitable for long-term storage. With liquids there is obviously a risk of leakage and release to the environment significantly higher than for properlystored solid material. The Department has been working on this by preparing and soliciting public comment on an EIS and, for the past four years, readying FCanyon and FB-Line at Savannah River for operation should that be the alternative selected to solidify the plutonium liquids. An intensive review of FB-Line is currently underway to ensure that all deficiencies identified by the Working Group and others are corrected.

Processing of the plutonium liquids in F-Canyon has begun, and they will be solidified and in a form suitable for storage by early 1996.

DOE will also remove radioactive contamination from the Department's shutdown facilities as part of the Decontamination and Decommissioning process, but, while important, these activities generally have a lower priority than stabilizing liquids and reactive solids unless there is a significant potential to affect the Department's workers or the public. One case where workers are potentially affected is in some offices at Hanford which are located in retired facilities where there may be contamination under the paint. Personnel are being moved out of those offices on an expedited basis.

The cessation of nuclear weapons production has dramatically altered the landscape of the Environmental Management Program. The identification of vulnerabilities and the actions to correct these vulnerabilities represent a significant addition to our cleanup program during the last eighteen months. Well over a billion dollars a year will be devoted to safely characterizing and storing this material pending ultimate disposition.

In summary, $\mathrm{DOE}$ is working vigorously on the problems discussed in the Plutonium Working Group Report. Many actions have been completed but much remains to be done. The job of cleaning up the legacy of fifty years of nuclear weapons production is a difficult, complicated one which will take many years to complete, but we will complete it-safely-for the public and for our workers.

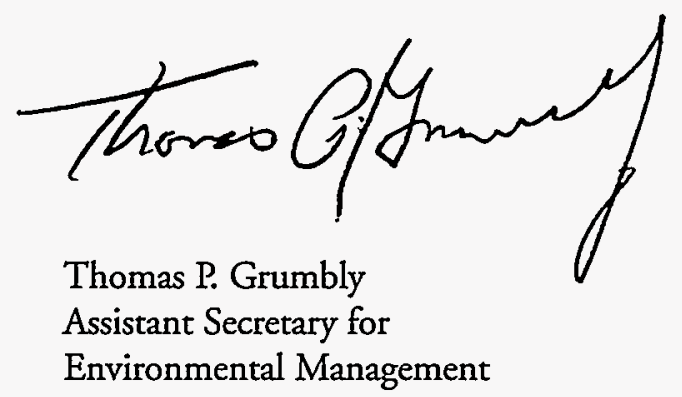




\section{FACILITY VULNERABILITY}

\section{CORRECTIVE ACTION}

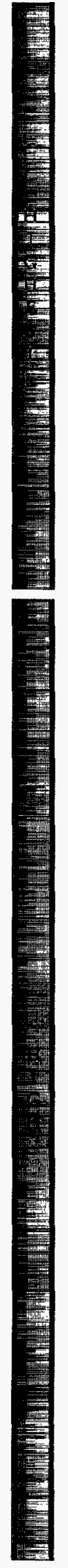

Plutonium in forms and packaging or containers which pose hazards. Liquids which could leak, plutonium in contact with plastic and reactive scrap/residues in drums.

Both buildings have structural deficiencies. Safety equipment in Building 771 could fail during an earthquake and the walls of Building 776 could fail during an earthquake or very high winds.
Interim measures to protect the workers are completed. These include venting the bottles with plutonium liquids and placing them in shielded gloveboxes, restricting access, alarm systems, and spill and leak contingency plans.

Solidification of liquids has been underway for the last year; 385 bottles have been solidified to date and four tanks have been drained. Under the present schedule, all liquids will be solidified by December 1997.

For residues, some of which are reactive, action plans and technical justification for safe storage criteria will be completed by April 1995. Filtered vents will be installed on the remaining drums to prevent buildup of hydrogen gas by October 1995.

Repackaging of plutonium metal to remove plastic is underway and will be completed by October 1995.

By September 1997 for Building 771 and June 1998 for Building 776, all plutonium metals and oxides will be stabilized and repackaged as necessary and relocated to new storage vaults being constructed in Building 371, the most seismic resistant building on site.

These vulnerabilities are associated with aging facilities and plutonium accumulation. The final corrective action is decontamination and decommissioning of the facilities. In the interim, potential for release of contamination is low because the material is safely contained and the air leaving the building passes. through a High Efficiency Air Filter System. Surveillance, monitoring, access control and safety controls will be continued.

Interim measures taken almost a year ago to reduce the risk to workers will remain in effect. The liquids are stored in vault-type rooms with restricted access; sludges are being stabilized to reduce the need for working with the material in gloveboxes; air is exhausted through multiple filter stages to protect on-site workers and the public.

An Environmental Impact Statement to determine the preferred method of stabilizing liquids and reactive materials at Hanford has been underway for one year and will be issued for public comment in August 1995.

DOE issued the standard for safe interim storage of plutonium metal and oxides in December 1994. A characterization plan to determine suitability of plutonium for interim storage will be developed by March 1995 and implemented in FY95 and FY96.

The plutonium nitrate containers that may not be properly vented to prevent hydrogen gas buildup will be vented by December 1995 .

Another 30 containers of plutonium chloride and fluoride liquids, if they leaked, could damage the outer container. They will be repackaged by December 1995. 


\section{MOST VULNERABLE FACILITIES}

\section{FACILITY VULNERABILITY CORRECTIVE ACTION}

\begin{tabular}{|c|c|c|}
\hline $\begin{array}{l}\text { Rocky Flats } \\
\text { B-779 } \\
\text { B-707 } \\
\text { B-371 }\end{array}$ & $\begin{array}{l}\text { Plutonium in liquids, } \\
\text { reactive materials in } \\
\text { inappropriate packaging, } \\
\text { radioactive contamination } \\
\text { and holdup. } \\
\text { Packages of plutonium in } \\
\text { contact with plastic. } \\
\text { Seismic and safety system } \\
\text { concerns. }\end{array}$ & $\begin{array}{l}\text { Interim measures to protect the workers are completed. These include venting the bot- } \\
\text { tles with plutonium liquids and placing them in shielded gloveboxes, restricting access, } \\
\text { alarm systems, and spill and leak contingency plans. } \\
\text { For residues, some of which are reactive, action plans and technical justification for safe } \\
\text { storage criteria will be completed by April } 1995 \text {. Filtered vents will be installed on the } \\
\text { remaining drums to prevent buildup of hydrogen gas. } \\
\text { Repackaging of plutonium metal to remove plastic is underway and will be completed } \\
\text { by October } 1995 \text {. } \\
\text { By December } 1996 \text { for Building } 779 \text { and March } 2001 \text { for Building } 707 \text {, all plutonium } \\
\text { metals and oxides will be stabilized and repackaged as necessary and will be moved to } \\
\text { new storage vaults being constructed in Building } 371 \text {, the most seismic resistant build- } \\
\text { ing on site. }\end{array}$ \\
\hline
\end{tabular}

Savannah River Storage of large amounts of F-Canyon plutonium materials in liquid H-Canyon form.

DOE is giving high priority to stabilization of these materials. F-Canyon has just completed rigorous operational readiness reviews to identify and correct problems.

Processing of plutonium liquids in F-Canyon started February 1995. The F-Canyon plutonium stabilization will be completed in 1996.

A draft Environmental Impact Statement for plutonium liquids in H-Canyon is under preparation for public comment and a ROD is expected in May 1995. If processing is selected in the ROD, the H-Canyon plutonium-242 liquids will be stabilized by the end of 1997 and the H-Canyon plutonium-239 liquids by early 2000 .

$\begin{array}{ll}\text { Hanford } & \text { Presence of radioactive } \\ \text { Retired } & \text { contamination and holdup } \\ \text { Facilities } & \text { in areas with structural, } \\ & \text { safety system and } \\ & \text { occupancy concerns. }\end{array}$

The principal concern with these vulnerabilities is continuing use for office space in areas which may have painted over contamination. The offices in Building 231-Z will be closed in March 1995 and any other identified office spaces closed by December 1995. In the interim, workers in these buildings have been advised of precautionary measures to prevent inadvertent contamination.

These vulnerabilities will be completely resolved when these facilities are decontaminated and decommissioned but this has a lower priority than the other actions underway.

$\begin{array}{lll}\text { Los Alamos } & \text { Storage of plutonium } & \text { This material will be examined and repackaged as necessary. Plutonium metal and } \\ \text { National } & \text { materials in reactive forms. } & \begin{array}{l}\text { oxides will be repackaged to the DOE standard to be issued in December 1994. An } \\ \text { implementation plan will be completed in March 1995. }\end{array}\end{array}$
TA-55

The recently discovered eight bulged containers of plutonium ash were repackaged and

Lawrence Storage of plutonium Livermore materials in reactive forms. National Laboratory Building 332 all 108 containers of plutonium ash are now stored in vented and filtered overpacks in the vault to minimize further problems.

Characterization of the uncharacterized plutonium materials and packaging is underway. Action plans will be established for safe long term storage by December 1995 .

In the interim, compensatory measures are in place to minimize the hazard to workers. These include bi-monthly inspection of containers and repackaging if necessary. Respiratory protection is required. 


\section{TABLE OF CONTENTS}

BACKGROUND: ENVIRONMENT, SAFETY AND HEALTH PLUTONIUM
VULNERABILITY ASSESSMENT $\quad \ldots \ldots \ldots \ldots \ldots \ldots \ldots \ldots \ldots \ldots \ldots \ldots \ldots \ldots \ldots \ldots$

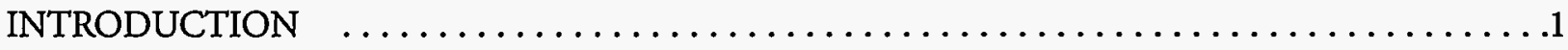

Response to Significant Conclusions from the Working Group Report $\ldots \ldots \ldots \ldots \ldots \ldots \ldots . \ldots 2$

Defense Nuclear Facilities Safety Board Recommendation $94-1 \quad \ldots \ldots \ldots \ldots \ldots \ldots \ldots \ldots \ldots$

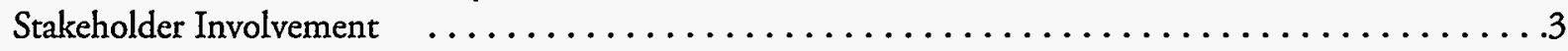

MANAGEMENT PROCESS $\quad \ldots \ldots \ldots \ldots \ldots \ldots \ldots \ldots \ldots \ldots \ldots \ldots \ldots \ldots \ldots \ldots \ldots \ldots$

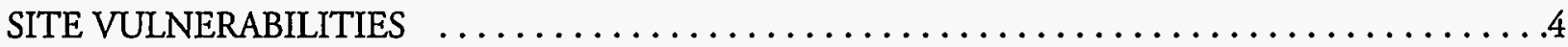

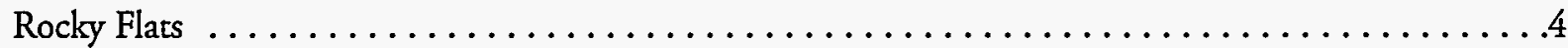

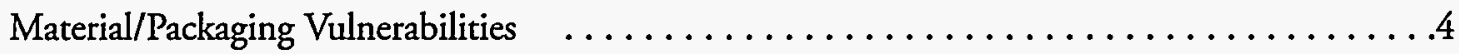

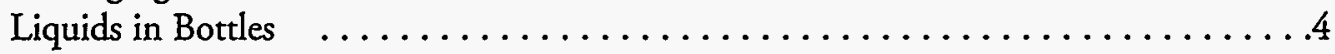

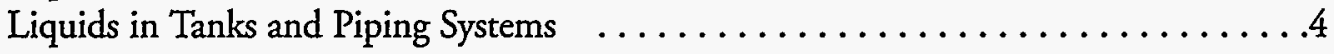

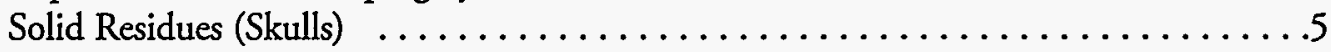

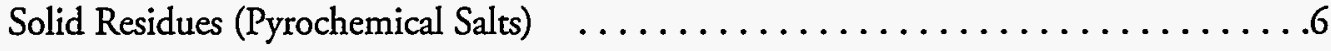

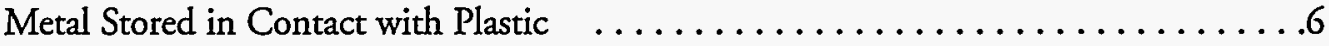

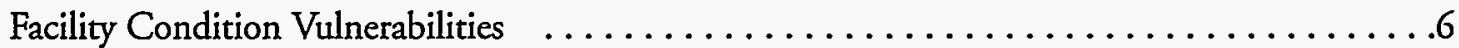

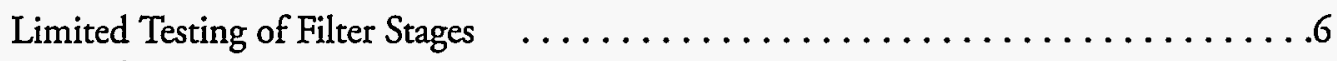

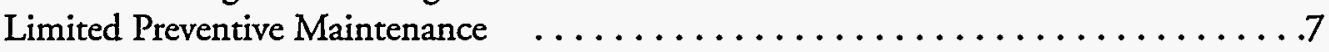

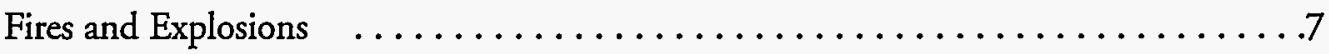

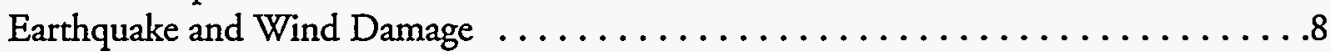

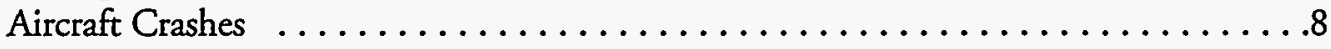

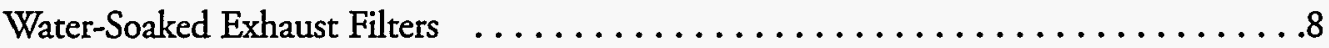

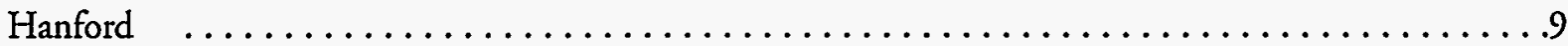

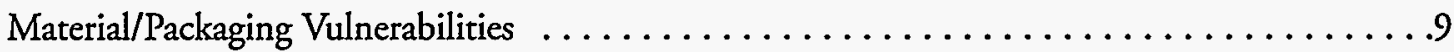

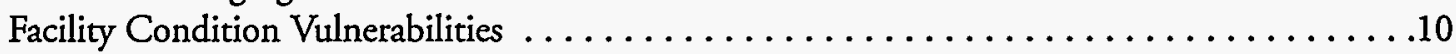

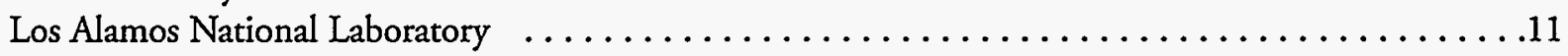

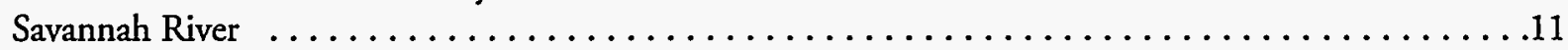

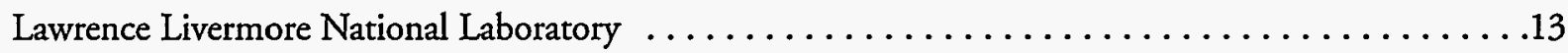

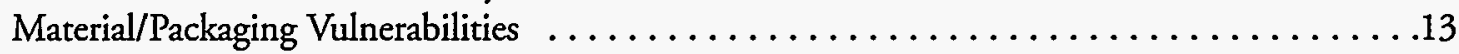

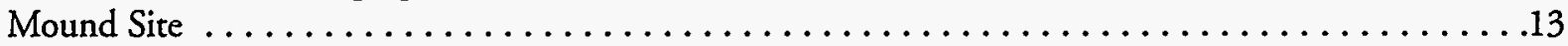

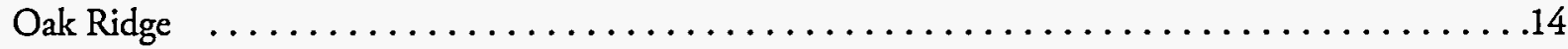

\section{COMPLEX-WIDE INSTITUTIONAL VULNERABILITIES IDENTIFIED IN THE}

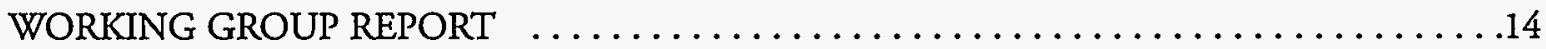

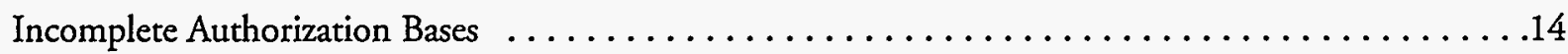

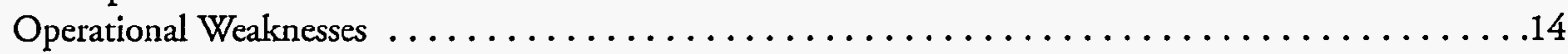

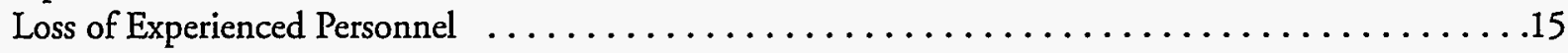

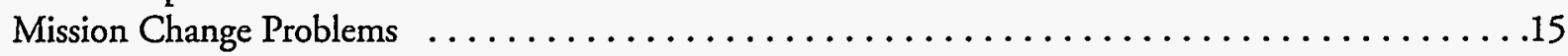

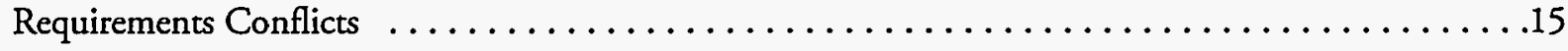

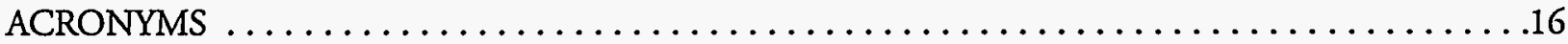

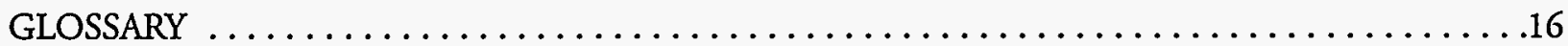

ATTACHMENT A CORRECTIVE ACTION SCHEDULE

ATTACHMENT B RESPONSE TO DNFSB RECOMMENDATION 94-1 


\section{BACKGROUND: ENVIRONMENT. SAFETY AND HEALTH PLUTONIUM VULNERABILITY ASSESSMENT}

The U.S. Department of Energy (DOE) is currently storing approximately 26 metric tons of plutonium, excluding plutonium in intact nuclear weapons, spent nuclear fuel, radioactive waste and the inventory at Pantex, which is classified. The plutonium materials are stored in various forms and in a variety of facilities throughout the DOE Complex. Many of the DOE facilities with plutonium in storage have not operated since weapons production was shut down in 1990. At that time, the shurdown was considered temporary and little attempt was made either to empty the piping, tanks, or equipment or to place the plutonium in containers and packages that would provide safe storage for an extended period of time. As a result thousands of containers of plutonium are vulnerable to leakage or rupture and pose a potential hazard to the Department's workers, the public, and the environment.

On March 15, 1994, Energy Secretary Hazel O'Leary directed the Office of Environment, Safety and Health (EH) to conduct the Plutonium Environment, Safety and Health Vulnerability Assessment. EH formed a Working Group that included representatives from the Department's program and field offices and from site management and operations $(\mathrm{M} \& \mathrm{O})$ contractors, as well as members of the public. Following the process and protocols developed by the Working Group, EH conducted the vulnerability assessment.

The Working Group identified 299 vulnerabilities at 13 sites within the DOE Complex in their report, Plutonium Working Group Report on Environmental, Safety and Health Vulnerabilities Associated with the Department's Plutonium Storage (Plutonium Working Group Report, DOE/EH-0415).

\section{NUMBER OF MOST SIGNIFICANT} VULNERABILITIES

Rocky Flats 28

Hanford Site

Los Alamos National Laboratory

Savannah River Site

Lawrence Livermore National Laboratory

Mound Site

Oak Ridge Site

Total
The significance of each vulnerability was evaluated according to its estimated likelihood and potential consequences. For example, if a vulnerability could result in high worker exposures but the initiating event was very unlikely, such as an earthquake, the vulnerability was classified as having high consequence and low likelihood. The Plutonium Working Group Report shows a range of significances; the most serious vulnerabilities have the highest consequences to the Department's workers, the public, or the environment.

\section{INTRODUETION}

This Plutonium Vulnerability Management Plan describes the Department of Energy's response to the vulnerabilities identified in the Plutonium Working Group Report which are a result of the cessation of nuclear weapons production. The Department has not waited for the findings of the Working Group to act on the urgent problems. The most egregious problems noted in the Plutonium Working Group Report, such as bulging or ruptured containers and leaking pipes, were corrected soon after discovery by site personnel. Work is underway on the more significant vulnerabilities at all of our sites, including solidifying liquids at Rocky Flats, preparing documentation necessary to stabilize plutonium liquids at Savannah River and characterizing and repackaging material as required at all sites. Final corrective actions will take years, but the work is well underway.

The responses contained in this document are only part of an overall, coordinated approach designed to enable the Department to accelerate conversion of all nuclear materials, including plutonium, to forms suitable for safe, interim storage. The overall actions being taken are discussed in detail in the Department's Implementation Plan in response to the Defense Nuclear Facilities Safety Board (DNFSB) Recommendation 94-1. This is included as Attachment B. Site Integrated Stabilization Management Plans are being prepared which document the activities for each nuclear material at each site to complete our conversion effort as rapidly as is practical. These Site management plans will include actions necessary to correct all of the 299 vulnerabilities noted in the Plutonium Working Group Report. The Department will issue in July 1995 a summary of the actions in the Site management plans on the 299 plutonium vulnerabilities.

The Nuclear Materials Stabilization Task Group (as described below and in Attachment B) is responsible for leading and coordinating the Department's response to the vulnerabilities identified by the Working Group, including preparation of the Site Integrated Stabilization Management Plans discussed 


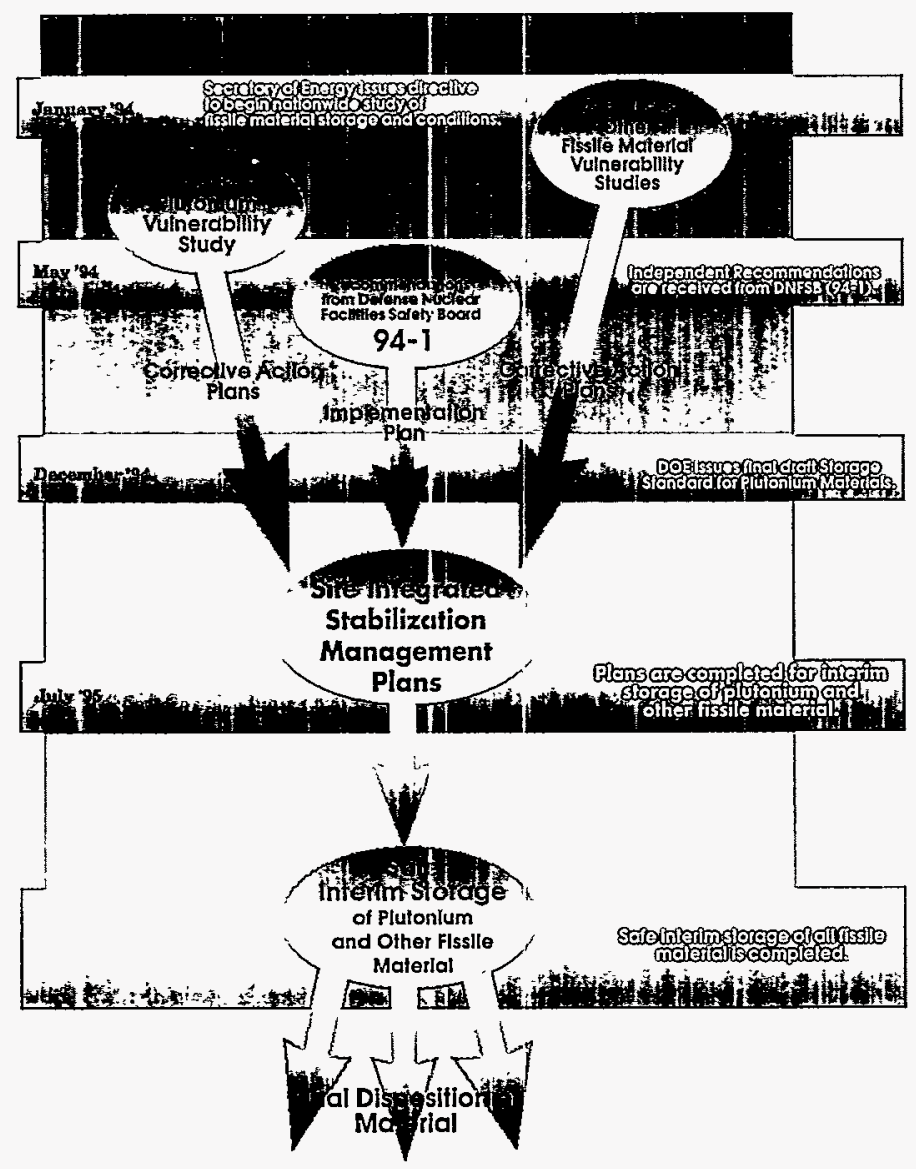

OVERVIEW OF PLAN FOR LONG-TERM MANAGEMENT OF THE DEPARTMENT'S SURPLUS MATERIALS

above and preparation of detailed corrective action plans (CAPs) for each vulnerability. Program offices in DOE Headquarters and the cognizant field organizations will be responsible for completion of the activities in the CAPs. Field organizations will submit periodic reports to the program offices and to the Nuclear Materials Stabilization Task Group stating their progress relative to commitments in the CAPs so that appropriate management action can be taken to ensure that adequate progress is made. Periodic status reports will also be submitted to the Under Secretary by the Nuclear Materials Stabilization Task Group personnel.

The Management Plan identifies both the compensatory measures in place and the proposed corrective action(s) for eliminating or mitigating those vulnerabilities that were rated the most significant by the Working Group in each category of potential effect, i.e., in terms of their potential to affect workers, the public, or the environment. The Plan also addresses the institutional vulnerabilities and conclusions from the Plutonium Working Group Report. Milestones and end dates for corrective actions for each significant vulnerability are included where available.

\section{RESPONSE TO SIGNIFICANT CONCLUSIONS FROM THE WORKING GROUP REPORT}

The Working Group concluded that the Department's inventory of plutonium presents significant hazards to its workers, the public, and the environment; that the hazards have not been aggressively addressed; and that the Department needs a strong, centrally coordinated program to achieve safe interim storage of plutonium. The Working Group further noted that site-specific programs to correct vulnerable plutonium storage conditions must be established, tracked and given high-priority management attention.

This Management Plan is an aggressive, centrally coordinated program to achieve safe interim storage of plutonium. Priority will be given to plutonium liquids, chemically reactive scrap/residues, and packaging with plastic or other organics. Much of the Department's plutonium inventory, including plutonium in holdup, will be better characterized as a result of the corrective actions now being taken. Management priorities at some sites are also being reassessed to focus more closely on those facilities identified as most vulnerable. As sites evaluate their institutional vulnerabilities, such as the loss of qualified staff, the Department will compensare for them. Standards or guidelines for packaging, storage, and surveillance of plutonium scrap/residues and liquids are being developed and implemented.

\section{DEFENSE NUCLEAR FACILITIES SAFETY BOARD RECOMMENDATION 94-1}

The Department's Implementation Plan in response to DNFSB Recommendation 94-1 (Attachment B) covers a broad range of nuclear materials including material related to the plutonium vulnerabilities addressed in this report and spent fuel vulnerabilities addressed in an earlier report. This Implementation Plan contains an Integrated Program Plan (IPP) describing how the

\section{UNDER SECRETARY'S STATEMENT}

"Developing corrective action plans now will also help assure timely action and support the Department's response to DNFSB Recommendation 94-1, specifically as they relate to stabilization and safe storage of various forms of plutonium materials."

Under Secretary

Charles B. Curtis

July 22, 1994 
Department will accelerate conversion of these materials into forms suitable for safe interim storage. Site Integrated Stabilization Management Plans are being completed which document the activities for the nuclear materials at each site in response to the objectives and requirements of the IPP.

Progress of the Department's nuclear material stabilization activities will be monitored through the site plans and compared with the IPP. The need for management action will be identified in part through this comparison with the site plans, which will be updated monthly.

The Department is committed to stabilizing the materials identified in Recommendation 94-1 in conjunction with correcting the vulnerabilities identified in the Plutonium Vulnerability Assessment and the Spent Nuclear Fuel Vulnerability Assessment. The Department's Strategic Alignment Initiative currently in progress is considering organizational changes appropriate to the issues. For the present, a Nuclear Materials Stabilization Task Group will be established to provide the integration structure for the management of material stabilization and reporting within the DOE organization as described in Attachment B.

The Nuclear Materials Stabilization Task Group will have the following responsibilities:

- Provide, through the Under Secretary, program direction and policy for the integrated management of the stabilization of nuclear materials.

- Designate materials within the scope of the project.

- Form and direct an Integration Working Group that will identify and evaluate stabilization requirements, capabilities, operational barriers, and integration opportunities.

- Direct the research and technology development needed to support the project.

- Form and direct a Research Committee that will identify research and rechnology requirements, evaluate proposals for addressing requirements, and prepare appropriate task directions for laboratory work.

- Develop the research and facilities sections of the Integrated Program Plan and other reporting vehicles necessary to monitor progress. Control changes to the Integrated Program Plan.

- Determine the facilities, capabilities and critical skills to be maintained and the length of maintenance.
- Direct trade studies necessary for determining preferred alternatives for treating and storing the materials included in the program.

- Advise senior line managers of schedule variances and their impacts on commitments and progress to desired end-states, and recommended appropriate management action.

- Initiate the development of procedures and standards needed for the program.

- Report quarterly to the Under Secretary the progress of the Department in implementing the Integrated Program Plan, recommending appropriate actions to address funding or progress shortfalls.

- Initiate reports to the Defense Nuclear Facilities Safety Board on changes to milestones in the Implementation Plan for the Board's Recommendation 94-1, and an annual report to the Board on the progress toward meeting the commitments in the Implementation Plan.

\section{STAKEHOLDER INVOLVEMENT}

Stakeholders, including representatives of affected organizations and interested members of the public, attended briefings when the Working Group arrived at each DOE site and when the Working Group had completed its review at the site. At some sites, stakeholders participated in the assessment. The Department also shared initial raw data and preliminary results with stakeholder participants.

Each sire will develop its action plans in close cooperation with its stakeholders. Public participation was a fundamental part of the assessment, and it will be a fundamental part of the solution.

\section{MANAGEMENT PROCESS}

$D O E$ places a high priority on the corrective actions described in this document and expects them to mitigate or eliminate these 46 significant plutonium vulnerabilities. The corrective actions will be managed through a structured process to assure that milestones are met. If delays are encountered, DOE management will be informed and will take action to minimize them.

As discussed earlier, the Nuclear Materials Stabilization Task Group is responsible for leading and coordinating the Department's response to the vulnerabilities identified by the Working Group, including preparation of detailed CAPs. Program offices in DOE Headquarters and the cognizant field organizations will be responsible for completion of the activities in the CAPs. 
Field organizations will submit periodic reports to the program offices and to the Nuclear Materials Stabilization Task Group stating their progress relative to commitments in the CAPs so that appropriate management action can be taken to ensure progress. Periodic status reports will also be submitted to the Under Secretary and the Assistant Secretary for Environmental Management by the Task Group, and an exception report will identify any schedule problems.

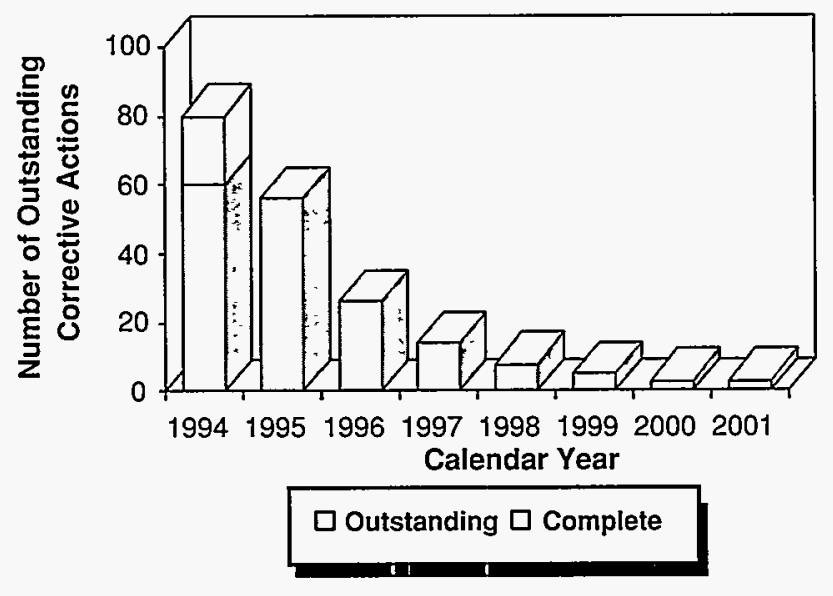

PROJECTED REMEDIATION PROGRESS

\section{SITE VULNERABILITIES}

The 46 most significant vulnerabilities are grouped by site in this section. The 15 vulnerabilities that have both the highest consequences to workers and the highest likelihoods do not affect the public or the environment because they involve relatively small releases of plutonium into the work areas. Such releases could cause high exposures to workers in the immediate area but would have negligible consequences outside of facilities. Most of these vulnerabilities arise from material/packaging weaknesses, which compromise the first, and sometimes only, barrier between a worker and plutonium.

The italicized descriptions of vulnerabilities throughout this section are adapted from the Plutonium Working Group Report. Vulnerability Assessment Form numbers are in parentheses.

\section{ROCKY FLATS}

\section{MATERIAL/PACKAGING VULNERABILITIES}

Five vulnerabilities involve the breach of a container because of the packaging or the physical condition of the material inside (RFP-371-06, RFP-771-06, RFP-776-06, RFP-707-05, RFP-
SW-R). Inadequate storage configurations can lead to hydrogen generation and possible container pressurization, volumetric expansion, formation of potentially pyrophoric materials, and compromise the integrity of tanks and piping systems. These vulnerabilities can be found in all of the plutonium storage buildings at the Rocky Flats Site. They involve most of the 27,609 material packages with the exception of the plutonium weapons components (pits). The following vulnerabilities represent the configurations that pose the most significant risks to the worker.

\section{Liquids in Bottles}

Building 771 bouses plutonium nitrate and chloride liquids in plastic bottles that could crack and leak.

There are 323 plastic bottles of higher-concentration plutonium liquids and 220 more bottles of lower-concentration liquids that are stored in gloveboxes in various buildings. Building 771 currently stores 255 botrles of higher concentration liquids and 89 bottles of lower concentration.

The plutonium liquids are being removed and solidified to eliminate this vulnerability; 385 bottles of liquids have already been solidified. The remaining 543 bottles are scheduled to be solidified by February 1997. An environmental assessment for stabilization of the higher-concentration liquids is necessary to support the above commitments and will be completed by April 1995 .

To minimize the probability and consequences of leaks while awaiting solidification, the higher-concentration (greater than 6 grams/liter total actinide) plutonium liquids in bottles have been removed from storage drums and placed in gloveboxes where they are isolated from contact with workers or the environment. They have also been vented and are periodically inspected. Venting reduces the potential stress on the bottles due to hydrogen gas buildup. The inspection program identifies degraded bottles so that they can be replaced before they leak.

\section{Liquids in Tanks and Piping Systems}

In Buildings 771 and 371 tanks and process piping are leaking plutonium nitrate liquids and are susceptible to operational errors causing release of radioactive material.

The liquids are being solidified to eliminate this vulnerability. For safery reasons, removal of liquids must be done very deliberately. About 6,500 liters in Building 371 will be removed through existing drain paths and processed by August 1996. To enable this activity requires equipment upgrades for the processing system in Building 371. These upgrades will be completed by November 1995, and by April 1996 preparations for precipitation in Building 771 will be complete to support the August 
1996 commitment. Removal of the remaining liquids requires installation of 2,800 additional drains in the low points of the piping and tanks. Planning for this work is underway.

After removal, the liquids will be solidified using existing, available equipment at the site. Four tanks in Building 771 have been drained to date. Six tanks in Building 371 will be drained and processed by November 1996. Eighty percent of the higher-concentration liquids and 50 percent of the lower-concentration liquids in these buildings will be solidified by May 1997. The remainder of the liquids will have been removed and solidified by December 1997 for Building 771 and by June 1999 for Building 371.

Interim measures have been taken to minimize risks to the plant workers from this vulnerability, including minimizing risks posed by the above-noted corrective actions. Access to areas where the potential for leakage exists is strictly controlled, alarm systems are in place to detect airborne contamination from the spills or leaks to alert personnel, and piping system components susceptible to leaks have been encased in plastic shrink wrap. Furthermore, the systems are routinely inspected for any problems. In the event that spills or leaks occur, spill plans and equipment and tank leak contingency plans have been developed and workers are trained to the response procedures.

\section{Solid Residues (Skulls)}

Building 777 contains three packages of pyrophoric plutonium metal casting skulls; Building 371 contains two.

Plutonium metal casting residue (skulls) stored onsite may be pyrophoric: the residue could burn when the drums are opened. Skulls are by-products of past plutonium casting operations and contain plutonium metal in a matrix of slag consisting of other metallic and oxide impurities. If ignited, it could cause breach of containment or initiate secondary fires or explosions. A drum containing three packages in Building 777 was, at the time of the vulnerability assessment, suspected of containing skulls. A review of process records and interviews with operations personnel later indicated that these packages contain tungsten filaments and pose a significantly smaller risk to the worker. Pyrophoric material was removed from this drum in December 1994.

A drum containing two packages in Building 371 may contain skulls. This drum will be moved to Building 707 where it can be inspected and the material inside can be thermally stabilized, if required, and repackaged for safe storage. This activity is scheduled to be completed in March 1995, at which time the vulnerability issues associated with skulls will be closed.

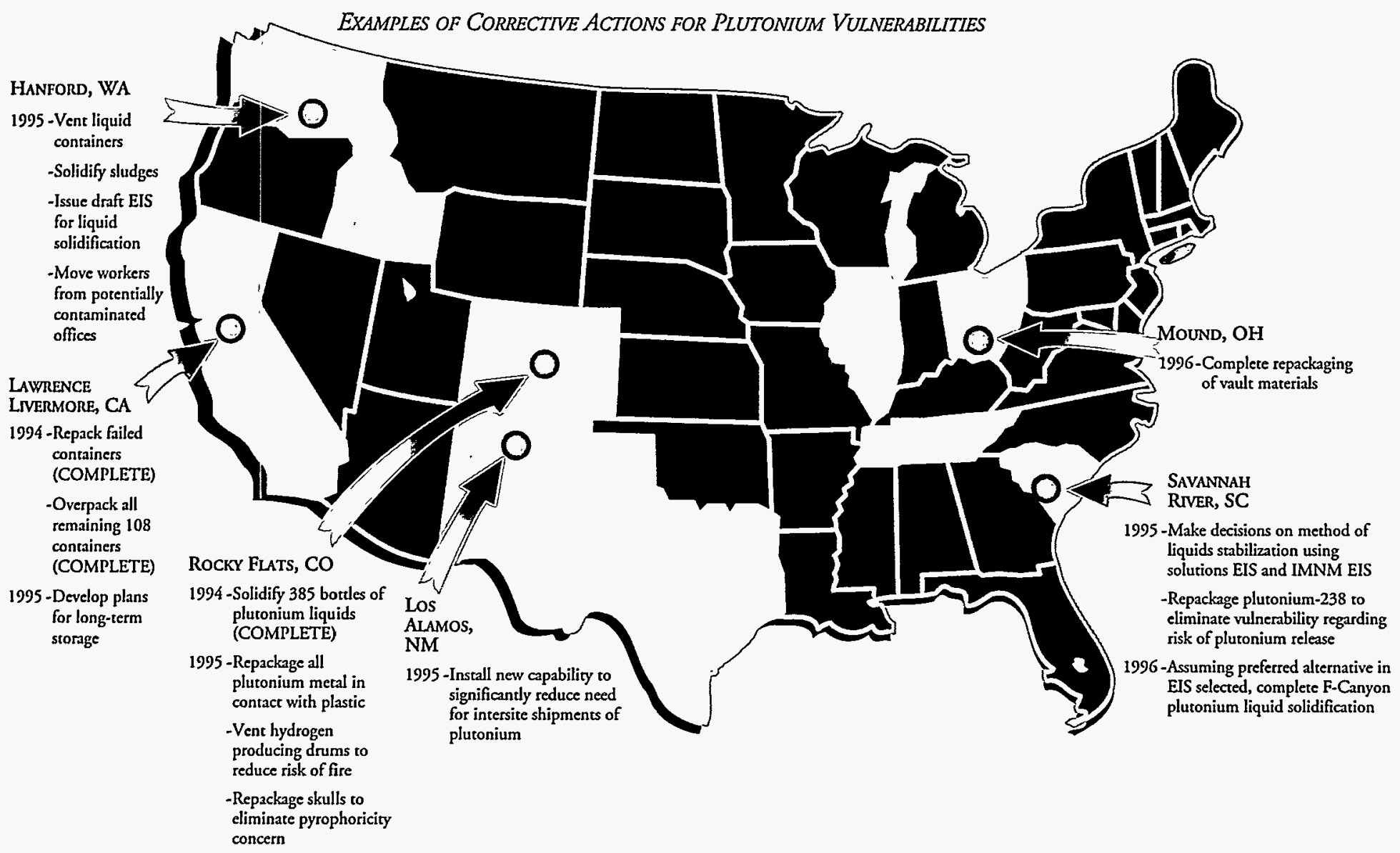


Solid Residues (Pyrochemical Salts)

Buildings 371 and 776 contain 5,942 pyrochemical salt packages that are water-absorbing and potentially corrosive, and chemically reactive.

Pyrochemical salt residues, stored sitewide, can react with water to form hydrogen. Another mechanism for hydrogen generation is the interaction of radiation with plastic. Some drums of electrorefining salts have been shown to have hydrogen concentrations approaching the lower explosive limit of 4 percent. Pressurization of unvented drums or the ignition of confined hydrogen could result in container rupture and a subsequent risk to workers.

To resolve this vulnerability, the Department will eliminate the cause of drum pressurization and hydrogen buildup by stabilizing and repackaging the salts. This will be accomplished by converting reactive metals to nonreactive oxides and eliminating plastic bottles as the primary layer of containment so as to remove the source of hydrogen. The stabilized salts will be repackaged into sealed metal containers and stored at Rocky Flats until an appropriate offsite repository is available. This complicated process requires the evaluation of data gathered over the past several months to ensure that the proper actions are taken with respect to different stored residues. Action plans with schedules for the activities described above will be completed by April 1995.

Near-term corrective actions will minimize the risk to the plant workers from the stored material by eliminating the possibility of pressure and hydrogen buildup in the drums. Filtered vents will be installed on those drums that do not already have them. The vents are designed to eliminate pressure buildup with filters that contain the contamination. To date, 940 drums of residues have been fitted with filtered vents. The vents will be installed on the remaining unvented 55-gallon drums of all residue types, including all forms of pyrochemical salts, by October 1995.

\section{Metal Stored in Contact with Plastic}

Buildings 371, 559, 707, 771, 776, 777, and 779 bouse up to 276 sealed containers of plutonium metal in contact with plastic. The containers may be subject to pressurization and formation of pyrophoric plutonium bydride.

This situation is being corrected by repackaging the plutonium metal so that it is not in direct contact with plastic. During repackaging, the loose plutonium oxide is brushed from the metal, treated, and packaged separately. Approximately 5 percent of the 276 packages have been brushed and repackaged. The remaining repackaging will be completed by October 1995 .
This activity will alleviate any near-term concerns. Precluding a recurrence of this vulnerability requires packaging the material in a container that meets the Department's standard for safe storage of plutonium metal and oxide, issued in December 1994. Compliance with the standard will be achieved by May 2002.

\section{FACILITY CONDITION VULNERABILITIES}

Five vulnerabilities at Rocky Flats result from collocated hazards and limited ventilation testing and maintenance. (RFP-559-04, RFP-707-03, RFP-771-04, RFP-776-04, RFP-779-04)

\section{Limited Testing of Filter Stages}

In all buildings except 559 and 707, only a limited number of High Efficiency Particulate Air (HEPA) filter stages are tested. Such limited testing casts doubt on the effectiveness of the filters.

Although some stages of the multiple-stage exhaust air filters at the site's plutonium buildings are not tested, the buildings' safety documentation takes credit for all of the installed filter stages. This vulnerability concerns taking credit for safety systems in safety documentation when those systems are not required to be tested.

Testing the filter stages requires that workers enter the large filter plenum in protective clothing. A number of personnel contamination incidents have resulted from this task. To reduce the hazard to the workers should protective clothing fail, some filter stages are deliberately not tested. The safety analysis for the buildings should recognize and reflect this fact.

As a result of this vulnerability, the Department initiated an extensive evaluation of each plutonium facility's filter systems to determine which filtration stages required testing in place and to ensure that the safety documentation accurately reflected the testing requirements. It was determined that the risk to the worker performing this test was sufficiently high, and the benefit of testing all filter stages sufficiently low, that not all filter stages should be tested. The safery documentation has been revised to reflect this and all filter stages required to be tested as a result of the evaluation will be tested. The last test of filter stages in Building 771 will be completed by June 1995 and will eliminate this vulnerability.

In addition to the above actions, each exhaust filter system has airborne contamination monitors in place to detect any release of material. If such a release were to occur, the site's emergency response procedures would be implemented. Each month officials from the Colorado Department of Public Health and Environment conduct reviews to independently verify that air quality standards have been met. 


\section{Limited Preventive Maintenance}

Buildings 771,776 , and 779 have only limited preventive maintenance of vital safety systems, including the ventilation system, making the safety systems susceptible to premature failure as they age.

The preventive maintenance program in the plutonium buildings at Rocky Flats is minimal because in previous years a higher priority was placed on maintaining production equipment and repairing aging safety-related equipment. Without preventive maintenance, safety-related equipment may not respond as required to prevent the release of contaminates.

To reduce this vulnerability, a plutonium facility maintenance program based on risk and failure probability will be developed. The maintenance program will include the features noted below. An implementation plan for the maintenance program is to be completed by March 1995 .

- List of vital safety systems and other systems required to ensure worker safety for the current mission,

- Manufacturers' preventive maintenance recommendations,

- Failure trending and maintenance history programs.

In the near term, Rocky Flats is performing operability testing on equipment as required by Operational Safety Requirements to minimize the probability and consequences of possible equipment failure. If failures occur, operations are suspended pending repair of the effected systems.

Four additional categories of vulnerability at Rocky Flats arise from facility conditions.

\section{Fires and Explosions}

Large internal fires and explosions in Buildings 559, 707, 771, 776, and 779 could breach confinement through failure of the ventilation systems or structures (RFP-SW-I, RFP-559-02, RFP-70702, RFP-771-02, RFP-776-02, RFP-779-02, RFP-776-01). These buildings have over 8,000 drums with plutonium scrap/residues that contain combustible materials, increasing the likelihood of energetic releases of plutonium during building fires or explosions.

Fires and explosions could be initiated from human error or equipment failures and potentially breach the facility, releasing contamination. Until the building is completely decontaminated and decommissioned, these vulnerabilities will exist.

Several activities have been initiated to significantly reduce the likelihood of this event. The flammable and explosive hydrogen gas that builds up inside residue drums and could increase the magnitude of a fire is being vented from the drums to eliminate this hazard. Of the residue drums, 940 drums have been fitted with filtered vents that release the hydrogen and retain the contamination, 2,000 more will be vented by October 1995, and the remaining will be vented in 1996 . The plutonium materials, excluding the residues, wastes and holdup, are scheduled for removal from buildings 707, 771, 776, and 779 between December 1996 and March 2001, significantly reducing the quantity of materials at risk for release. Final residual plutonium removal will not occur until the plutonium held up in the equipment, auxiliary support systems and facility structures is packaged as waste from the decontamination and decommissioning activities.

Because of severe storage space limitations, waste and residue drums containing combustible materials are stored throughout the plutonium facilities. Although the storage space meets the requirements of the Resource Conservation and Recovery Act and DOE Orders, this vulnerability highlights the need to reevaluate the current storage with the long term in view. This evaluation will be completed by April 1995, and any subsequent actions will be included in the IPP (see section entitled Defense Nuclear Facilities Safety Board Recommendation 94-1).

Several compensatory measures mitigate these vulnerabilities, until the material can be vented and/or removed from these facilities. Automatic sprinklers have been installed and nonessential combustibles have been removed. Gas cylinders needed for welding operations are allowed in plutonium areas for the minimum amount of time required to complete the maintenance job. Extensive training operarions and administrative controls are in place to reduce human errors during operations where the risk of fire exists.

During maintenance or modification activities, plutonium buildings may contain high-pressure oxygen and acetylene cylinders that could cause fires or explosions or become missiles.

During maintenance or modification activities that require welding, the high-pressure oxygen and acetylene bottles could cause fires or explosions or could become missiles if the valves failed. Such an internal explosion could breach the facility structure and release radioactive material directly into the atmosphere.

Administrative controls have already been modified to require the removal of any oxygen or acetylene bottles used for maintenance work except during the actual maintenance activities. During such welding operations, their use is strictly controlled 
through formal work control and welding authorization approvals, thereby minimizing this vulnerability.

All other large oxygen and acerylene cylinders have been removed from plutonium buildings. Two pressurized bottles (one acetylene and one hydrogen) are utilized on a continuous basis for the operation of two separate instruments for analyzing plutonium. This vulnerability has been minimized by replacing the bottles with smaller ones and "hard piping" the bottles to the instruments.

\section{Earthquake and Wind Damage}

Buildings 559, 707, 771, 776, and 779 are susceptible to earthquake damage to building structures or safety systems. (However, portions of Building 707 Annex and Building 779 bave been upgraded to withstand the design basis earthquake and maintain confinement.) Buildings 776 and 559 are susceptible to damage from high winds (RFP 559-08, RFP-707-07, RFP-771-08, RFP776-08, RFP-779-08, RFP-779-A).

Building damage from earthquakes or wind could potentially cause a release of plutonium from material containment systems, thereby exposing the public and environs. For the most part, the preferred alternative to reinforcing the structures to resist earthquakes and wind damage is to eliminate these vulnerabilities by removal of the plutonium from the buildings, which is in concert with the site's clean-up mission.

Building 559 will be used for analyzing plutonium for an extended period of time. Therefore, the risk related to this vulnerability for Building 559 has been significantly reduced by removing most of the previously held material and limiting the total amount of plutonium authorized in the facility at any one time to less than 2 kilograms. The risk that an earthquake would cause equipment to fall on the plutonium containers is further reduced by storing these materials in vaults, which contain only fire suppression systems above the material.

After vaults have been constructed in Building 371 , the plutonium is to be removed from the other buildings and stored in the new Building 371 vaults, the most seismic-resistant on site, according to the following schedule: Building 991, October 1995; Building 779, December 1996; Building 776/777, June 1998; Building 771, September 1997; and Building 707, May 2000. Engineering and construction of the vaults, which is in progress, will be completed by October 1995 . Final residual plutonium removal will not occur until the plutonium held up in the equipment, auxiliary support systems and facility structures is packaged as waste from the decontamination and decommissioning activities.

\section{Aircraft Crashes}

Aircraft crashes into Buildings 559, 776, and 779 would result in structural damage and offite release of plutonium (RFP-559-05, RFP-776-10, RFP-779-10).

As discussed above, for buildings 779 and 776 this vulnerability will be eliminated by December 1996 and June 1998, respectively, as the site consolidates and repackages its inventory of plutonium. The vulnerability has been significantly reduced for Building 559 by removing most of the previously held material and limiting the total amount authorized in the facility at any one time to less than 2 kilograms.

\section{Water-Soaked Exhaust Filters}

Water spray systems are used to protect HEPA filters from fires. Water-soaked filters could fail, thus releasing plutonium offsite (RFP-SW-O).

The air pressure placed on filters clogged with water and debris could result in holes being blown through the filter media and release of radioactivity to the environment.

An automatic water spray system and a manual water deluge system were installed in filter plenums to help protect the filters from fire damage. These systems were designed and installed as

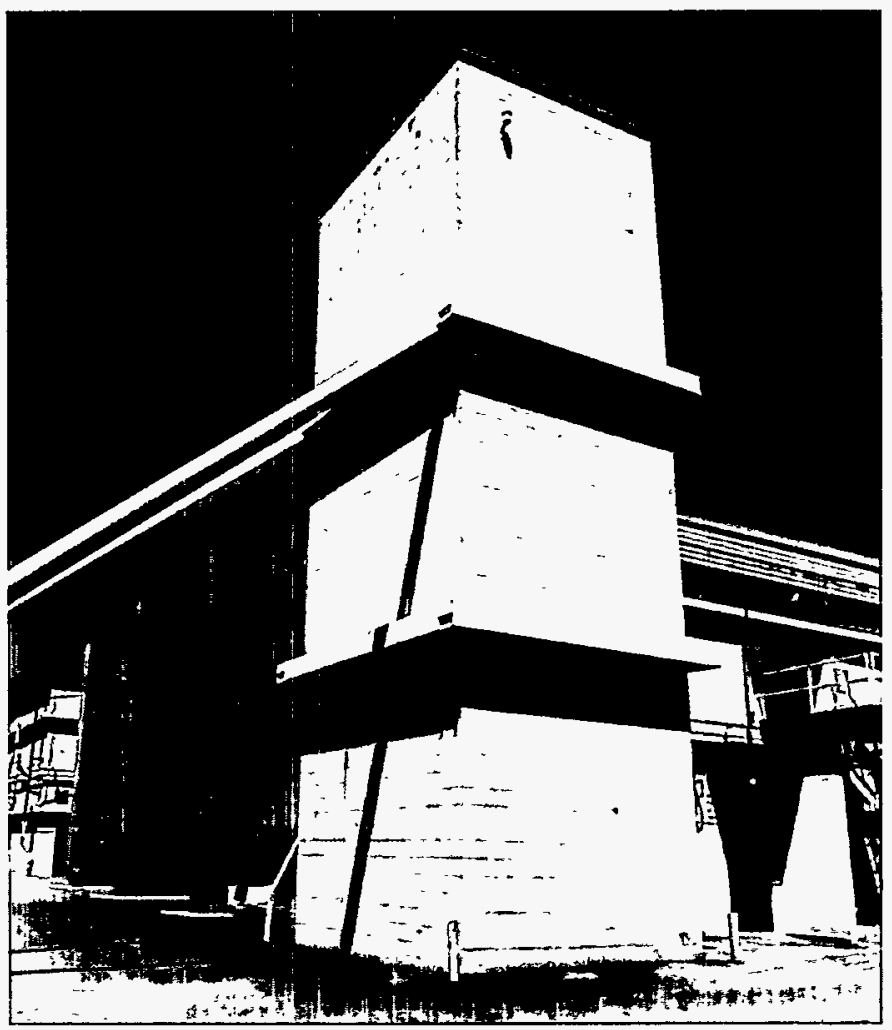

REINFORCED STRUCTURE FOR INCREASING SEISMIC RESISTANCE AT ROCKY FLATS 
a result of lessons learned from the 1969 fire in Building $776 / 777$. The automatic spray system activates when elevated temperatures are sensed in a heat chamber located before the filter plenum. The spray cools the air and reduces the risk of spreading fire to the first stage of filters. The heat chambers are also equipped with metal screens to prevent the water and burning combustible material from entering the plenum. The first filter stage has the potential to become saturated and plugged when the water deluge system is utilized. This system is manually operated and is intended for use only as a last resort to prevent the filters from igniting and creating a direct path to the outside environment. The deluge system is operationally tested each year by spraying water on the filters. Failures from wet filters have never occurred during testing. Upon activation of the deluge system, the filters are monitored continuously. If filter media failure occurs, the fan systems are to be turned off, thereby eliminating the large pressure differentials across the filters. The multiple stages of HEPA filtration would prevent release to the outside environment.

Breaches of facility integrity or confinement system failures at Rocky Flats can result in a direct pathway for the release of plutonium material to the environment (RFP-SW-G).

This vulnerability concerns the potential leakage of radioactive material through exhaust HEPA filter systems. The corrective actions for this vulnerability are the same as previously described for Limited Testing of Filter Stages.

\section{HANFORD}

\section{MATERIAL/PACKAGING VULNERABILITIES}

Over 110 containers with plutonium nitrate liquids in the Phutonium Finishing Plant (PFP) bave plastic inner bottles susceptible to embrittlement. About 30 of these bave chlorides or fluorides that would damage the stainless steel outer container if the inner container leaked. An additional 30 containers may be unvented and thus could be accumulating flammable bydrogen gas (RL3.1.3.1).

This vulnerability arises from PFP's current storage of containers of plutonium-bearing liquids left over from previous process campaigns. These liquids generate hydrogen gas as a result of radiolysis. Newer containers have automatic, filtered vents which preclude accumulation of the hydrogen gas and the resultant pressure buildup. Some older containers have manual vent valves which may have been left in the closed position. A documentation review shows that up to 7 percent of the containers may not be properly vented. If the vent were closed and the hydrogen gas buildup in the container were sufficient, a fire or explosion could occur upon venting. In a sealed container, pressurization could increase the risk of worker injury. Personnel outside the immediate area and the environment are protected by the storage building and its filtered exhaust system.

During 1995 the Department will inspect the suspect containers and ensure that they are properly vented. For the long term, the liquids will be stabilized through conversion into solids. An Environmental Impact Statement (EIS) is being prepared to determine the preferred method for stabilizing this and other plutonium-bearing material at Hanford. The draft EIS is expected to be issued for public comment in August 1995.

Until stabilization of these materials is complete, interim measures will remain in effect to minimize the risk of personnel injury and to minimize hazards to the public or the environment. The liquids are stored in vault-type rooms to provide the required security and to restrict unnecessary worker access. Air in the storage rooms is exhausted through a filtered system. To guard against sparks, every container is electrically grounded and only nonsparking tools are used to open the containers. Additionally, procedures require the workers to wear protective clothing and respirators during any activity that involves opening the containers.

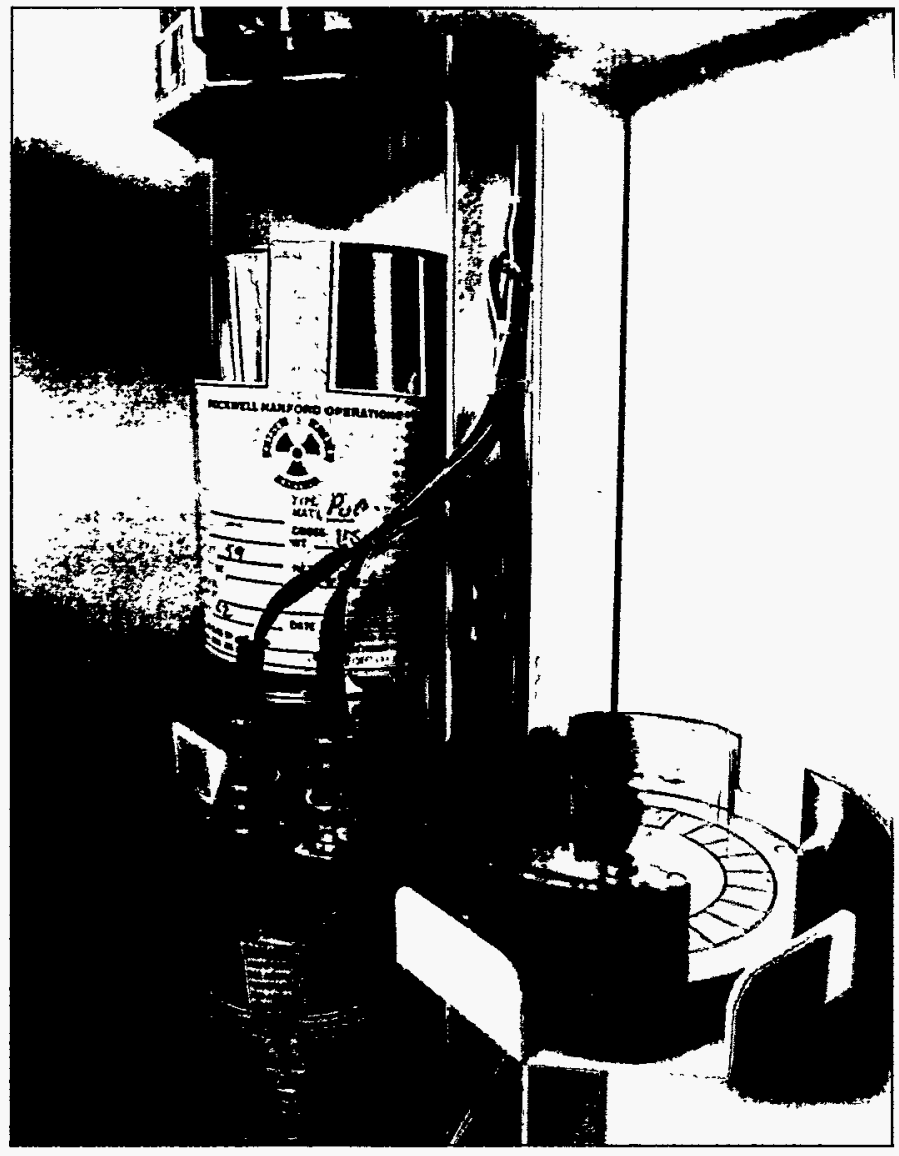

INSTRUMENTED STORAGE PEDESTALS AT HANFORD MONITOR PACKAGES FOR SHAPE AND TEMPERATURE CHANGES 
To mitigate the vulnerability related to potential leakage of plutonium chloride and fluoride liquids, the liquids will be repackaged into new containers by September 1995.

PFP bas 700 containers of unstable and reactive plutonium scrap/residues stored in vaults in packages of unknown design life (RL-3.1.3.2; RL-3.1.3.3). Radiolysis, gas generation and corrosion could cause package breach and worker exposure.

This plutonium is not suitable for long-term storage either because it may generate hydrogen due to the effects of radiation, potentially causing failure of storage containers and risk to the worker, or because the Department does not have sufficient knowledge of the packaging configuration of some of this plutonium to ensure that it is suitable for long-term storage.

The corrective action for these vulnerabilities is to stabilize the material and store it in a manner that precludes gas generation. An EIS is being prepared to select the best alternative for stabilizing the material. The draft EIS will be issued for public comment in August 1995. At the completion of this EIS, stabilization will proceed to eliminate the vulnerability. In conjunction with the EIS effort, the Department is performing a series of interim actions (covered under separate NEPA documentation) to address immediate areas of concern. These include ongoing thermal stabilization of the plutonium-bearing sludges to be completed in August 1995.

To further address this vulnerability, the Department will generate a characterization plan by March 1995 to determine which items are not characterized sufficiently to be listed as acceptable for interim storage. Following this breakdown, the items that are identified as lacking characterization will be further evaluated to determine the relative risks they pose. Implementation of this plan will be carried out in FY95 and FY96. Additional expedited stabilization activities will be proposed on the basis of risk and availability of stabilization process equipment.

Until stabilization of the material is complete, interim measures will remain in effect to reduce the risk to workers from can pressurization. These include routine monitoring of the containers for evidence of pressurization (bulging), air-conditioning of the vault rooms to reduce can swelling due to changes in outside air temperature, and strict storage requirements for the type and form of the material to be stored. If a can were to rupture despite the protective measures, workers would be instantly alerted. The air is continuously sampled for radioactive contamination. Unusual levels of radioactivity activate the air sampler alarm. Should the inspection or electronic monitoring discover a bulged can, the condition causing the bulging would be corrected, and the material repackaged and returned to storage. Workers are required to wear protective clothing, including respirators, during any part of the process of working with a bulging can.

PFP has 1,278 containers of plutonium metal, oxide or scrap/residues with incomplete materiallpackaging information and unknown design lives (RL-3.1.3.4). These containers and packages are aging and could allow air inleakage, leading to breach of packaging.

At PFP and in other Departmental facilities, plutonium is typically stored in an inner slip lid can within outer mechanically sealed cans. This storage design was intended for in-process storage during weapons production. No specific data exists on the service life of this type of storage configuration. The unknown package design life constitutes a vulnerability. However, some items currently in storage are over 25 years old and are showing no signs of deterioration.

The corrective action for this vulnerability will be issuance and implementation of a new DOE Storage Standard describing the requirements for long-term storage containers for plutoniumbearing materials. The first such standard, for plutonium metal and high-concentration oxides, was issued in December 1994. It will cover approximately one-half of the inventory at PFP. An implementation plan for this standard will be prepared by March 1995. As stated earlier, the plan will also cover those materials which can be packaged to meet the intent of the standard even though their concentration is less than 50 percent by weight plutonium.

The interim compensatory measures for containers of unknown package design life include monitoring the containers and repackaging if any problems are detected.

\section{FACILITY CONDITION VULNERABILITIES}

Fifteen of Hanford's retired facilities retain plutonium in equipment or underneath sealants such as paint (RL-3.3.1.1).

Several of Hanford's former plutonium-handling facilities are now used for nonnuclear activities (offices, shops, etc.). The contamination of these facilities that occurred in the past was cleaned up by manual methods and what could not readily be removed was fixed in place with paint. The concern is that workers could inadvertently and unknowingly uncover the contamination and thereby be exposed.

As an immediate action, all affected workers will be informed of the possibility of contamination under the paint in their offices and of precautionary measures they should take. 
An assessment of all facilities to identify specific areas of buildings that need to be vacated is underway and will be completed by March 1995. It has already been decided that offices in Building 231-Z must be vacated and this will be accomplished by March 1995. Relocation of personnel from other areas identified by the facilities assessment will be completed by December 1995 .

Breaches of facility integrity or confinement system failures at Hanford could result in a direct pathway for the release of plutonium material to the environment. Some facilities have combustible structures and roofs; fires could result in offsite releases of plutonium (RL-3.3.1.2).

This vulnerability concerns the possibility of a major structural fire at retired facilities. If the onsite Hanford Fire Department with the assistance of the local city fire departments were unable to contain such a fire, the residual contamination in the structure could be released directly to the environment. Since plutonium is no longer handled in these facilities, the only way to significantly reduce or eliminate the vulnerability is to complete decontamination and decommissioning (D\&D) of the vulnerable structures. Deactivation of some of these facilities is underway. Deactivation of Building 308 will be completed in 1998 and Building 309 in 1999. A schedule for all of the required D\&D will be developed and included in the IPP.

\section{LOS ALAMOS NATIONAL LABORATORY}

Shipment of plutonium samples across open roads at Los Alamos National Laboratory could result in events or accidents causing a breach to the transportation packaging and release of the sample materials directly to the environment (TA-55-4).

Every week one-liter plastic bottles containing plutonium-contaminated liquid waste from analyses are packaged in a sealed vessel and transported from TA-55 to the Chemistry and Metallurgy Research (CMR) Building for analysis and back to TA-55 for disposal.

Los Alamos will consolidate analytical capabilities in a single laboratory at TA-55 to significantly reduce the need for shipment of routine samples between buildings. The necessary steps include (1) installation of already procured equipment, (2) development of operational procedures, and (3) training of personnel. Old gloveboxes and equipment in the designated laboratory, will be removed and a new glovebox and equipment will be installed. The proposed timeline for the above activities is as follows:
- Complete glovebox installation by July 31, 1995;

- Complete operating procedures by August 31, 1995;

- Train and qualify personnel by September 30, 1995; and

- Begin operating metals analysis line by September 30, 1995.

Until the analytical capabilities are consolidated, compensatory measures are in place to reduce the probability that materials would be released to the environment. These measures include minimizing the number of shipments and ensuring that all access roads are blocked and traffic is halted during transportation. Security forces maintain the road closure during transport, and a HAZMAT unit follows the sample vehicle.

\section{SAVANNAH RIVER}

Plutonium liquids stored in large tanks in the F-and H-Canyons can precipitate and cause inadvertent criticality. These criticality events could cause releases of plutonium through the off-gas systems. (SRS-FC-02, SRS-HC-02)

The continued storage of plutonium liquids in $\mathrm{F}$ - and H-Canyon increases the risk of potential accidents such as nuclear criticality. The corrective action for these vulnerabilities is to convert the liquids into a solid form suitable for safe interim storage.

A draft EIS that addresses options for converting the F-Canyon plutonium liquids has been issued for public comment, with a Record of Decision expected in January 1995. The Department is currently reviewing public comments on the draft EIS. The options being considered in the EIS are as follows:

- Convert the liquids to safe, storable plutonium metal through operation of the F-Canyon and the FB-Line. Should this option be selected, the plutonium metal would be stored and eventually converted to a form suitable for long-term storage.

- Continue to store the liquids in the existing tanks (i.e., take no action).

- Continue to store the liquids in the existing tanks while a process is developed to vitrify the plutonium and new facilities are installed in F-Canyon.

- Transfer the liquids to high-level waste tanks for eventual vitrification in the Defense Waste Processing Facility.

- Convert the liquids to plutonium oxide through modified operation of F-Canyon and FB-Line, producing oxide instead of metal. 
Of the several options evaluated in the EIS, stabilizing these liquids by processing through existing equipment in F-Canyon and FB-Line to produce plutonium metal suitable for interim storage can be completed soonest and poses the least technical development risk. If this option is selected, stabilization of the liquids could begin in 1995 and be completed in 1996.

Corrective actions for the $\mathrm{H}$-Canyon plutonium liquids (plutonium-242 and plutonium-239) are being developed as part of another draft EIS which has not yet been issued for public comment. Alternatives being considered include:

- Process the liquid in H-Canyon to remove fission products and other materials that would interfere with subsequent stabilization steps. Transfer the separated plutonium to the HBLine for conversion to a low-fired oxide.

- Continue storage under active management (i.e., take no action).

- Continue to store the material in H-Canyon until it can be discharged to the H-Area high-level waste tanks. Then vitrify the material at the Defense Waste Processing Facility. (This option is being considered for the plutonium-239 liquids only.)

- Process the liquid to an oxide as in the first option; then vitrify the plutonium in a proposed process in F-Canyon. (This option is being considered for the plutonium-239 liquids only.)

Public comments will be solicited on the draft EIS. The Record of Decision for this EIS is expected in May 1995. Of the options to be evaluated, stabilizing these liquids by processing through existing equipment in $\mathrm{H}$-Canyon and HB-Line to produce plutonium oxide suitable for interim storage is the fastest and poses the least technical development risk. If the option to process the liquids to an oxide is selected, stabilization of the plutonium-242 liquids (approximately 28 percent of the plutonium liquids in H-Canyon) could be started in mid-1996 and would be finished in late 1997. Stabilization of the plutonium239 liquids could not begin until early 1999 and could be completed no sooner than early 2000 . The portion of the facility needed for stabilization of these liquids has not previously been used and must undergo extensive startup preparations.

Until the F-and H-Canyon liquids are stabilized, compensatory actions to reduce risk will continue. Strict control of the tank liquid chemistry is maintained through a sampling and monitoring program. The presence of neutron poisons in the tanks reduces the risk of nuclear criticality.
Holdup in the Savannab River Site's Old HB-Line, Building 235-F; and $F$-Canyon's retired facilities could result in release of plutonium material to the environment, especially during $D \& D$ activities (SRS-OHBL-2, SRS-FC-5, SRS-B235-1).

Three Savannah River Plant vulnerabilities are associated with aging facilities and plutonium accumulation. The final corrective action for all these vulnerabilities is complete D\&D of the facilities, which will take years to finish. In the interim, the potential for release of contamination to the environment is low because the nuclear materials located within these facilities are currently safely contained and because all exhaust air is filtered through a HEPA system. However, the risk will increase as these facilities age and they undergo D\&D activities in the future. Until that time, these vulnerabilities will be managed through the continued application of effective surveillance, monitoring, access control, and radiological health and safety controls, coupled with programs to effectively decontaminate and decommission these facilities in future years at a pace determined by priority and funding.

Breaches of plutonium-238 packaging containment at the Savannah River Site in combination with degraded facility conditions could result in a release of plutonium material to the environment (SRS-B235-6).

Pressure buildup in plutonium-238 containers over a period of decades could lead to container failure and release of contamination. The corrective action for this vulnerability is to vent and repackage the material into a form suitable for interim storage.

The pressure buildup in plutonium-238 containers results from radioactive decay of the plutonium, which produces nonradioactive helium gas. At the Savannah River Site, 15 welded stainless steel containers are located in Building 235-F, each holding a single 1.6-inch-diameter ceramic sphere of iridiumencapsulated plutonium-238 oxide.

Some of these containers have been in storage for up to 17 years. The calculated maximum-theoretical internal helium pressures inside the stainless steel containers are approaching one-half of the pressure that could lead to container failure. It is estimated that it would take several decades for the pressure to build to levels that could lead to container failure. Even if the stainless steel container failed, the potential for release of contamination to the environment would be low because the plutonium is in an encapsulated ceramic form and because any release would be filtered before reaching the environment. 
To correct this vulnerability, all 15 of these containers will be repackaged by May 1995, many years before a problem might be expected with the current containers. This will be accomplished at the HB-Line facility (specifically designed for handling plutonium-238 oxide), where they will be opened, vented, and the material repackaged into a container specially designed for storage and shipment of plutonium-238. The new container is designed to eliminate pressure buildup during interim storage. The repackaged material will then be safely monitored and stored for eventual use in future National Aeronautics and Space Administration (NASA) programs.

Pending completion of corrective actions, compensatory measures to reduce risk include periodic inspections, continuous air monitoring of the storage area, rigorous application of radiological health and safety controls, and limited access to the storage area.

\section{LAWRENCE LIVERMORE NATIONAL LABORATORY}

\section{MATERIAL/PACKAGING VULNERABILITIES}

Building 332 houses 282 plutonium containers of uncharacterized materials and unknown package configurations, subjecting workers to unknown hazards (LLNL-B332-02). Of these, 108 packages contain plutonium ash. Eight of them bulged recently, probably because of radiolysis of moisture and pressure buildup.

The eight bulged cans were repackaged and all 108 cans of ash are now stored in vented and filtered overpacks in the vault.

The corrective action for this vulnerability is to characterize the materials in the plutonium containers and establish and follow safe-storage criteria for those materials. The characterization program is underway and includes collecting existing data, inspecting materials with poor or nonexistent information, repackaging items that do not meet state-of-the-art packaging techniques, and documenting all pertinent information in the LLNL Special Nuclear Material database.

By December 1995, Livermore will establish action plans for safe long-term storage for all excess materials. The plans will be based on information derived from the characterization program as of that date and information from other, similar efforts underway at the Rocky Flats site and throughout the DOE Complex. The characterization program will be completed by January 1997 and will provide information from which to confirm or revise the assumptions made in the December 1995 action plans.
Pending storage of this material according to the final safe-storage criteria, compensatory measures are in place to minimize the hazard to workers. These include bi-monthly inspections to ensure the integrity of the storage cans and repackaging of containers that display an abnormal condition. Personnel use appropriate protective measures, including respiratory protection, during the inspection and repackaging processes.

\section{MOUND SITE}

Plutonium packages (e.g., Radioisotope Thermoelectric Generators, oxides, metals) are stored in the T-Building which does not provide HEPA filtration confinement in the event of packaging failures (MD-02, MD-10).

These two vulnerabilities are of low likelihood, but with potential for high consequences to the public and the environment. In a small number of containers, constituents may have been packaged with plutonium. Some of the older materials in sealed containers in storage vaults are not completely characterized. Further, approximately 40 primary containers were packaged for storage several years ago with little documentation on the nature of inner layer packaging. The T-Building vaults do not have a HEPA-filtered ventilation confinement system. Packaging failures could result in releases to the vaults and subsequently to the environment.

To correct this vulnerability all of these packages will be opened, the contents identified, and the plutonium metal stabilized and repackaged in containers suitable for safe interim storage. This

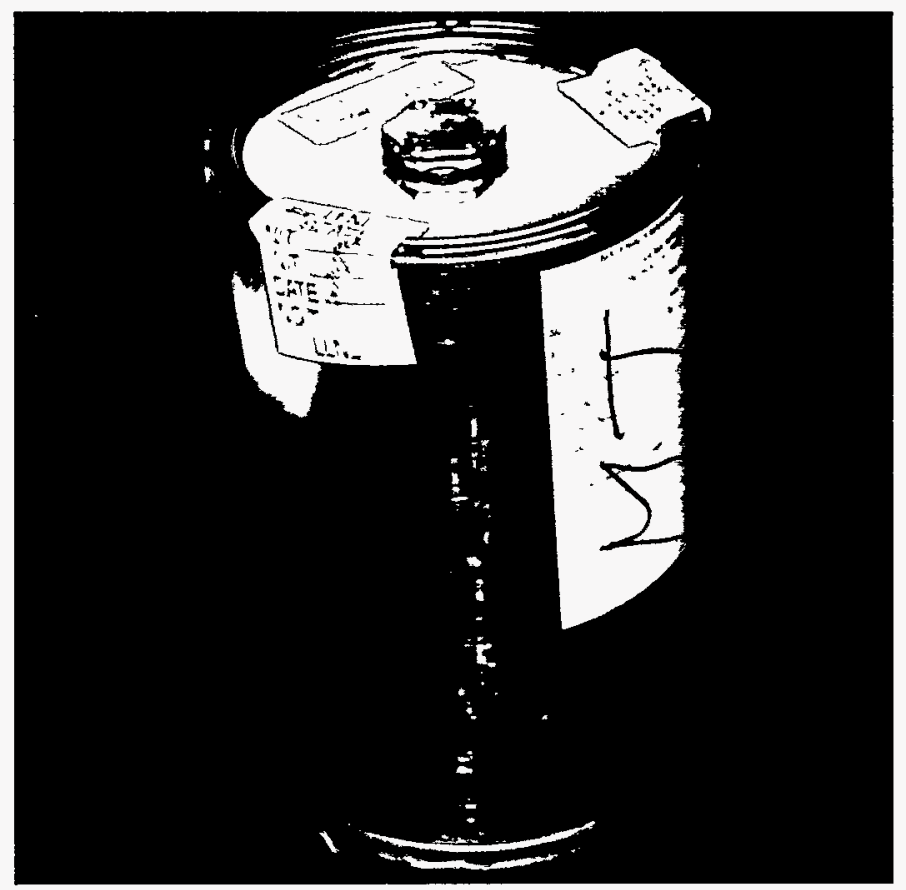

LAWRENCE LIVERMORE OVERPACK CAN 
will be accomplished in the Drum Opening Facility, construction of which is nearing completion at Mound, and in the Mound North Analytical Line. Final packaging will be completed by September 1996.

Pending completion of the repackaging effort, compensatory measures are in effect at Mound to reduce the hazard to personnel. These include the control of personnel access, fire protection (e.g., sprinklers), and continuous air monitoring of the storage vaults. In addition, frequent visual surveillance, surface contamination swipes of packages, and periodic radioactive readings are conducted to ensure that significant releases would be detected quickly.

\section{OAK RIDGE}

Breaches of containers with unknown packaging configurations at Oak Ridge in combination with degraded facility conditions could result in a release of plutonium material to the environment (OR4, OR-11).

These two vulnerabilities at Oak Ridge are of low likelihood, but high consequence to workers and the environment. One arises from uncertainties regarding material packaging. Several buildings have packages of plutonium and other transuranics for which the first-layer containment is unknown. To correct this vulnerability, containers with unknown packaging configurations will be placed in a glovebox, opened, surveyed, inventoried, and repackaged for shipment and disposal. This activity is projected for completion by December 1996. The outer storage containers will be inspected during material control and accountability inventories for evidence of deterioration.

The other vulnerability involves the Building 9213 source storage vault. Corrosion and aging may lead to breach of containers and subsequent contamination and personnel radiation exposure. The source storage vault contains many radioactive sources, some of which are transuranic, two of which are plutonium. Building 9213 is intended for interim storage of these sources. Corrective actions will include a review of the source storage practices for Building 9213 by March 1995 and correction of any identified deficiencies.

Compensatory measures in place include the control of personnel access in the storage areas and air sampling of the vault areas during the next three inventory periods and provide technical justification for continuance of air sampling.

\section{COMPLEX-WIDE INSTITUTIONAL VULNERABILITIES IDENTIFIED IN THE WORKING GROUP REPORT}

In addition to the site-specific vulnerabilities discussed earlier, the vulnerability assessment includes several institurional vulnerabilities, which are summarized in this section. Institutional vulnerabilities are weaknesses in administrative or management controls that, should they remain uncorrected, can cause recurrence or aggravation of physical vulnerabilities.

\section{INCOMPLETE AUTHORIZATION BASES}

Most plutonium facilities do not bave complete and updated authorization bases (safety analyses, operational safety requirements, safety and operational limits, and administrative controls consistent with their current Environmental Management missions).

A DOE-wide program under EM's Office of Safety and Health is addressing, on a priority basis, the need for approved and current authorization bases for EM facilities throughout the DOE Complex. A similar program exists for the Office of Defense Program facilities. This activity was initiated as a result of the prior Spent Fuels Vulnerability Assessment. The Department's response to DNFSB 94-1 also addresses this issue, committing the Department not only to preparing an IPP, but also to taking action to meet the requirements of DOE 5480.31, Startup and Restart of Nuclear Facilities. Within this Order are requirements for order compliance as part of the ORR. Two facilities (Building 707 at Rocky Flats and F-Canyon at Savannah River) have successfully completed ORRs in 1994.

\section{OPERATIONAL WEAKNESSES}

The most commonly identified institutional vulnerabilities are operational weaknesses such as problems with conduct of operations, excessive maintenance backlogs, incomplete surveillance of materiallpackaging and equipment conditions, poor radiation protection, and poor configuration control.

Operational weaknesses are being addressed throughout the DOE Complex by enhanced training and retraining activities at all major sites. A mentor system to further improve conduct-ofoperations discipline is in place at Los Alamos National Laboratory and Rocky Flats. These enhancements are described in the responses to prior DNFSB recommendations. Facilities scheduled for stabilizing materials will be restarted in accordance with DOE 5480.31, which contains requirements designed to ensure that facilities are not operated prior to correcting operational weaknesses. 


\section{LOSS OF EXPERIENCED PERSONNEL}

Operators, engineers, and managers experienced in plutonium production processing and knowledgeable about plant histories (e.g., contamination incidents) have left as a result of retirement, layoffs, and mission changes.

The Department is addressing this problem throughout the DOE Complex in accordance with the Department's Implementation Plan for DNFSB Recommendation 93-3, Improving the Technical Capability in Defense Nuclear Facilities Programs and Training and Qualification.

Specifically, we are developing written Qualification Standards for technical personnel which will describe required competencies and associated knowledge, skills and abilities which must be satisfied by those individuals who occupy jobs which are critical to nuclear safety, including those which relate to handling of plutonium. Codifying these requirements will assist us in ensuring that experience and knowledge critical to job performance is not lost when an employee leaves the job and will help ensure that the training and knowledge base necessary for a person to occupy a given position, such as a newly-hired person, will be met.

The Qualifications Standards will be issued by May 1995. The Qualification Program will be implemented, i.e., each covered individual will have determined where additional training is required, by December 1995.

Additional actions that are being taken include staffing field operations with additional personnel to provide oversight to operations and using the national laboratories to provide additional technical strengths to operations, e.g., the use of Los Alamos to support Rocky Flats.

\section{MISSION CHANGE PROBLEMS}

The mission for most plutonium facilities changed suddenly from weapons production to interim storage. The facilities, packaging, and administrative controls were not designed for extended storage of plutonium.

This vulnerability is being addressed by a combination of activities discussed earlier in the Management Plan. These activities include stabilizing and repackaging material so that it is suitable for interim storage, interim corrective actions until the stabilization/repackaging can be accomplished, revising safety documentation so that it is consistent with the new facility mission, and revising training and administrative controls to be consistent with the new mission.

\section{REQUIREMENTS CONFLICTS}

Conflicting or contradictory requirements affect most sites. Site contractors are sometimes required by state regulators to inspect plutonium materials containing bazardous waste components frequently (often daily). At some sites, interpretation of safeguards and security inspection requirements results in excessive numbers of workers performing the necessary tasks.

While not all requirements conflicts can be readily resolved, preplanning and stakeholder involvement will help to minimize these conflicts. The IPP will provide the stakeholders with the Department's plans, and potential conflicts with other regulatory agencies can be identified and addressed in a timely manner. In many cases, resolution of a conflict may result in improved and accelerated disposition of a vulnerability. Participation by stakeholders and by a fully informed public may also facilitate early resolution of conflicts. 
CAP corrective action plan

CMR Chemistry and Metallurgy Research (Building), LANL

DNFSB Defense Nuclear Facilities Safety Board

D\&D Decontamination and Decommissioning

DOE U.S. Department of Energy

EH DOE Office of Environmental, Safety and Health

EIS Environmental Impact Statement

EM DOE Office of Environmental Management

HEPA high efficiency particulate air (filter)

IPP Integrated Program Plan

LANL Los Alamos National Laboratory

LLNL Lawrence Livermore National Laboratory

$\mathrm{M} \& \mathrm{O}$ management and operations

NASA National Aeronautics and Space Administration

NEPA National Environmental Policy Act

ORNL Oak Ridge National Laboratory

PFP Plutonium Finishing Plant

RFP Rocky Flats Plant

RL Richland (Hanford)

RTG Radioisotope Thermoelectric Generator

SRS Savannah River Site actinide - any element in a series of elements of increasing atomic numbers beginning with actinium (89) or thorium (90) and ending with element of atomic number 103.

facility condition vulnerabilities - potential for failures of physical barriers such as equipment, buildings, or safety systems; and holdup of plutonium in a facility.

gloveboxes - filtered and ventilated enclosures that allow handling of hazardous materials without direct worker contact with the material.

institutional vulnerabilities - administrative or management weaknesses that are underlying causes or significant contributors to material/packaging and facility condition vulnerabilities.

material/packaging vulnerabilities - related to design deficiencies and degradation of plutonium materials and packaging due to corrosion, radiolytic damage, or changes in plutonium form.

pyrophoric - capable of spontaneous ignition in air at or below room temperature in the absence of added heat, shock, or friction.

radiolysis - chemical decomposition by the action of radiation.

skulls - low-density residues from plutonium metal casting operations that have a high surface area, making them pyrophoric.

thermal stabilization - a process of converting potentially pyrophoric plutonium into a stable form which is more safe for storage and transportation.

transuranic materials - elements having atomic numbers greater than that of uranium (i.e., 92).

Working Group - the Plutonium Working Group, made up of over 150 DOE staff, site contractors, consultants, and stakeholders, who planned and directed the plutonium vulnerability assessment. 


\section{ATTACHMENT A}

\section{CORRECTIVE ACTION SCHEDULE}




\section{ROCKY FLATS}

RFP-371-06 Container failures could occur

RFP-776-06 due to packaging or the physi-

RFP-707-05 cal condition of the material

RFP-771-01 in storage. Tanks and piping

RFP-SW-R containing plutonium liquids are susceptible to operational transfer errors. These conditions could result in worker contamination and exposure. $\underline{\text { Liquids }}$

Interim measures to minimize risk (e.g., restricted access, alarm systems, plastic shrink wrap, spill and leak contingency plans)

Vent bottles and place in gloveboxes

Solidify liquids in 385 bottles in Building 771

Drain four tanks in Building 771

Decision to accelerate liquids schedule

Environmental assessment for liquid stabilization

Equipment upgrade for the processing system in Building 371

Building 771 preparations complete

6,500 liters in Building 371 will be processed

Six tanks in Building 371 drained and processed

Complete solidification of liquids in bottles

Solidify $80 \%$ of high-level liquids and $50 \%$ of low-level liquids

Complete solidification of Building 771's liquids

Complete solidification of Building 371's liquids

Complete

Complete

Complete

Complete

Complete

Apr 1995

Nov 1995

Apr 1996

Aug 1996

Nov 1996

Feb 1997

May 1997

Dec 1997

Jun 1999

$\underline{\text { Skulls }}$

Packages in Building 777 suspected to contain skulls

do not have skulls but will be repackaged

Inspect and repackage as necessary, packages in

Building 371 suspected to contain skulls

Complete

Mar 1995

Residues

Action plans and technical justification for safe-storage criteria

Vent residue drums

Apr 1995

Oct 1995

Metals

Repackage first $5 \%$ of metal to remove plastic

Repackage remaining metal to remove plastic

Complete

Oct 1995

Publish DOE Storage Standard

Repackage per DOE Storage Standard

Complete

May 2002

Develop implementation plan for Preventive Maintenance Program

Mar 1995

Test all required HEPA filters
RFP-707-03 ed ventilation system testing

RFP-771-04 and maintenance could lead to

RFP-776-04 loss of confinement.

RFP-779-04

RFP-SW-I Large internal fires and explo-

RFP-559-02 sions in these buildings may

RFP-707-02 breach confinement through

RFP-771-02 failure of the ventilation sys-

RFP-776-02 tem or structure.
Remove unnecessary oxygen and acetylene bottles, reduce the size and hard pipe the instrument bottles

Administrative controls on location and use of oxygen and acetylene Install fire detection and suppression systems, remove combustible materials, and implement operator training and administrative controls Evaluate storage of residues and waste in plutonium areas

Filter vent 940 residue drums

Filter vent 2000 more residue drums

Filter vent remaining residue drums

Construct new seismic-resistant vaults in Building 371

Remove plutonium metal and oxide from Building 991 to new vaults

Remove plutonium metal and oxide from Building 779 to new vaults

Remove plutonium metal and oxide from Building 771 to new vaults

Remove plutonium metal and oxide from Building 776/777 to new vaults

Remove plutonium metal and oxide from Building 707 to new vaults
Complete

Complete

Complete

Apr 1995

Complete

Oct 1995

1996

Oct 1995

Oct 1995

Dec 1996

Sep 1997

Jun 1998

May 2000 


\section{VULNERABILITIES}

\section{CORRECTIVE ACTION STEPS}

SCHEDULE

\section{ROCKY FLATS (continued)}

RFP-559-08 These buildings are susceptible RFP-707-07 to earthquake damage to buildRFP-771-08 ing structures or safety systems. RFP-776-08 Buildings 776 and 559 are susRFP-779-08 ceptible to damage from high RFP-779-A winds.
Upgrade portions of two buildings to withstand earthquakes

Reduce vulnerability of Building 559 by removal of most plutonium and administrative controls on the remainder

Construct new seismic-resistant vaults in Building 371

Remove plutonium metal and oxide from Building 779 to new vaults

Remove plutonium metal and oxide from Building 771 to new vaults

Remove plutonium metal and oxide from Building 707 to new vaults

As the site consolidates and repackages its plutonium as covered in the other vulnerabilities, this vulnerability will be eliminated for Building 779 and 776 . The vulnerability has been significantly reduced for Building 559 by removal of most plutonium and administrative controls on the remainder.
RFP-559-05

RFP-776-10

RFP-779-10
Aircraft crashes into these buildings could result in structural damage and off site release of plutonium. protect HEPA filters from fires. Water-soaked filters could fail, releasing plutonium off sire.

RFP-SW-G Breaches of facility integrity or confinement system failures could result in a direct pathway for the release of plutonium to the environment.
Test all required HEPA filters

Develop implementation plan for Preventive Maintenance Program
Complete

Complete

Oct 1995

Dec 1996

Sep 1997

Mar 2001

Not

applicable

\begin{tabular}{ll} 
RFP-SW-O & $\begin{array}{l}\text { Water spray systems are used to } \\
\text { protect HEPA filters from fires. } \\
\text { Water-soaked filters could fail, } \\
\text { releasing plutonium off site. }\end{array}$ \\
\hline RFP-SW-G & $\begin{array}{l}\text { Breaches of facility integrity or } \\
\text { confinement system failures } \\
\text { could result in a direct pathway } \\
\text { for the release of plutonium to } \\
\text { the environment. }\end{array}$
\end{tabular}

\section{HANFORD}

\begin{tabular}{ll}
\hline RL-3.1.3.1 & Container failures could occur \\
RL-3.1.3.2 & due to the physical condition of \\
RL-3.1.3.3 & the material in storage, which \\
RL-3.1.3.4 & $\begin{array}{l}\text { could result in worker contami- } \\
\text { nation and exposure. }\end{array}$
\end{tabular}

RL-3.1.3.1

RL-3.1.3.2

RL-3.1.3.3 nation and exposure.
Interim measures to reduce risk (e.g., liquids in vaults, restricted access, filtered air)

Publish DOE Storage Standard

Release Characterization Implementation Plan

Release draft EIS for cleanout and deactivation of PFP

Complete thermal stabilization of plutonium bearing sludge

Implement a program to repackage chloride and fluoride liquids

Properly vent suspect containers of plutonium nitrate
Complete

Mar 1995
RL-3.3.1.1 Fifteen retired facilities have plutonium remaining in equipment or underneath sealants such as paint.

\section{Complete assessment of affected facilities}

Close offices in Building 231-Z

Close all other office spaces in these facilities
Complete

Complete

Mar 1995

Aug 1995

Aug 1995

Sep 1995

Dec 1995
Mar 1995

Mar 1995

Dec 1995

\footnotetext{
RL-3.3.1.2 Breaches of facility integrity or confinement systems could result in a direct pathway for release of plutonium to the environment. Fires could result in off site releases of plutonium.
} Deactivation of Building 308 Deactivation of Building 309 1998 Decontamination and decommissioning of facilities

Note 1: Schedule still under development and will be in the Site Integrated Stabilization Management Plan. 


\section{LOS ALAMOS NATIONAL LABORATORY}

LANL-TA-55-4 Transport of plutonium samples across open roads could result in accidents releasing sample materials to the environment.
Significantly reduce the need for shipment by constructing metal analysis capability at TA55

Sep 1995

\section{SAVANNAH RIVER}

$\begin{array}{ll}\text { SRS-FC-02 } & \text { Plutonium liquids stored in large } \\ \text { SRS-HC-02 } & \begin{array}{l}\text { tanks in the F- and H-canyons are } \\ \text { unsuitable for extended storage. }\end{array}\end{array}$
unsuitable for extended storage.
Issue draft EIS for plutonium liquids in F-Canyon

Record of Decision for F-Canyon plutonium liquids

Record of Decision for H-Canyon plutonium liquids

Expected completion of $\mathrm{H}-$ Canyon plutonium-242 liquids

stabilization if processing selected in ROD (Note 2)

Expected completion of F-Canyon plutonium liquids stabilization if processing selected in ROD (Note 2)

Stabilization of plutonium-239 liquids in H-Canyon (Note 2)

Nuclear materials located within these facilities are currently safely contained.

Decontamination and decommissioning of the facilities
Complete

Complete

May 1995

Late 1997

1996

Early 2000

SRS-OHBL-2 Holdup in Old HB-Line, Building

SRS-B235-1 235-F, and F-Canyon could result

SR-FC-5 in release of plutonium to the environment, especially during decontamination and decommissioning.

Note 1

SRS-B235-6 Breaches of plutonium-238 packages in combination with degraded facility conditions could resule in release of plutonium to the environment.

\section{LAWRENCE LIVERMORE NATIONAL LABORATORY}

LLNL-B332-02 Workers are subject to unknown hazards from 282 plutonium containers that have uncharacterized material and unknown package configurations.
Repackage bulged cans and overpack all cans of ash

Compensatory measures to minimize hazards to workers

Develop characterization program

Establish action plans for safe long-term storage for all excess materials

Complete characterization program implementation

1




\section{ATTACHMENT B}

\section{RESPONSE TO DNFSB RECOMMENDATION 94-1}




\section{DEFENSE NUCLEAR FACILITY SAFETY BOARD}

\section{RECOMMENDATION 94- 1}

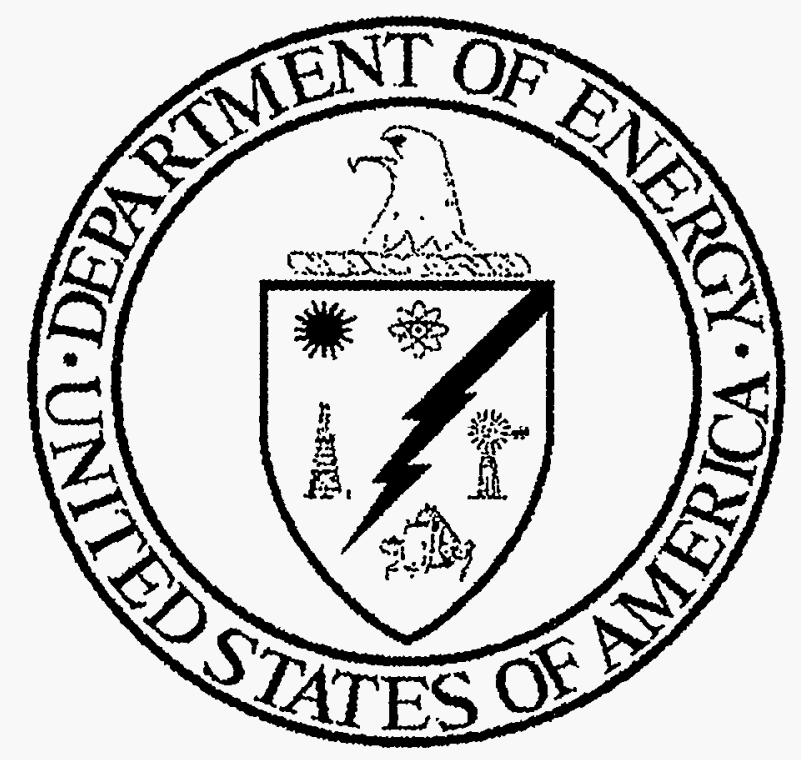

IMPLEMENTATION PLAN

FEBRUARY 28, 1995 


\title{
DNFSB Recommendation 94-1 \\ Implementation Plan \\ February 28, 1995
}

\author{
Table of Contents
}

Section 1: $\quad$ Executive Summary $\ldots \ldots \ldots \ldots \ldots \ldots \ldots \ldots \ldots \ldots \ldots \ldots \ldots$

Section 2: $\quad$ Organization and Management $\ldots \ldots \ldots \ldots \ldots \ldots \ldots \ldots \ldots$

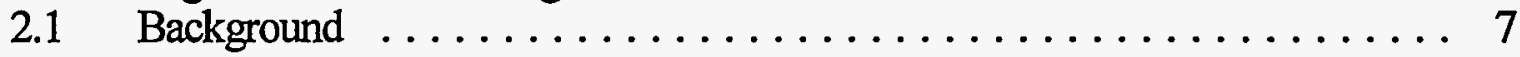

2.2 Integration and Management Method $\ldots \ldots \ldots \ldots \ldots \ldots \ldots \ldots$

2.3 Project Approach ......................... 13

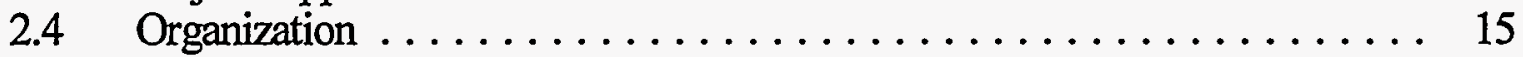

2.5 Organization and Functions $\ldots \ldots \ldots \ldots \ldots \ldots \ldots \ldots \ldots \ldots \ldots \ldots$

2.5.1 Nuclear Materials Stabilization Task Group . . . . . . . . 15

2.5.2 Integration Working Group . . . . . . . . . . . . . 17

2.5.3 Research and Technology Development (R\&TD) Steering

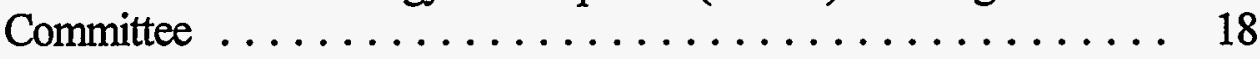

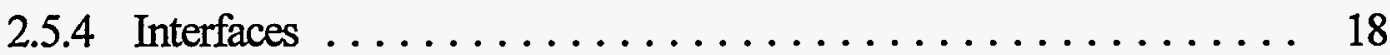

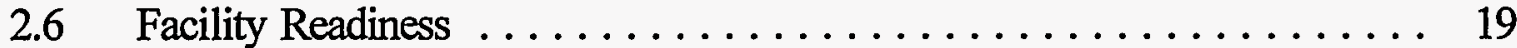

2.7 Integrated Research and Technology Development . . . . . . . . . 23

2.7.1 Background ........................ 23

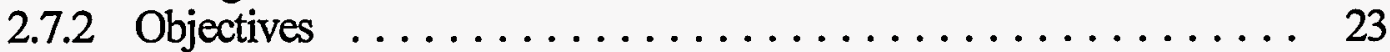

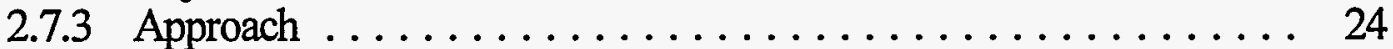

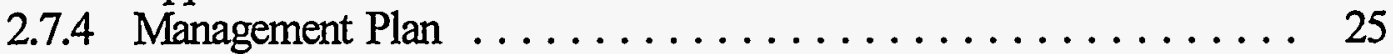

2.7.5 Milestones and Commitments ................ 25

2.8 General Issues . . . . . . . . . . . . . . . . . . . . . . . . 25

2.8.1 Relationship to Plutonium Vulnerability Assessment . . . . . . 25

2.8.2 Impact of Presidential Decision Directive 13 on Stabilization .... 26

2.8.3 Impact of International Inspections on Stabilization . . . . . . 26

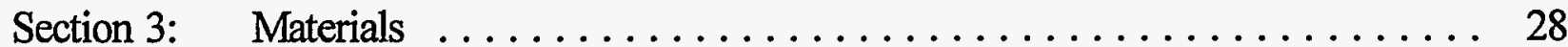

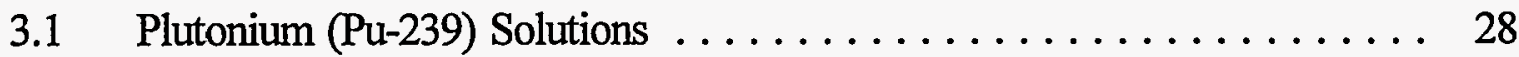

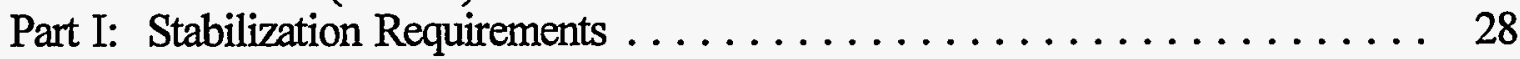

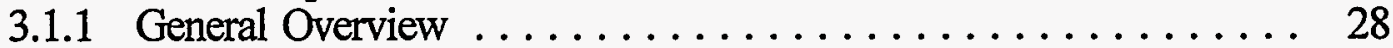

Part II: Plutonium Solution Integration Activities $\ldots \ldots \ldots \ldots \ldots \ldots \ldots .30$

Part III: Individual Solutions at Rocky Flats . . . . . . . . . . . . . 32

3.1.2 Plutonium (Pu-239) Solutions at Rocky Flats . . . . . . . 32

3.1.3 Plutonium Solutions at the Savannah River Site $\ldots \ldots \ldots \ldots . . . .33$

3.1.4 Plutonium (Pu-239) Solutions at Hanford . . . . . . . . . . 34

3.1 .5 Key Milestones . . . . . . . . . . . . . . . . 36 
3.2 Plutonium Metals and Oxides $(>50 \%$ assay) $\ldots \ldots \ldots \ldots \ldots \ldots \ldots$

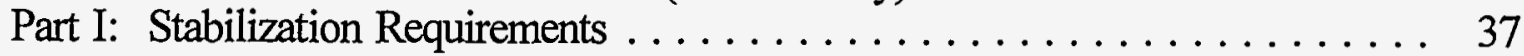

3.2.1 General Overview . . . . . . . . . . . . . . . . . . . . 37

Part II: Plutonium Metal and Oxide ( $>50 \%$ Assay) Integration Activities . . . . . 41

Part III: Individual Site Activities . . . . . . . . . . . . . . . . . . . . . . 44

3.2.2 Implementation Approach for Rocky Flats Plutonium Metals and Oxides .............................. 44

3.2.3 Implementation Approach for Savannah River Plutonium Metals and Oxides ........................... 45

3.2.4 Implementation Approach for Hanford Plutonium Metals and Oxides ............................ 46

3.2.5 Implementation Approach for Los Alamos Plutonium Metals and Oxides . . . . . .................... 47

3.2.6 Implementation Approach for Lawrence Livermore Plutonium Metals and Oxides . . . . . . . . . . . . . . . . . 48

3.2.7 Implementation Approach for Other DOE Site Plutonium Metals and Oxides .......................... 49

3.2.8 Key Milestones . . . . . . . . . . . . . . . . . . . . . . . 49

$3.3 \quad$ Plutonium Residues and Mixed Oxides $(<50 \%$ assay $) \ldots \ldots \ldots \ldots \ldots 50$

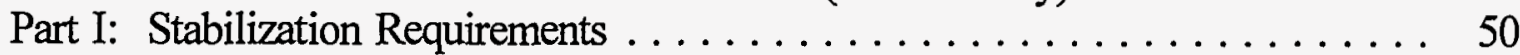

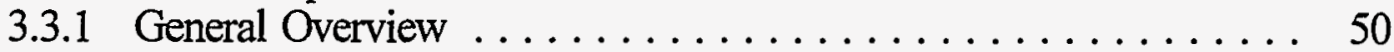

Part II: Plutonium Residues and Mixed Oxides Integration Activities . . . . . . . 55

Part III: Individual Site Activities . . . . . . . . . . . . . . . . . . . 59

3.3.2 Rocky Flats Plutonium Residues . . . . . . . . . . . . . 59

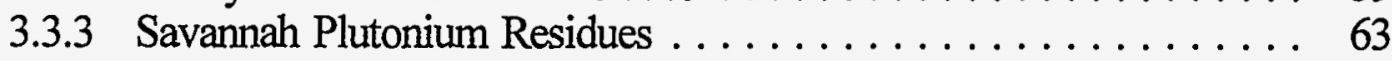

3.3.4 Hanford Plutonium Residues . . . . . . . . . . . . . . . . . . . 65

3.3.5 Los Alamos Plutonium Residues . . . . . . . . . . . . . . . . . . 68

3.3.6 Lawrence Livermore Plutonium Residues . . . . . . . . . . . . . . 70

3.3.7 Other Plutonium Residues . . . . . . . . . . . . . . . 71

3.3-8 Key Milestones . . . . . . . . . . . . . . . . . 72

$3.4 \quad$ Special Isotopes $\ldots \ldots \ldots \ldots \ldots \ldots \ldots \ldots \ldots \ldots \ldots \ldots \ldots$

Part I : Stabilization Requirements . . . . . . . . . . . . . . 73

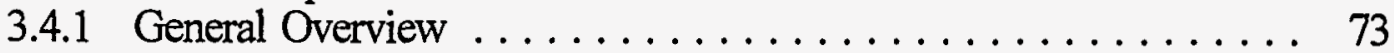

Part II: Special Isotopes Integration Activities $\ldots \ldots \ldots \ldots \ldots \ldots \ldots \ldots \ldots 77$

Part III: Individual Site Activities . . . . . . . . . . . . . . . . . . . . . . 79

3.4.2 Savannah River Americium-Curium Solution ............ 79

3.4.3 Savannah River H-Canyon Plutonium-242 Solution . . . . . . . . . 80

3.4.4 Savannah River H-Canyon Neptunium Solution . . . . . . . . . . . 81

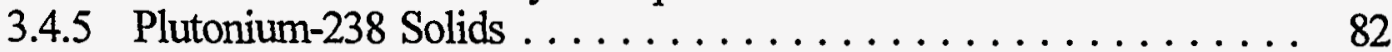

3.4.6 Other Special Isotope Concerns . . . . . . . . . . . . . . . . . 83

3.4.7 Key Milestone Schedule . . . . . . . . . . . . . . . . . . . 83

3.5 Uranium . . . . . . . . . . . . . . . . . . . . . . . 84

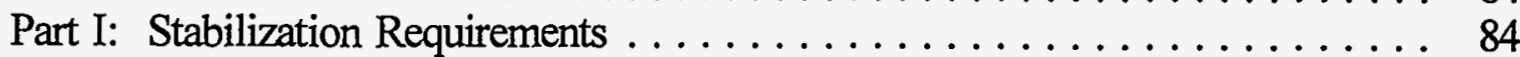

3.5.1 General Overview ...................... 84

Part II: Uranium Integration Activities $\quad \ldots \ldots \ldots \ldots \ldots \ldots \ldots \ldots . \quad \ldots 7$

Part III: Individual Site Activities . . . . . . . . . . . . . . . . . . . . 89

3.5.2 Uranium Solutions at Rocky Flats . . . . . . . . . . . 89 
3.5.3 Uranium Solutions at Savannah River . . . . . . . . . . . . 89

3.5.4 Uranium Residues Needing Stabilization at Oak Ridge ... . . . 90

3.5.5 Los Alamos Uranium Residues . . . . . . . . . . . . . . . . . . 92

3.5.6 Idaho Enriched Uranium Materials . . . . . . . . . . . . . . . . . . 92

3.5.7 Key Milestones . . . . . . . . . . . . . . . . . . . . 93

$3.6 \quad$ Spent Nuclear Fuel $\ldots \ldots \ldots \ldots \ldots \ldots \ldots \ldots \ldots \ldots \ldots \ldots$

Part I: Stabilization Requirements $\ldots \ldots \ldots \ldots \ldots \ldots \ldots \ldots \ldots \ldots \ldots$

3.6.1 General Overview ...................... 94

Part II: Spent Nuclear Fuel Integration Activities . . . . . . . . . . . . 98

Part III: Individual Site Activity Plans . . . . . . . . . . . . . . . 103

3.6.2 Hanford Spent Nuclear Fuel . . . . . . . . . . . . . . . . 103

3.6.3 Savannah River Spent Nuclear Fuel $\ldots \ldots \ldots \ldots \ldots \ldots$. . . . 107

3.6.4 Idaho Spent Nuclear Fuel . . . . . . . . . . . . . . . 112

3.6 .5 Key Milestones . . . . . . . . . . . . . . . . . . 114

Appendix A - List Of Acronyms And Abbreviations $\ldots \ldots \ldots \ldots \ldots \ldots$

Appendix B - Glossary . . . . . . . . . . . . . . . . . . . . . . . . 119

\section{Figures and Tables}

Figure 2.2-1: Nuclear Material Stabilization Task Group

Implementation Plan Material Categories . . . . . . . . . . . . 10

Figure 2.3-1: Stabilization Integration Process $\ldots \ldots \ldots \ldots \ldots \ldots \ldots \ldots$.

Figure 2.4-1: Nuclear Materials Stabilization Task Group $\ldots \ldots \ldots \ldots \ldots 16$

Figure 3.1-1: Plutonium Solutions Stabilization $\ldots \ldots \ldots \ldots \ldots \ldots \ldots \ldots$

Table 3.2-1: Plutonium Metals . . . . . . . . . . . . . . . . . . . 37

Table 3.2-2: Plutonium Oxides ( $>50 \%$ Assay) $\ldots \ldots \ldots \ldots \ldots \ldots \ldots \ldots$

Figure 3.2-1: Metal and Oxide Stabilization ................ 42

Table 3.3-1: Summary of Plutonium Residue and Mixed Oxides $(<50 \%$

Assay) ............................ 51

Figure 3.3-1: Pu Residues and Mixed Oxides Flow Chart $\ldots \ldots \ldots \ldots \ldots .53$

Table 3.3-2: Rocky Flats Residues . . . . . . . . . . . . . . . 60

Figure 3.3-2: Rocky Flats Residues - Item Description Codes (IDC)

Risk Breakouts ........................... 61

Table 3.3-3: Savannah River Residues . . . . . . . . . . . . . . . . . . . . . 64

Table 3.3-4: Hanford Plutonium Residues $\ldots \ldots \ldots \ldots \ldots \ldots \ldots \ldots 6$

Table 3.3-5: Plutonium Inventory . . . . . . . . . . . . . . . 68

Table 3.3-6: Baseline Processing Approach by Residue Category . . . . . . . . 69

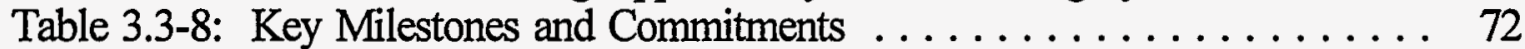

Table 3.4-1: Special Isotopes Holdings $\ldots \ldots \ldots \ldots \ldots \ldots \ldots \ldots \ldots$

Figure 3.4-1: Management of Special Isotopes . . . . . . . . . . 78

Table 3.5-1: Materials Requiring Stabilization or Conversion for

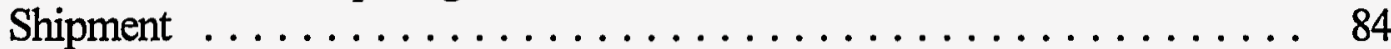

Figure 3.5-1: HEU Disposition . . . . . . . . . . . . . . . 88

Table 3.6-1: DOE Spent Nuclear Fuel Inventory Summary . . . . . . . . 96

Figure 3.6-1: SNF Program Technical Functions . . . . . . . . . . . . . . 99 


\section{Section 1: Executive Summary}

The Defense Nuclear Facilities Safety Board (DNFSB or the Board) issued Recommendation 94-1 on May 26, 1994. The Department of Energy (DOE or the Department) accepted the Board's Recommendation on August 31, 1994, and hereby submits its Implementation Plan. The Board noted, in Recommendation 94-1, that it was concerned that the halt in production of materials to be used in nuclear weapons froze the manufacturing pipeline in a state that, for safety reasons, should not be allowed to persist unremediated. Specifically, the Board expressed concern about certain liquids and solids containing fissile materials and other radioactive substances located in spent fuel storage pools, reactor basins, reprocessing canyons; and various other facilities once used for processing and weapons manufacture. The Department acknowledges and shares the Board's concerns and has developed this integrated program plan to address these urgent problems.

The measures outlined in this plan to stabilize nuclear materials constitute the first step in implementing an integrated management process to address these urgent issues. The implementation plan establishes the Headquarters Nuclear Materials Stabilization Task Group,reporting directly to the Under Secretary, is established to specifically address the stabilization of nuclear materials. This Task Group will integrate activities across the sites and the material categories, making the most efficient use of the complex's facilitiesvand will examine methods and alternatives for improving practices and schedules as this effort progresses.

The Department has broadened the scope of the response to Recommendation 94-1 to include additional bulk liquids and solids containing fissile materials and other radioactive substances in spent fuel storage pools, reactor basins, reprocessing canyons, processing lines and various facilities which require conversion to forms, or establishing conditions, suitable for safe interim storage. The scope was broadened to ensure that similar materials under similar conditions receive the same degree of management attention as those noted by the Board in its Recommendation.

This Implementation Plan is organized into two major sections:

- Organization and Management - Details the systems engineering approach and responsibility and the formation of the Nuclear Materials Stabilization Task Group for ensuring the Department achieves the commitments detailed in the Implementation Plan. An Integration Working Group (IWG), composed of technical representatives from key sites, will support and report to the Task Group for purposes of ensuring the best integration of materials stabilization between sites. A Research and Technology Development (R\&TD) Steering Committee will support and report to the Task Group on research and technology development needs for the integrated stabilization program.

- $\quad$ Materials - Organizes materials by types; that is: plutonium solutions, plutonium metals and oxides ( $>50 \mathrm{wt. \%})$, plutonium residues and oxides ( $<50 \mathrm{wt} . \%)$, special isotopes, selected uranium, and spent nuclear fuel. Each material discussion provides the overall plans and timelines for stabilization activities across the complex. 
The commitments contained herein are summarized below. In most cases, the Department meets the time periods recommended by the Board for conversion and placement in safe, secure storage of the material. In cases where the recommended time frame cannot be met, compensatory measures to ensure safety have been, and will continue to be taken until all such materials are in a safe and suitable form. The reasons for not meeting Other actions are being considered which would result in the acceleration of stabilization activities; however, many of the committed actions are contingent upon environmental and other trade studies that have not yet been completed. The completion dates noted in this Implementation Plan are based on the assumption that preferred alternatives of the studies will be selected. In the event a situation arises that presents an imminent hazard to workers, the public, or the environment, the Department will take whatever action is necessary to mitigate the risk.

\section{Summary of Departmental Commitments to DNFSB Recommendation 94-1}

\section{Sub-recommendation (1):}

That an integrated program plan be formulated on a high priority basis, to convert within 2-3 years the materials addressed in the specific recommendations below, to forms or conditions suitable for safe interim storage. This plan should recognize that remediation will require a systems engineering approach, involving integration of facilities and copabilities at a number of sites, and will require attention to limiting worker exposure and minimizing generation of additional waste and emission of effluents to the environment. The plan should include a provision that, within a reasonable period of time (such as eight years), all storage of plutonium metal and oxide should be in conformance with the draft DOE Standard on storage of plutonium now being made final.

\section{Commitment:}

This Implementation Plan is the integrated program plan. It provides the schedules and major milestones in each material category for achieving the recommended objectives. It will be modified by future program direction and schedule adjustments.

All separated plutonium metal and oxide will be repackaged to meet the metal and oxide storage standard by May 2002. A trade study will be completed by May 15, 1995 that will examine the need to complete this activity for all sites by 2002 . The study will consider factors such as risk to workers and public, radiation exposure to personnel, waste minimization, discharges to the environment, cost impacts, and impact on other activities. Based upon the results of the study, the Department may propose an alternate schedule for certain sites. 


\section{Sub-recommendation (2):}

That a research program be established to fill any gaps in the information base needed for choosing among the alternate processes to be used in safe interim conversion of various types of fissile materials to optimal forms for safe interim storage and the longer term disposition. Development of this research program should be addressed in the program plan called for by (1) above.

\section{Commitment:}

By May 1995, a Research and Technology Development Steering Committee will be established to define, coordinate and monitor research and technology development efforts to support nuclear material stabilization activities and to ensure a core of technology development activity exists to support nuclear material stabilization. By November 1995, the steering committee will have assessed current research and technology development efforts against complex-wide nuclear material stabilization needs, identified areas where initial research and technology development efforts are to be strengthened, and presented this analysis to the Nuclear Materials Stabilization Task Group in a comprehensive research and technology development plan. Research and technology development efforts will be measured against the comprehensive plan, which will be annually updated.

\section{Sub-recommendation (3):}

That preparations be expedited to process the dissolved plutonium and trans-plutonium isotopes in tanks in the F-Canyon at the Savannah River Site into forms safer for interim storage. The Board considers this problem to be especially urgent.

\section{Commitment:}

A stabilization method for the Savannah River Site F-Canyon has been selected and stabilization of plutonium solutions began in February 1995 and will be completed by January 1996. A conceptual design report for the stabilization of americium/curium solutions will be completed by December 1995. All americium/curium solutions will be stabilized by September 1998. Other solutions, not specifically mentioned in this recommendation but addressed in this plan, will be stabilized in accordance with the following schedule:

Pu solutions (Rocky Flats) . . . . . . . . . . . . . . . . . . June 1999

Pu solutions in PUREX (Hanford) . . . . . . . . . . . . . . August 1995

Pu solutions in PFP (Hanford) . . . . . . . . . . . . . . . . . . January 1999

Pu-239 solution in H-Canyon (Savannah River Site) . . . . . . . . . . . August 1999

Pu-242 solution in H-Canyon (Savannah River Site) . . . . . . . . . . . November 1997

Neptunium solutions in H-Canyon (Savannah River Site) . . . . . . . December 2002 HEU Solutions (Rocky Flats) . . . . . . . . . . . . . . . . . . . December 1996 HEU Solutions (Savannah River Site) . . . . . . . . . . . . . . December 1997 


\section{Sub-recommendation (4):}

That preparations be expedited to repackage the plutonium metal that is in contact with, or in proximity to, plastic or to eliminate the associated existing hazard in any other way that is feasible and reliable. Storage of plutonium materials generated through this remediation process should be such that containers need not be opened again for additional treatment for a reasonably long time.

\section{Commitment:}

All plutonium metal in direct contact with plastic will be repackaged by December 1995. Plutonium metal in proximity to plastic will be repackaged when the capability exists for meeting the Department's storage standard, unless surveillance detects containers requiring immediate repackaging.

\section{Sub-recommendation (5):}

That preparations be expedited to process the containers of possibly unstable residues at the Rocky Flats Plant and to convert constituent plutonium to a form suitable for safe interim storage.

\section{Commitment:}

Higher risk residues at the Rocky Falts Environemtal Technology Site will be stabilized as follows:

Vent 2,045 residue drums with potential hydrogen building . . . . . . . October 1995 Vent inorganic residues and wet/miscellaneous residues .......... October 1996 Bulk $(6,000 \mathrm{kgs}$ of high-hazard pyrochemical salts . . . . . . . . . . . May 1997 High-hazard sand, slag, and cruciable and graphite fines . . . . . . . . . . May 1997 Remainder (4,000 kgs) of high-hazard pyrochemical salts . . . . . . . December 1997 High-hazard combustibles . . . . . . . . . . . . . . . . . . . . November 1998 Repackage inorganic ixides and wet/miscellaneous residues . . . . . . . . May 2002

Residues at other sites, not specifically addressed in this recommendation will be stabilized according to the following schedules:

Pu Residue Sludge at Hanford . . . . . . . . . . . . . . . . . . September 1995 46 Packages of Ash at Hanford . . . . . . . . . . . . . . . . . . . . March 1996 All other residues at Hanford . . . . . . . . . . . . . . . . . . . May 2002 $220 \mathrm{kgs}$ of residues at Los Alamos National Laboratory . . . . . . . . . October 1995 Sand, slag \& crucibles at Savannah River . . . . . . . . . . . . . . December 1997 All other residues at Savannah River . . . . . . . . . . . . . . . . May 2002 


\section{Sub-recommendation (6):}

That preparations be expedited to process the deteriorating irradiated reactor fuel stored in basins at the Savannah River Site into a form suitable for safe interim storage until an option for ultimate disposition is selected.

\section{Commitment:}

The method for stabilizing fuel and targets at the Savannah River Site will be selected by June 1995. As an interim remedial measure, fuel storage basin water chemistry upgrades will be completed by May 1996. Pending the outcome of the Interim Management of Nuclear Materials Environmental Impact Statement (EIS), targets will be stabilized by September 1996; fuel dissolution will be completed by November 1999. Stabilization of resultant uranium solutions will be completed by April 2000.

\section{Sub-recommendation (7):}

That the program be accelerated to place the deteriorating reactor fuel in the $K$-East Basin at the Hanford Site in a stable configuration for interim storage until an option for ultimate disposition is chosen. This program needs to be directed toward storage methods that will minimize further deterioration.

\section{Commitment:}

A path forward for removing and storing fuel was selected in November 1994. Under the preferred alternative, fuel and sludge removal from K-Basins will be completed by December 1999. Interim measures have and will be taken including installing a cofferdam between the K-East Basin and the reactor discharge chute by April 1995. Fuel and sludge characterization in hot cells will begin by April 1995.

\section{Sub-recommendation (8):}

That those facilities that may be needed for future handling and treatment of the materials in question be maintained in a usable state. Candidate facilities include, among others, the Fand H-Canyons and the FB- and HB-Lines at the Savannah River Site, some plutoniumhandling glove box lines among those at the Rocky Flats Plant, the Los Alamos National Laboratory, and the Hanford Site, and certain facilities necessary to support a uranium handling capability at the Y-12 Plant at the Oak Ridge Site.

\section{Commitment:}

Sufficient capabilities will be retained to maintain future handling, treatment and safe storage of the materials addressed in this plan. A discussion of facilities currently in use or planned for use is included in Section 2.6. A comprehensive Integrated Facilities Requirements Plan will be prepared by December 1995. 


\section{Sub-recommendation (9):}

Expedited preparation to accomplish actions in items (3) through (7) above should take into account the need to meet the requirements for operational readiness in accordance with DOE Order 5480.31.

\section{Commitment:}

Facilities will be started or restarted in accordance with DOE Order 5480.31. These restart and start-up requirements will be taken into account in the development of the Integrated Facilities Requirements Plan. 


\section{Section 2: Organization and Management}

\subsection{Background}

When nuclear weapons were being produced and the stockpile was growing, the vast majority of fissile material scrap and materials from retired weapons was recycled. It was less costly to recover fissile materials from high assay scrap and retired weapons than to produce new material. As a result, very little scrap containing fissile material was considered surplus. Consequently, these materials were designed, handled, and packaged for short-term storage; therefore, when the weapon production lines were halted in the late 1980's, many materials were left in conditions unsuitable for longterm storage.

Recently, the Department of Energy (DOE) initiated activities to investigate the conditions of nuclear materials within the Department. Working groups were established to visit sites and assess the status of specific categories of nuclear material. The following reports provide a detailed description of the amount, location, condition and vulnerabilities associated with much of this material:

- $\quad$ Plutonium Working Group Report on Environmental, Safety and Health Vulnerabilities Associated with the Department's Plutonium Storage (Jamuary, 1995)

- $\quad$ Spent Fuel Working Group Report on Inventory and Storage of the Department's Spent Nuclear Fuel and Other Reactor Irrodiated Nuclear Materials and Their Environmental, Safety, and Health Vulnerabilities (November, 1993)

The Spent Fuel Working Group Report identified significant vulnerabilities causing the Department to initiate a trade study of alternative programmaticsolutions (i.e., a Programmatic Spent Nuclear Fuel Environmental Impact Statement Draft). This study is scheduled for issuance in April 1995 with a Record of Decision planned for June 1995.

The Defense Nuclear Facilities Safety Board (DNFSB) noted in Recommendation 94-1 in May 1994, and supporting staff reports in April 1994, that the halt in production of materials used in nuclear weapons froze the manufacturing pipeline in a state that, for safety reasons, should not be allowed to persist unremediated. The DNFSB noted special concern about specific liquids and solids containing fissile materials and other radioactive substances in spent fuel storage pools, reactor basins, reprocessing canyons and various facilities once used for processing and weapons manufacture.

The Departmental assessments identified above and the independent observations and concerns expressed by the DNFSB made the following issues clear: 
- There is an urgent requirement to address the growing technical problems associated with handling, stabilizing and storing excess nuclear material. These problems are especially noteworthy because the recent downsizing of the weapons complex has resulted in the loss, without replacement, of many of the skilled workers needed to correct the problems. This decreasing experience base, coupled with the increasing age of the facilities, makes the control of nuclear material and the prevention of inadvertent criticality events, uncontrolled exposure, and personnel contamination an increasing concern.

- The efforts to stabilize nuclear materials was heretofore limited to those undertaken by individual field organizations and constrained by each site's resources. Consequently, the stabilization of nuclear material was pursued with different priorities, assets and treatment techniques. Several mutually exclusive and, in some cases, duplicative programs evolved. Without a Departmental perspective, some options for solving the problem were not adequately assessed (e.g., transporting all material of a certain type to one site for processing, versus processing material at multiple sites).

These issues are growing more serious as evidenced by this Implementation Plan. The Department is strongly committed to marshalling the resources to stabilize its nuclear material safely.

\section{Key Assumptions}

In order to achieve the high-level commitments outlined in the Executive Summary, there are several underlying assumptions identified for each of the material categories presented in Section 3. These key assumptions include:

- $\quad$ Environmental and other trade studies will be used to develop alternatives; selection of a preferred alternative will be documented through Records of Decision. For most of the materials described in Section 3, the preferred alternatives identified as part of the NEPA process, are assumed to be consistent with the options described such that the milestone dates can be achieved. The NEPA process is a key aspect of stakeholder involvement.

- Adequate resources to address the identified issues will be made available in the time frame necessary to meet the milestones.

- The highly enriched uranium and plutonium contained in solutions/metals and oxides/residues/mixed oxides and spent nuclear fuel will be identified in the plan. 


\section{Key Challenges}

To achieve the objectives outlined previously several categories of challenges (i.e., potential barriers to progress) have been identified. These represent a roll-up of the material-specific challenges and barriers. These challenges include:

- Maintaining material handling, treatment, and storage capabilities. This involves compensating for using facilities beyond their nominal design life (aged facilities) and maintaining adequate personnel with the necessary critical skills while the Department undergoes personnel and budgetary cutbacks.

- Developing and implementing standards for handling, storing, and transporting nuclear materials, including a uniform risk classification scheme, that are compatible with as yet undeveloped disposition criteria.

- Developing and applying actions to rapidly remediate unacceptable conditions while ensuring necessary and sufficient compliance with applicable regulations including the National Environmental Policy Act (NEPA). This may involve negotiation with applicable state, national and international regulatory agencies.

- $\quad$ Researching and developing technologies and processes needed in order to progress toward disposition of certain classes of nuclear materials including certain categories of plutonium residues and spent nuclear fuel.

\subsection{Integration and Management Method}

Integration of the Department's nuclear material stabilization activities will be monitored through the management plans described below. The need for management action to set milestones will be identified in part through these plans, which will be updated monthly.

Integrated Program Plan (IPP): This Implementation Plan is the baseline IPP called for by Recommendation 94-1. The Plan will address the stabilization of the material categories identified in Figure 2.2-1, and will be modified by program decisions or as schedules change due to changes in program requirements.

Integrated Stabilization Management Plan (ISMP): This Plan will be composed of Material Integration Plans, the Research and Technology Development Plan, and Facilities Plans. These component plans will describe the complex-wide activities to be performed for all nuclear material categories.

Material Integration Plans (MIPs): Each MIP is the composite of the Site Integrated Stabilization Management Plans (SISMP) for each material category. 


\section{Nuclear Material Stabilization Task Group Implementation Plan Material Categories}

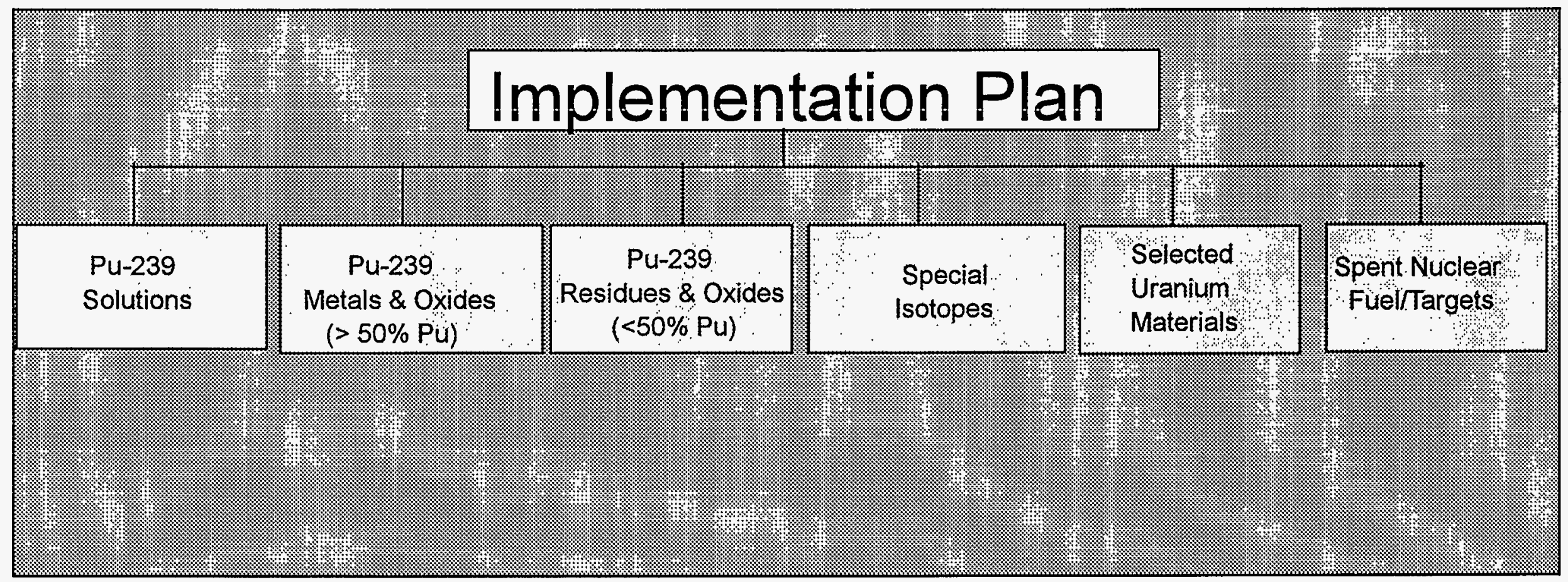

Figure 2.2-1 
Site Integrated Stabilization Management Plans (SISMPs): The SISMP documents the site activities for the management of the nuclear material categories at each site. They will contain milestone schedules that are driven by the objectives and requirements contained in the IPP. They will also contain a specific subsection, a Facilities Plan (FP) that will discuss what facilities and facility capabilities will be used to undertake the site-wide stabilizationa activities.

Integrated Facilities Requirements Plan (IFRP): This Plan will describe, for the complex, the facilities and facility capabilities needed to stabilize nuclear materials. It will take into account facility start-up, restart, operational and maintenance requirements.

Integration of Special Nuclear Fuel related activities has been underway using a similar process. Section 3.6 provides greater detail. This SNF process will be modified to more closely align it with the process developed to address the other material categories. Specifically, the SNF Program Plan will be that category's Material Integration Plan. It will be modified and structured to account for those commitments and required activities promulgated by the IPP and the spent fuel portions of the associated SISMP's. The SNF Program Plan will be provided to the Task Group for incorporation into the ISMP to facilitate tracking and reporting of commitments and milestones.

The basic systems engineering process that will be applied to develop the technical solutions for stabilizing nuclear material is illustrated in Figure 2.2-2. This process is designed to ensure the Department's priority and standards for stabilizing nuclear material are reflected in well structured, integrated programs. Throughout this process the Task Group will be guided by the following high-level objectives:

- $\quad$ Manage the program through consistent Departmental strategies.

- Integrate facilities, capabilities and priorities throughout the program.

- Base programmatic decisions on a clear understanding of the problem, the definition of goals or end-state, and analysis of alternative paths that takes into account, as a minimum, the following issues:

- Limiting worker exposure.

- Minimizing generation of additional waste.

- Minimize emission of effluent to the environment.

- Avoid the generation of mixed waste.

- Assess the corporate effort and identify:

- Future processing facility and storage capacity needs.

- Consolidation opportunities.

- Cost efficiencies available through technology development and application, and inter-site cooperation. 


\section{Basic Systematic Approach for Nuclear Material Stabilization}

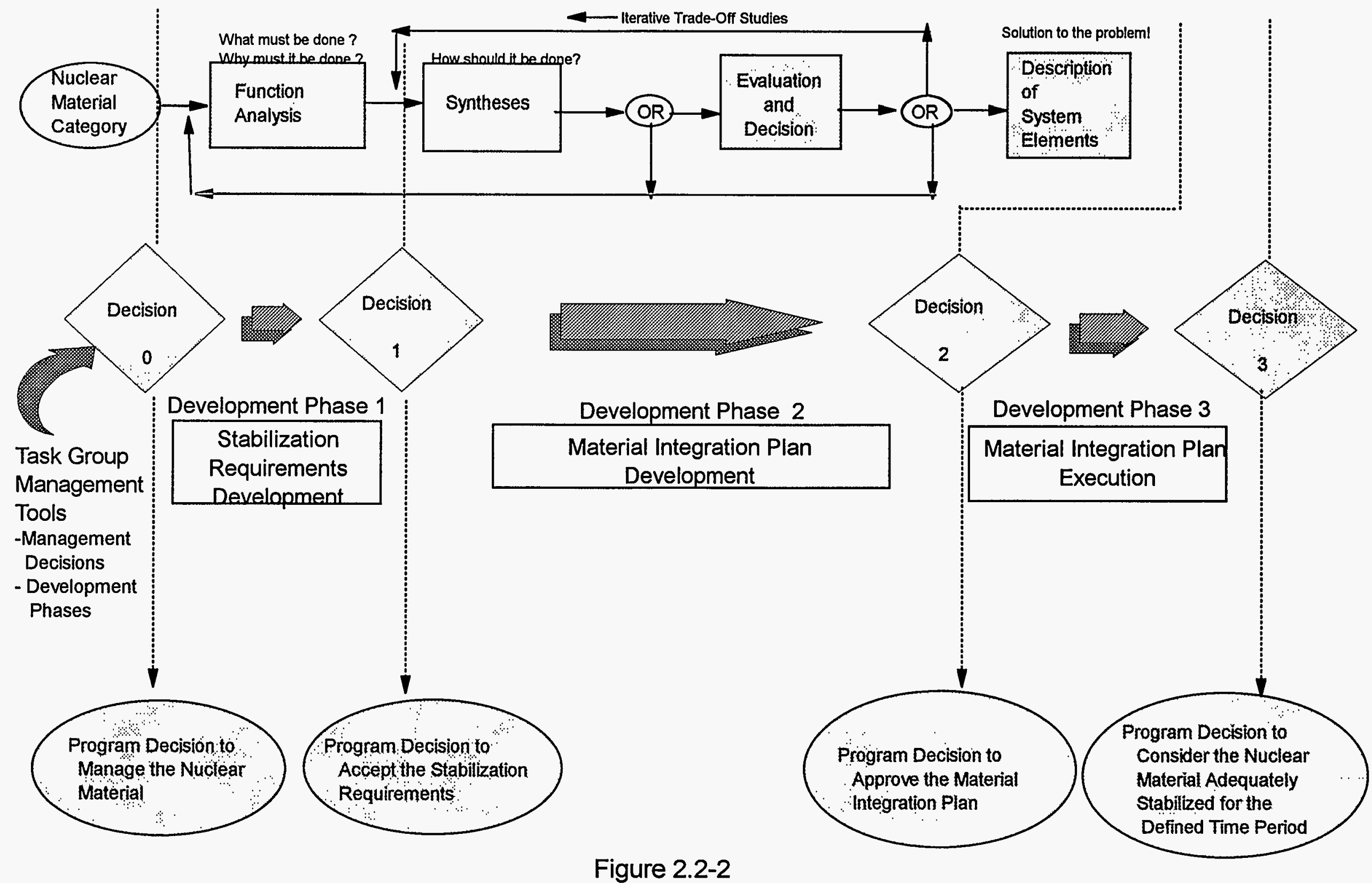




\subsection{Project Approach}

Specific activities that the Task Group will use to plan, develop and monitor activities are illustrated in Figure 2.3-1. Activities related to each material category will be scheduled and accomplished with a series of decisions, development phases, and products to produce well structured Material Integration Plans that contain:

- $\quad$ Early project definition with clear description of desired end-state.

- Quantifiable assessments of alternatives options (trade-off studies).

- Quantitative measurement of progress through the use of Performance Measures with Schedule and Performance Baselines.

- $\quad$ Auditable records of key programmatic decisions and issues.

- Clear identification of organizational responsibility for Headquarters and Field organizations.

Trade studies will be needed to evaluate and optimize the total stabilization effort. The Material Integration Plans will identify these trade studies and the dates for their completion.

The process displayed in Figure 2.3-1 can be tailored by the Task Group to be more responsive to program management requirements and to integrate the activities required to develop, evaluate, and select programmatic alternatives. On a case-by-case basis, a distinct decision to select alternatives, either as part of the NEPA process or as a result of an independent trade study, in Development Phase 2 may be conducted. The relationship of the Task Group objectives to both programmatic and site-specific NEPA processes may be strengthened by formally recording a programmatic ROD. This formal acknowledgement of the alternative will allow the RODs from ongoing NEPA processes to be formally incorporated into the program planning process.

Each material category presented in Section 3 of this Implementation Plan contains three major parts:

$\begin{array}{ll}\text { Part } & \text { Contents } \\ \text { I } & \text { Requirements } \\ \text { II } & \text { Material Integration Approaches } \\ \text { III } & \text { Individual Site Activities }\end{array}$

This format was developed to clearly illustrate the integrated, material based approach taken to structure stabilization activities. Site activities are scheduled to accomplish the overall Departmental objectives.

The individual site activities are delineated to illustrate the fact that stabilization activities are already in progress, albeit not yet part of an integrated Departmental effort. 
- Designate materials within the scope of the project.

- $\quad$ Form and direct an Integration Working Group that will identify and evaluate stabilization requirements, capabilities, operational barriers, and integration opportunities.

- Direct the research and technology development needed to support the project.

- $\quad$ Form and direct a Research and Technology Development (R\&TD) Steering Committee that will identify research and technology requirements, evaluate proposals for addressing requirements, and prepare appropriate task directions for laboratory work.

- Develop an Integrated Stabilization Management Plan and other reporting vehicles necessary to monitor progress. Control changes to the Integrated Program Plan.

- Determine the facilities, capabilities and critical skills to be maintained and the length of maintenance.

- $\quad$ Direct trade studies necessary for determining preferred alternatives for treating and storing the materials included in the program.

- $\quad$ Advise senior line managers of schedule variances and their impacts on commitments and progress to desired end-states, and recommend appropriate management action.

- Initiate the development of standards and procedures needed for the program.

- $\quad$ Report quarterly to the Under Secretary the progress of the Department in implementing the Integrated Program Plan, recommending appropriate actions to address funding or progress shortfalls.

- Initiate reports to the Defense Nuclear Facilities Safety Board on changes to milestones in the Implementation Plan for the Board's Recommendation 94-1, and an annual report to the Board on the progress toward meeting the commitments in the Implementation Plan.

\subsubsection{Integration Working Group}

The Integration Working Group will be responsible to the Task Group for the following:

- Identifying, recommending, and coordinating support tasks related to the integration of material activities among multiple sites, using focus teams as required to define requirements for specific actions and issues 
- Developing a database of material stabilization needs for each site and the capabilities that exist at all sites that may be usable

- $\quad$ Performing trade studies on alternative treatment and storage strategies, using Systems Engineering as a tool for evaluating quantitative and qualitative benefits and costs, especially options for intersite transfers of materials

- Establishing tools for analyzing and measuring program requirements, impacts, and success (functional diagrams that depict key options and decision points; definitions of end-states; uniform assumptions on shipping, costing, performance measurement; etc.)

- Identifying options and program recommendations for dealing with materials at smaller sites.

\subsubsection{Research and Technology Development (R\&TD) Steering Committee}

The committee wil be responsible to the Task Group for identifying technology gaps and other core technology needs, prioritizing activities, monitoring progress, evaluating alternatives and downselecting activities, and developing and submitting plans. Section 2.7 provides details of the Research and Technology Development program together with management roles and responsibilities.

\subsubsection{Interfaces}

A number of non-direct-line organizations within DOE have responsibility for issues associated with nuclear materials management and stabilization that will directly relate to the activities described in this Implementation Plan. The Task Group will ensure that all related activities are integrated and coordinated to prevent duplication of effort and conflicting actions. The potential synergies resulting from the integration of technologies, capabilities (facilities), and materials will be missed if the Task Group "stovepipes" planning by material categories. Therefore, an overarching integration strategy will be developed and implemented through the effective interaction among the Task Group, materials program officials, the Integration Working Group, and the Research and Technology Development Steering Committee. Specific examples of related organizations include the following:

- The Office of Waste Management (EM-30) is responsible for the complex-wide management of DOE-owned spent nuclear fuel including the resolution and management of all issues and commitments delineated in this Implementation Plan. Policy and budgetary guidance, including the associated planning and execution documentation, to affect complex-wide integration of spent nuclear fuel activities remains the responsibility of this office. Communication will be initiated and maintained with the Task Group to ensure an accurate status of activities to resolve issues raised by Recommendation 94-1. 
- $\quad$ The Office of Technology Development (EM-50) is responsible for conducting all technology development efforts for the Office of Environmental Management.

- The Office of Materials Disposition (MD) is responsible for assessing longterm storage and ultimate disposition options associated with strategic and surplus fissile material.

- The Office Strategic Planning and Policy (EM-4) is leading a department-wide Materials in Inventory (MIN) effort to assess all nuclear materials in DOE that are no longer in use.

- The Office of Civilian Radioactive Waste Management (RW) is responsible for establishing waste acceptance criteria for certain categories of nuclear wastes and managing the disposition of civilian spent nuclear fuel.

- $\quad$ Office of Environment and National Defense (PO-9) is responsible for coordination with applicable material management policies and initiatives.

\subsection{Facility Readiness}

\section{Operational Readiness}

Recommendation 9 stated, "Expedited preparations to accomplish actions in items (3) through (7) above should take into account the need to meet the requirements for operational readiness in accordance with DOE Order 5480.31."

It is the Department's policy that the start-up of new or restart of existing facilities will be in accordance with the requirements of DOE Order 5480.31. This order defines the requirements for the scope and depth of readiness reviews prior to start-up and the appropriate approval levels for the start-up activities. It also defines the prerequisites required before the readiness review is conducted, the appropriate level of independence of the readiness review team, and the role of the Department's independent oversight of the readiness review activity.

For each facility/operation identified for use through this Implementation Plan and in the Material Integration Plans, the application of the appropriate requirements of DOE Order 5480.31 will be applied as facilities are restarted or new facilities are started up.

\section{Future Use of Facilities}

Recommendation 8 stated, "That those facilities that may be needed for future handling and treatment of the materials in question be maintained in a usable state. Candidate facilities include, among others, the F- and H-Canyons and the FB-and $H B$-Lines at the Savannah River Site, some plutonium-handling glove box lines among those at the Rocky Flats Plant, the Los Alamos National Laboratory, and the Hanford 
Site, and certain facilities necessary to support a uranium handling capability at the $Y$ 12 Plant at the Oalk Ridge Site."

Many of the materials covered by this Recommendation will remain in safe interim storage for long periods before their final disposition. During this period some of the materials may have to be handled, treated, or repackaged. Therefore, certain facilities and capabilities throughout the complex must be retained to ensure that repackaging or other treatment can be performed when required.

The Task Group will determine which facilities and capabilities to maintain and how long to maintain them. Sufficient capabilities will be retained to leave the Department cost-effectively prepared for its future missions, including maintenance of safe storage facilities.

Because of aging Departmental facilities and the long time periods that may be involved, DOE Standard DOE-STD-1079-93, Guide for Operational Configuration Management Program (Including the Adjunct Programs of Design Reconstitution and Aging Management), will be used to guide the management of such facilities.

The following is a list of facilities that are being, are or are currently planned to be, used to stabilize and/or store materials. For the purposes of this Plan, the list is merely the point of departure from which the integrated set of facilities will be developed. The decisions on facilities will be based, in part, upon the development of standards or methods for treatment.

\begin{tabular}{|c|c|c|}
\hline Facility & Material & Function \\
\hline \multicolumn{3}{|l|}{ SAVANNAH RIVER } \\
\hline $\begin{array}{l}\text { K/L/P Reactor } \\
\text { Disassembly Basins }\end{array}$ & Spent Fuel and Targets & $\begin{array}{l}\text { Pool Storage (until } \\
\text { Processed) }\end{array}$ \\
\hline $\begin{array}{l}\text { Receiving Basin for } \\
\text { Offsite Fuels (RBOF) }\end{array}$ & Spent Fuel and Targets & $\begin{array}{l}\text { Pool Storage and Ion } \\
\text { Exchange Resin } \\
\text { Regeneration }\end{array}$ \\
\hline F-Canyon & $\begin{array}{l}\text { Plutonium Materials } \\
\text { Spent Fuel/Targets } \\
\text { Special Isotopes }\end{array}$ & $\begin{array}{l}\text { Processing } \\
\text { Am/Cm Vitrification }\end{array}$ \\
\hline FB-Line & Plutonium Materials & $\begin{array}{l}\text { Solutions, residues and } \\
\text { scrap stabilization }\end{array}$ \\
\hline H-Canyon & $\begin{array}{l}\text { Plutonium Materials } \\
\text { Spent Fuel/Targets } \\
\text { Special Isotopes }\end{array}$ & Processing \\
\hline
\end{tabular}




\begin{tabular}{|c|c|c|}
\hline Facility & Material & Function \\
\hline HB-Line & $\begin{array}{l}\text { Uranium and Plutonium } \\
\text { Materials } \\
\text { Special Isotopes }\end{array}$ & $\begin{array}{l}\text { Solutions, residues, and } \\
\text { scrap stabilization }\end{array}$ \\
\hline SRTC Bldg. 772 F & All Types & Analytical Chemistry \\
\hline \multicolumn{3}{|l|}{ ROCKY FLATS } \\
\hline Bldg. 371 & $\mathrm{Pu}$ Metal and Oxides & $\begin{array}{l}\text { Storage } \\
\text { Thermal Stabilization } \\
\text { Repackaging }\end{array}$ \\
\hline Bldg 886 & Uranium Solutions & $\begin{array}{l}\text { Drain and Blend } \\
\text { Solutions }\end{array}$ \\
\hline Bldg 771 & $\begin{array}{l}\text { Plutonium Solutions } \\
\text { Plutonium Metal and } \\
\text { Oxide }\end{array}$ & $\begin{array}{l}\text { Stabilization } \\
\text { Storage }\end{array}$ \\
\hline Bldg 707 & $\begin{array}{l}\text { Plutonium Metal and } \\
\text { Oxide } \\
\text { Pu Residues }\end{array}$ & $\begin{array}{l}\text { Repackaging } \\
\text { Oxide Thermal } \\
\text { Stabilization } \\
\text { Storage } \\
\text { Repackaging } \\
\text { Some processing } \\
\end{array}$ \\
\hline Bldg 779 & $\begin{array}{l}\text { Pu Metal } \\
\text { Pu Residues }\end{array}$ & $\begin{array}{l}\text { Storage } \\
\text { Repackaging and/or } \\
\text { processing }\end{array}$ \\
\hline Bldg 776/777 & $\begin{array}{l}\text { Pu Metal } \\
\text { Pu Residues }\end{array}$ & $\begin{array}{l}\text { Storage } \\
\text { Repackaging and/or } \\
\text { processing }\end{array}$ \\
\hline Bldg 559 & Pu Samples & Analytical Chemistry \\
\hline LOS ALAMOS & & \\
\hline TA-55 & Various Pu forms & Processing \\
\hline CMR & Various Materials & $\begin{array}{l}\text { Analytical Chemistry, } \\
\text { Uranium }\end{array}$ \\
\hline TA-50 & $\begin{array}{l}\text { Various Uranium and } \mathrm{Pu} \\
\text { forms }\end{array}$ & Liquid Waste Treatment \\
\hline
\end{tabular}




\begin{tabular}{|c|c|c|}
\hline Facility & Material & Function \\
\hline TA-54 & $\begin{array}{l}\text { Various Uranium and } \mathrm{Pu} \\
\text { forms }\end{array}$ & Solid Waste Management \\
\hline B 332 Plutonium Facility & $\begin{array}{l}\text { Pu Metal, Pu Oxide, Pu } \\
\text { Residue Processing }\end{array}$ & $\begin{array}{l}\text { Processing, Stabilization, } \\
\text { Repackaging, Storage }\end{array}$ \\
\hline \multicolumn{3}{|l|}{ HANFORD } \\
\hline Conditioning Facility & Spent Fuel/Sludge & Fuel/Sludge Conditioning \\
\hline $\begin{array}{l}\text { Bldgs 324/325/327 Hot } \\
\text { Cells }\end{array}$ & Spent Fuel/Sludge & $\begin{array}{l}\text { Characterization and } \\
\text { stabilization process } \\
\text { development }\end{array}$ \\
\hline PFP & $\mathrm{Pu}$ Materials & Stabilization \\
\hline Canister Storage Building & Spent Fuel/Sludge & Storage \\
\hline \multicolumn{3}{|l|}{ INEL } \\
\hline $\begin{array}{l}\text { CPP-666 Fuel Storage } \\
\text { Area }\end{array}$ & Spent Fuel & $\begin{array}{l}\text { Storage (fuel awaiting } \\
\text { dry storage) }\end{array}$ \\
\hline $\begin{array}{l}\text { CPP-749 Dry Storage } \\
\text { Wells (New Generation) }\end{array}$ & Spent Fuel & $\begin{array}{l}\text { Dry Storage of Spent } \\
\text { Fuel }\end{array}$ \\
\hline \multicolumn{3}{|l|}{ OAK RIDGE } \\
\hline ORNL Bldg 7503 & $\begin{array}{l}\text { Molten Salt Reactor } \\
\text { Materials (MSRE) }\end{array}$ & Stabilization \\
\hline $\begin{array}{l}\text { ORNL Bldg } 3525 \text { Hot } \\
\text { Cell }\end{array}$ & MSRE & Material Conversion \\
\hline Y-12 Bldg 9212 & HEU & $\begin{array}{l}\text { Chemical Processing, } \\
\text { Casting, and Packaging, }\end{array}$ \\
\hline \multicolumn{3}{|l|}{$\begin{array}{l}\text { LAWRENCE } \\
\text { LIVERMORE }\end{array}$} \\
\hline B 332 & Plutonium & Processing \\
\hline
\end{tabular}




\subsection{Integrated Research and Technology Development}

\subsubsection{Background}

Research and technology development on actinide materials, particularly uranium and plutonium, was extensive during the 1945-1990 time period. This work was generally mission oriented (nuclear weapon and power reactor fuels) but a substantial effort was devoted to fundamental research. As a result, the Department possesses an extensive fundamental chemistry and metallurgy data base on high purity uranium and plutonium. In contrast to the data base on high purity materials, the knowledge base for the behavior of residues is woefully inadequate. Most scrap residues and materials that were generated during plutonium and uranium metal preparation and machining were packaged and stored without being characterized. The packaging standards were ad hoc or nonexistent and inconsistent among the various DOE sites. The Department has recently published long-term storage criteria for plutonium metal and characterized plutonium oxide. However, a technical basis does not exist to develop adequate standards for characterization, treatment, and safe storage of nonoxide and nonmetal materials in residues throughout the complex. Residues, as well as other processing intermediates, are now stored at several sites under conditions that cannot assure safety.

With increasing frequency, the complex is experiencing unexpected and unsafe behavior from various materials in storage such as excessive generation of hydrogen gas, container pressurization, generation of pyrophoric materials that threaten ignition and spread of radioactive contamination, and leakage from containers of radioactive solutions. Clearly corrective actions are needed. However, concerning residue storage, an adequate knowledge and technology base does not exist. Research and technology development is needed to resolve both near-term and long-term problems.

\subsubsection{Objectives}

DNFSB Recommendation 94-1 defines the research objective as:

"That a research program be established to fill any gaps in the information base needed for choosing among the alternate processes to be used in safe conversion of various types of fissile materials to optimal forms for safe interim storage and the longer term disposition."

To achieve this objective a research and technology development program with several elements is needed:

- A technology-specific program that is focused on storing materials safely, with concomitant development of storage criteria and surveillance requirements, centered around the 3- and 8-year storage upgrade targets. 
- A core technology program to augment the knowledge base about general chemical and physical processing and storage behavior and to assure safe interim nuclear material storage, until disposition policies are formulated.

- A research program that is consistent with long-range goals, that does not preclude disposition options, and that facilitates site decontamination and environmental remediation.

The Department will begin by identifying the requirements and standards for the selected storage state (interim or long-term). The present state of knowledge relevant to these requirements and standards must be identified. In situations where sufficient knowledge exists to ensure that the required standards can be met, no research and development are needed. On the other hand, the present state of knowledge may be inadequate and additional needs can be identified. These additional needs form the basis for required research and development which establishes a technical basis for the processing and storage options.

\subsubsection{Approach}

The research program will consist of two elements: a technology-specific research program and a core technology development program. The technology-specific research program consists of near-term tightly focused efforts. The program will include, but is not limited to, the following aspects of the plutonium storage and residue treatment: interim and long-term storage of plutonium metal, oxide, and residues, solution treatment, pyrochemical salt treatment, bagless and dustless transfer and storage technologies, surveillance, and combustibles treatment. All of these efforts are underway at various sites around the complex.

The core technology program will focus on overarching long-term problems and can be viewed as a combination of three research areas: 1) continuation of technologyspecific research and technology development, 2) development of new applications for existing technologies, and 3) development of new technologies for old and new problems. A few of the research areas that will be studied are alternate storage forms for plutonium metal and oxide, processes for unique feeds, and advanced combustible and fluid waste treatment.

Many of the near-term uranium problems are less serious than those involving plutonium. Uranium research and technology development needs will be assessed as the program is developed. Resource levels will be identified when the Research and Technology Development program is developed.

Research and technology development efforts are underway to support the placement of spent fuel into safe, secure interim storage. The coordination of these efforts is achieved through the Technology Integration Technical Working Group established by the Office of Spent Fuel Management in June 1993. A Technology Integration Plan, 
SNF-PP-FS-002, was issued in December 1994. This plan delineates and details all planned and proposed technology development activities needed to support the spent nuclear fuel program.

\subsubsection{Management Plan}

Research and technology development requirements will be identified and evaluated by the Research and Technology Development (R\&TD) Steering Committee.

The Committee will be responsible to the Nuclear Material Stabilization Task Group for accomplishing the following:

- Assessing the current program for known research and technology requirements

- $\quad$ Evaluating research proposals

- $\quad$ Preparing and maintaining the R\&TD plan and estimating costs

- Coordinating with other research activities

- Drawing upon special expertise outside the Department (e.g., Universities, etc.)

- Defining tasks for accomplishment by laboratories

- $\quad$ Conducting periodic workshops focused on well defined-problems used by the Task Group to gather the data necessary to make informed decisions.

\subsubsection{Milestones and Commitments}

Research and Technology Development (R\&TD)

Steering Committee Established .................. May 1995

R\&TD Steering Committee Prepares R\&TD Plan . . . . . . . . November 1995

\subsection{General Issues}

\subsubsection{Relationship to Plutonium Vulnerability Assessment}

In March 1994, the Secretary of Energy commissioned a comprehensive assessment to identify and prioritize the environmental, safety, and health vulnerabilities that arise from the storage of plutonium in Department of Energy facilities and determine which are the most dangerous and urgent. These vulnerabilities include degradation in plutonium materials and packaging, and weaknesses in facilities and administrative controls that can result in inadvertent releases of plutonium to which workers and the 
public may be exposed, or that may contaminate the environment. This DOE-wide assessment identified 299 environment, safety, and health vulnerabilities of which 91 related to degradation of materials and packaging, 140 relate to facility inadequacy or degradation. and the remainder to institutional problems.

Most of the materials and packaging vulnerabilities are specifically covered or encompassed by the intent of DNFSB Recommendation 94-1. Many of the facility vulnerabilities, if left unattended, might preclude the safe use of facilities for future handling and treatment of the materials, which must be stabilized and stored. Because of the interrelation between the Recommendation and the Plutonium Assessment, the Task Group will monitor the actions being taken to address the vulnerabilities identified in the Plutonium Vulnerability Assessment.

A similar relationship exists between Recommendation 94-1 and the SNF Working Group Report; essentially, the 94-1 issues represent a subset of the deficiencies identified in the SNF Working Group Report. The Office of Waste Management will monitor the corrective actions associated with both documents, reporting progress related to Recommendation 94-1 to the Task Group as necessary.

\subsubsection{Impact of Presidential Decision Directive 13 on Stabilization}

The United States does not encourage the civil use of plutonium and, accordingly, does not itself engage in plutonium reprocessing for either nuclear power or nuclear explosive purposes. The proposed processing activities are necessary to alleviate immediate and urgent environmental, safety and health concerns associated with the shutdown of reprocessing in the Department's weapons complex. These management efforts will not undermine broader U.S. nonproliferation efforts that are focused on stemming the buildup of plutonium stocks in the civil nuclear fuel cycle. Further, the Secretary of Energy has prohibited the use for nuclear explosive purposes of the Pu239 or highly enriched uranium arising from these reprocessing activities.

\subsubsection{Impact of Intemational Inspections on Stabilization}

In his September 27, 1993, nonproliferation statement, the President said that the United States would submit United States fissile material no longer needed for our deterrence to inspection by the International Atomic Energy Agency. The President also proposed a multilateral convention prohibiting the production of highly enriched uranium or plutonium for nuclear explosives or outside international safeguards -- a fissile material cutoff treaty. The United States has signed an agreement with Russia prohibiting the use of newly produced plutonium for weapons. This agreement also calls for the negotiation of a bilateral total ban on the production of plutonium for nuclear weapons. The Department has established a close liaison with the Department of State regarding the implementation of these nonproliferation efforts. 
Each of these nonproliferation commitments entails varying levels of verification that over time will have an important impact on the application of safeguards within the Department's complex. Although plans are still under development to fulfill these commitments on an interagency basis, the Department expects that for the next several years these nonproliferation commitments will largely affect storage facilities for separated fissile materials. As a result, the application of multilateral or bilateral safeguards is not expected to create schedule delays for stabilization activities required by this implementation plan. 


\section{Section 3: Materials}

\subsection{Plutonium (Pur239) Solutions}

\section{Part I: Stabilization Requirements}

\subsubsection{General Overview}

\section{Background}

Approximately 412,000 liters of $\mathrm{Pu}-239$ solutions exist throughout the DOE complex, primarily at Rocky Flats, Savannah River, and Hanford. These plutonium nitrate and chloride solutions were in the process of being converted to a purified plutonium metal or oxide at the time of shutdown, or in facility process system hold-up.

\begin{tabular}{|c|c|c|c|c||}
\hline Site & $\begin{array}{c}\text { Type of } \\
\text { Material }\end{array}$ & $\begin{array}{c}\text { Plutonium } \\
\text { Kg }\end{array}$ & Quantity & Location \\
\hline Rocky Flats & $\begin{array}{c}\text { Pu-239 } \\
\text { Solutions }\end{array}$ & 143 & $\begin{array}{l}30,000 \\
\text { liters }\end{array}$ & $\begin{array}{c}\text { Bldgs 371,559, } \\
771,776 / 777, \\
779\end{array}$ \\
\hline $\begin{array}{c}\text { Savannah } \\
\text { River Site }\end{array}$ & $\begin{array}{c}\text { Pu-239 } \\
\text { Solutions }\end{array}$ & Classified & $\begin{array}{c}354,000 \\
\text { liters }\end{array}$ & $\begin{array}{c}\text { F-Canyon } \\
\text { H-Canyon }\end{array}$ \\
\hline Hanford & $\begin{array}{c}\text { Pu-239 } \\
\text { Solutions }\end{array}$ & 358 & $\begin{array}{c}4,800 \\
\text { liters }\end{array}$ & $\begin{array}{c}\text { Plutonium } \\
\text { Finishing Plant }\end{array}$ \\
\cline { 2 - 5 } & $\begin{array}{c}\text { Pu-239 } \\
\text { Solutions }\end{array}$ & 9 & $\begin{array}{c}22,700 \\
\text { liters }\end{array}$ & PUREX \\
\hline
\end{tabular}

\section{Overview of Concems}

Plutonium nitrate and chloride solutions are currently being stored in configurations that were not designed for extended storage. The solutions are stored in plastic bottles, plastic lined tanks, stainless steel bottles and tanks, and process piping. These solutions, which range in concentration from 0.25 to 300 grams of plutonium per liter, represent some of the most significant vulnerabilities to the worker, but pose a low risk to the public or the environment. There is no question that solutions are not suitable for safe interim storage and must, therefore, be solidified. 
Leaking solutions pose the first area of concern. Solutions stored in plastic bottles at Rocky Flats and Hanford can become brittle due to radiolysis and acid reactions, and have leaked in the past. Hanford stores plastic bottles in stainless steel cans, which can degrade and leak if the plastic bottles fails. Corrosion of tanks and piping used for extended storage of acidic solutions at Rocky Flats and Savannah River is also of concern because of potential for leaks in the tanking system gaskets, seals and welds.

An additional area of concern is related to hydrogen generation. Radiolysis will attack the organic storage containers generating a hydrogen gas. Hydrogen generation in unvented containers will increase the pressure on the storage container resulting in an increased rate of embrittlement and leakage. This ultimately leads to a fire and explosive hazard due to hydrogen gas buildup.

A lower likelihood but higher consequence related to solution storage is criticality. Solution storage configurations were designed to prevent criticality through geometrical shapes, administrative controls to limit plutonium concentrations, or the use of boric acid or raschig rings as neutron absorbers. However, unanticipated high local plutonium concentration due to plutonium precipitation could lead to criticality. This concern primarily applies to solutions stored in tanks.

\section{Applicable Sub-recommendations from DNFSB Recommendation 94-1}

Sub-recommendation 1:

That an integrated program plan be formulated on a high priority basis, to convert within two to three years the materials addressed in specific

recommendations below to forms or conditions suitable for safe interim storage.

Sub-recommendation 3:

That preparations be expedited to process the dissolved plutonium and transplutonium isotopes in tanks in the F-Canyon at Savannah River Site into forms safer for interim storage. The Board considers this problem to be especially ungent.

Sub-recommendation 5:

That preparations be expedited to process the containers of possibly unstable residues at the Rocky Flats Plant and to convert constituent plutonium to a form suitable for safe interim storage.

\section{Acceptance and Objectives}

DOE agrees with the importance and urgency to place these materials in a safer configuration, and is committed to completing the stabilization as expeditiously as possible. A significant portion (85\%) of the materials will be stabilized within three years, with the remaining solutions being stabilized within an additional two years. DOE has established the following objectives: 
- Minimize the likelihood and consequence of accidents through effective surveillance, compensatory measures, and responsive emergency actions.

- $\quad$ Stabilize all solutions as expeditiously as feasible.

- $\quad$ Place plutonium metal and oxide generated from stabilizing these solutions in a form suitable for safe interim storage by May 2002.

- $\quad$ Minimize waste generated from the stabilization activities and packaged to meet the appropriate waste acceptance criteria.

\section{Key Assumption}

- The outcomes from the NEPA process will be consistent with the options used to develop these schedules.

\section{Part II: Plutonium Solution Integration Activities}

\section{Approach}

The goal for the solutions across the complex is: to stabilize them as expeditiously as possible.

Complex-wide integration is necessary for technology transfers, establishing similar goals, and sharing lessons learned. Further integration, i.e. transferring solutions to another site for processing, is severely restricted by the current regulations. Regulation 10 CFR 71.63 states, "Plutonium in excess of 20 curies per package must be shipped as a solid." Intra-site integration is also essential between liquid stabilization activities and obtaining the capability to place metal and oxide in safe interim storage. Effective integration of these activities may reduce the need to handle the materials twice, thus avoiding unnecessary radiation exposure. Typical material stabilization activities are noted on Figure 3.1-1.

The key functions required to place the solutions in safe stable storage are as follows:

- Compensatory measures are established and implemented to reduce the likelihood and/or consequence of accidents, while awaiting stabilization.

- Characterize solutions to maintain safety and to prepare for upcoming stabilization activities.

- $\quad$ Stabilize solutions and place in safe temporary storage.

- Monitor the packages to ensure continued safe storage. 


\section{Plutonium Solutions Stabilization}

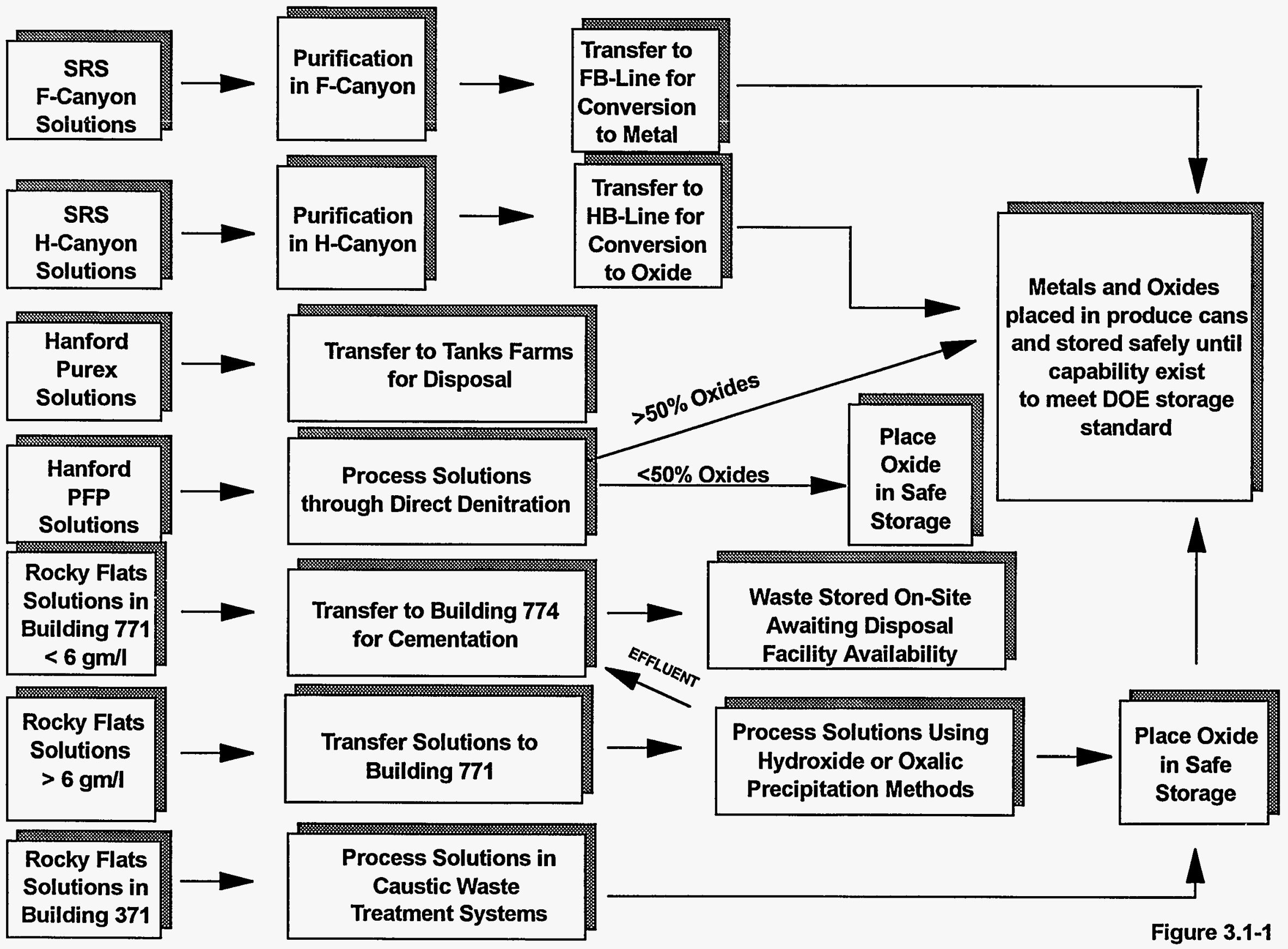


- $\quad$ Package the plutonium metal and oxides ( $>50 \% \mathrm{Pu})$ generated from the stabilization process to meet the requirements of DOE-STD-3014-94.

\section{Key Challenges}

- Utilizing aged facilities to stabilize the solutions.

- Maintaining the expertise needed to operate the facilities.

In recognition of these challenges, activities will be initiated to:

- Review budget requests to ensure the appropriate level of maintenance, training, and staffing in facilities are appropriate required for future stabilization or safe storage.

- Monitor site activities to ensure schedules are maintained and recommend alternatives to shorten the schedule, when appropriate.

\section{Part III: Individual Solutions at Rocky Flats}

\subsubsection{Plutonium (Pu-239) Solutions at Rocky Flats}

Solutions are present in Buildings 371, 559, 771, 776/777, and 779, with the majority being in Buildings 371 and 771 . The solutions at are stored in plastic bottles, tanks and pipes. While awaiting stabilization, several interim measures have been taken to minimize the risks of continued storage. The plastic bottles are being transferred to gloveboxes where they can be vented to decrease the rate of degradation and inspected to identify incipient failures in time to replace the bottles. Access to areas where the potential for leakage from tanks or pipes is strictly controlled. Alarm systems are in place to detect airborne contamination from spills or leaks, and alert personnel. Piping system flanges and valves have been encased in plastic shrink wrap to provide an additional barrier between the solutions and the workers.

Rocky Flats conducted the Actinide Solution Disposition Study to evaluate the different process and location options. The study concluded that the safest, least expensive, and quickest option was to utilize existing processes in Buildings 371, 374, 771 , and 774 to precipitate the high-level solutions and cementing other low-level solutions. Higher-level solutions at Rocky Flats are defined as greater than 6 grams of plutonium per liter. Low-level solutions are defined as less that 6 grams of plutonium per liter.

The following disposition plans will depend on the Environmental Assessment resulting in a Finding of No Significant Impact (FONSI), with the preferred option being selected. The NEPA analysis is scheduled to be completed in April 1995. 
The plutonium in these solutions is surplus to DOE's needs; therefore, Rocky Flats is solidifying as many solutions as possible through cementation. Some higher level solutions will require an additional precipitation step to remove the plutonium from the waste stream in order to meet waste disposal acceptance criteria and waste minimization goals.

All solutions stored in Buildings 559, 776/777 and 779 will be transferred to Building 771. Low-level solutions in Building 771 will then be transferred to Building 774 for cementation. Cementing the low-level solutions began in October 1993 and to date 1500 liters have been solidified. The high-level solutions will be processed in Building 771 using a hydroxide (for chloride solutions) and oxalate (for nitric solutions) precipitation method. The precipitate will be calcined and placed in temporary storage awaiting safe interim storage. The effluent will be transferred to Building 774 for cementation or further processing in carrier precipitation. All solutions in Building 771 will be stabilized by December 1997.

The solutions in Building 371 will be treated in the Caustic Waste Treatment System, which is a hydroxide precipitation process. The precipitate will be calcined and placed in safe interim storage. The effluent will be transferred to Building 374 for processing through carrier precipitation. The solutions in Building 371 will be stabilized by June 1999.

The liquid stabilization program will be integrated with current efforts to meet the safe storage criteria, DOE-STD-3014-94 for oxides in an effort to minimize handling the precipitates. However, the liquid stabilization activities will not be delayed to achieve this integration. The oxide, generated prior to obtaining the capability to meet the criteria in DOE-STD-3014-94 will be packaged to meet site storage requirements.

\subsubsection{Plutonium Solutions at the Savannah River Site}

The Pu-239 solutions are located in the F- and H- canyons at Savannah River. Until the solutions are stabilized the major area of concern is control of solution chemistry. Due to evaporation and radiolysis, solution chemistry requires continuous adjustments to avoid unanticipated concentration or precipitation of boron and ultimately the plutonium compounds, which may increase the potential for inadvertent criticality. Boron is added as a neutron poison and solution chemistry is adjusted to avoid precipitation of the boron and ultimately the plutonium. An increased sampling and surveillance program is in place to detect signs of deterioration. Minor leaks and spills are not a major concern since they will be contained within the canyons and fed back into the tanks without exposing the workers or posing a risk to the environment or public. Corrosion of tanking cooling water coils pose a risk of environmental release. F-Canyon solutions pose a more significant concern than H-Canyon solutions since the volume of Plutonium solutions in F-Canyon is an order-of-magnitude more than H-Canyon and exists in a wide variety of tanks and chemical conditions. 
The Record of Decision for the F-Canyon plutonium solutions was issued on February 2, 1995. The options considered for the Pu-239 solutions in the F-Canyon included no action, process to plutonium metal, process to plutonium oxide, and vitrification. The selected option was to operate F-Canyon to purify the solutions and transfer them to the FB-Line for conversion to metal. The stabilization of F-Canyon plutonium solutions began on February 3, 1995 with an expected completion of January 1996.

The plutonium metal produced from the FB-Line will be packaged to site storage standards (e.g., inside a produce can, bagged in plastic, and packed in an outer produce can) for temporary storage in one of the F-Area vaults. The metal will require repackaging to meet the DOE storage standard when the new safe interim storage containers, packaging capability, and new or modified vault storage becomes available. The processes and operations required represent routine operation of facilities which have been operated successfully for over 40 years. F-Canyon second plutonium cycle has been restarted. The FB-line Operational Readiness Review is complete and resolution of findings is in progress.

The Interim Management of Nuclear Materials (IMNM) EIS will identify a preferred alternative for stabilization of the Pu-239 solutions in the H-Canyon. The options considered for the solutions in the H-Canyon are no action, conversion to a low-fired oxide in H-Canyon and HB-Line, transfer to high-level waste tanks for vitrification in the Defense Waste Processing Facility (DWPF), vitrify in F-Canyon, process to metal in F-Canyon, and continued storage of these solutions under active management.

The proposed planning basis is to process the solution in H-Canyon to remove decay products and other material that would interfere with subsequent stabilization steps followed by transfer of Pu-239 to HB-Line Phase II for conversion to a low-fired oxide. Should this proposed option be selected, the plutonium oxide will be placed in temporary storage until the capability exists to meet the DOE storage standard. The ROD for the EIS is planned to be issued in June 1995. If the stabilization in HCanyon option is selected, stabilization operations will begin in February 1999, and completed by August 1999 for the Pu-239 solution in H-Canyon.

HB-Line Phase II start-up has been scheduled for early 1999 to allow for continuous operation to complete three campaigns, Pu-239 solution, mixed plutonium-uranium oxides and neptunium solutions. This schedule will coincide with the availability of new packaging and storage facilities for the resulting neptunium oxide. Safety of continued storage of the $\mathrm{H}$-Canyon plutonium solutions until stabilization is complete has been enhanced through additional sampling and monitoring activities.

\subsubsection{Plutonium (Pur239) Solutions at Hanford}

The solutions at Hanford are located in PUREX and the Plutonium Finishing Plant (PFP). Until stabilization of the solutions in PFP is complete, interim measures will remain in effect to minimize the risk to the worker, public and environment. By September 1995, all bottles will be inspected to ensure proper venting. The solutions 
are stored in vault-type rooms restricting unnecessary worker access. Air in the storage rooms is exhausted through a filtered system. To guard against sparks, every container is electrically grounded and only non-sparking tools are used to open the containers. Additionally, procedures require the workers to wear protective clothing and respirators during any activity that involves opening containers. The solution stored in PUREX are within a canyon protecting the workers, public, and environment from contamination risk.

The Plutonium Finishing Plant contains approximately 4,800 liters of plutonium bearing nitrate, chloride, and organic solutions. The 220 liters of chloride solutions will be stabilized by September 1995, during the developmental testing program.

The Hanford site has committed to its stakeholders to conduct an Environmental Impact Statement (EIS) on its clean-out and stabilization activities to assure proper environmental considerations are provided for all processes utilized during these activities. There are several technologies being evaluated for stabilization of these solutions. However, the technology selection will depend on the results of the developmental testing program and the outcome of the EIS. A Record of Decision is expected in June, 1996. Since direct denitration avoids a liquid waste stream and does not purify its product, two points important to Hanford stakeholders, it was the technology chosen to determine the schedule in this plan. The product from the direct denitration process will be an oxide with varying plutonium concentrations, some are expected to be below $50 \%$. The resulting oxide will be suitable for temporary storage, but for oxides greater than $50 \% \mathrm{Pu}$ additional processing and packaging steps are required to meet the criteria in DOE-STD-3014-94. If direct denitration is the preferred approach chosen from the EIS, the start-up of a direct denitration system could be started in June 1997, following procurement and installation of the production scale system. The stabilization of all solutions is scheduled to be completed by January 1999.

PUREX had approximately 22,700 liters of solution containing $9 \mathrm{kgs}$ of plutonium and 5 metric tons of uranium. A systems engineering study was conducted to determine the best approach to disposition these solutions. The preferred approach from the December 1993 study was to neutralize and dispose the solutions into the double-shell waste tanks at the tank farms. Transfer to the tank farms was initiated in June 1994, and is expected to be completed by August 1995. To date approximately 13,000 liters have been neutralized and transferred to the tank farms. 


\subsubsection{Key Milestones}

The following is list of the key milestones for stabilizing Pu-239 solutions. This is not intended to be an all encompassing list of milestones, but rather milestones that can be used as a rough measure of progress.

Rocky Flats:

Began cementing low concentrated solutions in Building $774 \ldots \ldots$ October 1993 Issue Finding of No Significant Impact for

Liquid Stabilization Environmental Assessment . . . . . . . . . . . April 1995

Stabilize $80 \%$ of high-level solutions and

$50 \%$ of low-level solutions (18,000 liters) . . . . . . . . . . . May 1997

Stabilize all solutions in Building 771 . . . . . . . . . . December 1997

Stabilize all solutions in Building 371 . . . . . . . . . . . . . June 1999

Savannah River Site:

F-Canyon:

ROD issued for F-Canyon Plutonium Solutions EIS . . . . . . . February 1995

Began F-Canyon processing operations . . . . . . . . . . . . February 1995

Convert 320,000 liters of solutions to metal . . . . . . . . January 1996

\section{H-Canyon:}

ROD issued for Interim Management of Nuclear Materials EIS . . . June 1995

Begin H-Canyon processing operations . . . . . . . . . . February 1999

Convert 34,000 liters of solutions to oxide . . . . . . . . . August 1999

Hanford:

Plutonium Finishing Plant (PFP) solutions:

ROD issued for PFP Clean-out and Stabilization EIS . . . . . . . June 1996

Complete technology development . . . . . . . . . . . . March 1996

Begin processing solutions . . . . . . . . . . . . . . . June 1997

Complete processing 4,800 liters $\ldots \ldots \ldots \ldots \ldots \ldots$ January 1999

PUREX solutions:

Began transfer to tank farms for disposal . . . . . . . . . . . . June 1994

Complete transfer of 22,700 liters to tank farms . . . . . . . . August 1995 


\subsection{Plutonium Metals and Oxides ( $>\mathbf{5 0} \%$ assay)}

\section{Part I: Stabilization Requirements}

\subsubsection{General Overview}

\section{Background}

The DOE currently manages over 14 metric tons of plutonium metal and oxide, which are not adequately packaged for long-term storage. Also, DOE manages over 6,000 sealed weapon components, principally stored at the Pantex Plant, containing plutonium. In general, the metal and oxide exists in several grades and forms, and are packaged in a multitude of configurations; most of which were prepared a number of years ago and are not suitable for interim, let alone long-term storage. The weapon components include assembled units retired from the National Nuclear Weapons Stockpile, which are not included within this implementation plan. Other special units, such as those manufactured for "shelf-life" studies, and special development orders are included in this plan Some of these will require processing for long-term storage.

Tables 3.2-1 and 3.2-2, respectively, summarize the quantities of plutonium metals and oxides currently in inventory at the various STET facilities in need of repackaging.

Table 3.2-1: Plutonium Metals

\begin{tabular}{|c|c|c|c|}
\hline Site & $\begin{array}{l}\text { SNM Inventory } \\
\text { (kgs) }\end{array}$ & $\begin{array}{l}\text { Number of } \\
\text { Items }\end{array}$ & Locations \\
\hline Rocky Flats & 6,600 & 3,403 & $\begin{array}{c}371,559,707,771,776 / 777,779 \text {, } \\
991\end{array}$ \\
\hline Hanford & 700 & 350 & $\mathrm{PFP}^{* *}, \mathrm{PNL}^{*}$ \\
\hline Los Alamos & 1,133 & 2,000 & TA-55, CMR, TA-18 \\
\hline Savannah River & Classified & 450 & FB-Line, 235F, SRTC \\
\hline Argonne-West & $* * *$ & $* * *$ & ZPPR, FMF, 752 \\
\hline Argonne-East & 0.45 & 210 & 200 \\
\hline Lawrence Livermore & 20 & 250 & \\
\hline Mound & 0.855 & 20 & $\mathrm{~T}, \mathrm{SWR}$ \\
\hline New Bnunswick & - & - & \\
\hline Oak Ridge & 0.3013 & 30 & $3027,3038,5505$ \\
\hline Sandia & 6.7 & 5 & NMSF \\
\hline Lawrence Berkeley & - & - & \\
\hline $\begin{array}{ll} & \text { PNL has 254 pa } \\
* & \text { PFP has about } 2 \\
* & \text { The major hold }\end{array}$ & $\begin{array}{l}\text { s of metal/oxid } \\
\text { items containing } \\
\text { about } 2,600 \mathrm{c}\end{array}$ & $\begin{array}{l}\text { onium mes. } \\
\text { ons of met }\end{array}$ & $\begin{array}{l}\text { and oxides. } \\
\text { oxides. }\end{array}$ \\
\hline
\end{tabular}


Table 3.2-2: Plutonium Oxides ( $>50$ \% Assay)

\begin{tabular}{||l|c|c|c||}
\hline \multicolumn{1}{|c|}{ Site } & $\begin{array}{c}\text { SNM Inventory } \\
\text { (kgs) }\end{array}$ & $\begin{array}{c}\text { Number of } \\
\text { Items }\end{array}$ & Locations \\
\hline Rocky Flats & 3,200 & 3,296 & $\begin{array}{c}371,559,707,771,776 / 777, \\
779,991\end{array}$ \\
\hline Hanford & 1,500 & 2,500 & PFP**, PUREX, PNL $^{*}$ \\
\hline Los Alamos & 721 & 2,000 & TA-55, CMR, TA-18 \\
\hline Savannah River & Classified & 550 & $\begin{array}{c}\text { FB-Line, HB-Line, } \\
235-F, \text { SRTC }\end{array}$ \\
\hline Argonne-West & $* * *$ & $* * *$ & ZPPR, 752, FMF \\
\hline Argonne-East & 0.48 & 695 & $200,306,315$ \\
\hline Lawrence Livermore & 102 & 154 & T, SWR \\
\hline Mound & 28.132 & 107 & - \\
\hline New Bnunswick & - & 83 & $3027,3038,5505,7920,7930$, \\
\hline Oak Ridge & 1.706 & 10 & HCF, ACRR, NMSF \\
\hline Sandia & 1.4 & 354 & $70,70 \mathrm{~A}, 70-147 \mathrm{~A}$ \\
\hline Lawrence Berkeley & 0.014 & & \\
\hline
\end{tabular}

* PNL has 254 packages of metal/oxide/residues.

** $\quad$ PFP has about 2,850 items containing plutonium metals and oxides.

*** The major holdings are about 2,600 containers of metals/oxides.

Additional materials will be generated at processing sites from the stabilization of other material forms.

\section{Overview of Concems}

Plutonium metal and oxide will require extended storage for many years while awaiting the long-term disposition option that will be determined through the Nuclear Material Disposition PEIS. Most of the plutonium stored in the DOE complex is in metal form. The most significant ES\&H vulnerabilities from the storage of plutonium metal stem from oxidation and radiolysis. Package failure can result from either normal oxidation or hydride-catalyzed oxidation. Current packaging configurations can allow air and moisture to enter, resulting in normal oxidation. When a container of plutonium metal also contains plastic bags or a food-pack can with synthetic material seals, the plastics and synthetic materials degrade. Oxidation of plutonium metal within existing storage containers presents the potential for breach of containment since the volume of the formed plutonium oxide is observed to be about $21 / 2$ times greater than the metal. Radiolytic and/or thermal reactions between the metal and 
plastics, moisture, and/or synthetics can also result in the formation of gases that can react with the plutonium to form pyrophoric plutonium hydride; and/or directly lead to containment failure via expansion or pressurization. Several plutonium metal container failures at LANL, other DOE sites, and in the United Kingdom emphasize the need to repackage the metal as well as note metal oxidation buildup.

The DOE has over 5 metric tons of plutonium in the form of plutonium oxide. The most significant vulnerabilities from the storage of plutonium oxide stem from radiolysis, pyrophoricity, and dispersibility. Oxide stored in proximity to plastic packaging can result in failures similar to those associated with metal. Pressure generated from radiolysis (1) or thermal reactions with plastic or absorbed moisture (2) can cause gas buildup and contribute to plutonium releases. In general, since plutonium oxide is a fine powder, like talcum powder, it poses a significant hazard relating to contamination incidents. Since it is also respirable, it poses unique hazards for workers. In addition, oxides generated by the corrosion of metal may contain metal fines and small amounts of hydride, both of which are pyrophoric.

The combinations of material and packaging configurations that require more urgent treatment include the plutonium metal in direct contact with plastic and the partially oxidized oxide (pyrophoric or reactive oxide). The section below summarizes the DOE approach to dealing with these materials, and specifically defines the materials in this category as well as the basis for priority actions.

\section{Applicable Sub-recommendations from DNFSB Recommendation 94-1}

Sub-recommendation 1b:

The plan should include a provision that within a reasonable period of time (such as eight years), all storage of plutonium metal and oxide should be in conformance with the draft DOE standard on plutonium now being made final. (NOTE: The DOE standard, DOE STD-3013-94, for packaging plutonium metal and oxide was issued December 1994.)

Sub-recommendation 4:

That preparations be expedited to repackage the plutonium metal that is in contact with, or in proximity to, plastic or to eliminate the associated existing hazard in any other way that is feasible or reliable. Storage of plutonium materials generated through this remediation process should be such that containers need not be opened again for additional treatment for a reasonably long time. 


\section{Acceptance and Objectives}

DOE concurs with the DNFSB recommendations and has established the following objectives:

- $\quad$ Assure safe storage conditions are maintained through surveillance and monitoring activities until processing to a safe storage state can be achieved.

- $\quad$ Repackage all plutonium metal in direct contact with plastic by December 1995.

- Material in close proximity to plastic will undergo periodic sampling, surveillance and monitoring and repackaging those forms or packaging configurations where problems are found on a priority basis.

- $\quad$ The term "in proximity to plastic" means that direct communication between the plutonium and the plastic is possible (i.e., there is no airtight container separating them).

- $\quad$ Repackage all separated plutonium metal to meet the metal and oxide storage standard by May 2002.

- $\quad$ Perform a trade study by May 1, 1995 that will examine the requirement to complete this activity for all sites by 2002 . The study will consider factors such as risk to workers and public, radiation exposure to personnel, waste minimization, discharges to the environment, cost, and impact on other activities. Based upon the results of the study, the Department may propose an alternate schedule for certain sites.

- Thermally stabilize all known reactive plutonium oxide by May 1997.

- Thermally stabilize and repackage all plutonium oxide to meet the metal and oxide storage standard by May 2002.

- Subject materials to a formal ongoing surveillance program as they are packaged and placed in storage.

- $\quad$ The surveillance program will be developed from research currently underway at Los Alamos.

- Transfer the metal and oxide between sites as a means of minimizing the number of sites required to place plutonium metal and oxide in safe interim storage. 
Key Assumptions

- $\quad$ The DOE Plutonium Metal and Oxide Storage Standard (DOE STD-3013-94) will be used throughout the complex to meet the 8-year milestone for the storage of metals and oxides ( $>50 \%$ assay).

- An integrated research and development program will be launched to develop the technologies to overcome current technical uncertainties and shortcomings such as design and manufacturing of a long-term storage container; packaging and stabilizing materials in accordance with the metal and oxide storage standard; interim and long-term surveillance needs; and, long-term storage behavior of metals and oxides.

- Interfaces with the Office of Fissile Material Disposition, Agreement for Mutual Reciprocal Inspections, and/or International Atomic Energy Agency (IAEA) Safeguards will be integrated. Issues include material form, packaging configuration, and term and capacity of storage.

- Metals and oxides in active programs or research and development inventories will be excluded in addition to "retired" weapon components from this implementation plan.

\section{Part II: Plutonium Metal and Oxide ( $>\mathbf{5 0} \%$ Assay) Integration Activities}

\section{Approach}

A complex-wide integrated approach will be pursued so that the most technically sound approaches will be used for similar materials independent of site; inter-site transfers will be considered for sites having insufficient capabilities or capacity; and, barriers to integration will be evaluated based on risk and cost. Strategies will be explored to enhance present on-site commitments, as well as options to consolidate repackaging and storage to a minimum number of sites by the Integration Working Group. The approach is shown in Figure 3.2-1, Metal and Oxide Stabilization. One specific integration opportunity is related to plutonium in close proximity to plastic; where each site is approaching this issue in a slightly different manner.

Functions required:

- Compensatory surveillance and monitoring activities to assure safe storage conditions are maintained.

- Priority repackaging of plutonium metal in direct contact with plastic, or synthetic materials. 


\section{Metal and Oxide Stabilization}

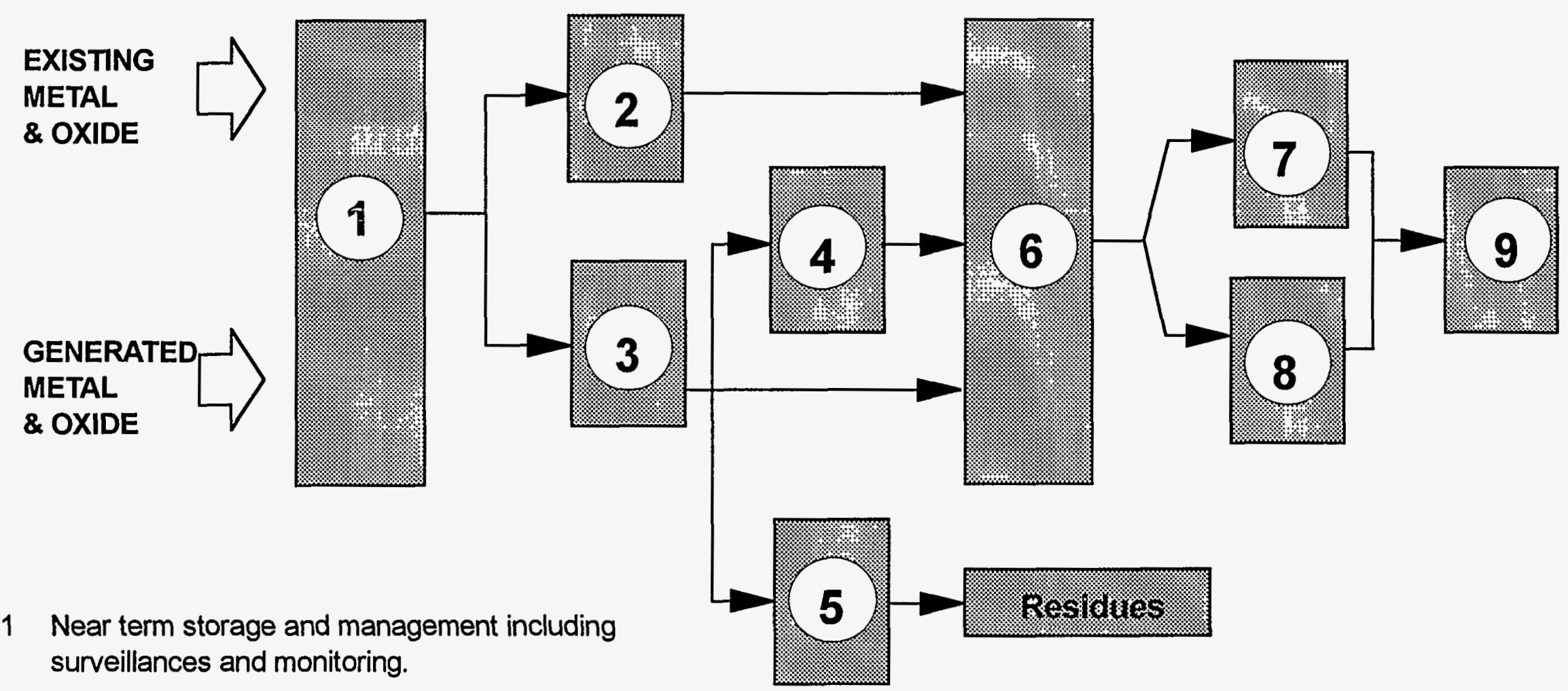

2 Repackaging known hazards (e.g., metal in direct contact with plastic, reactive oxides, etc.) on site storage standards.

3 Characterization to select and prioritize treatment.

6 Management to site storage standards.

7 Ship to alternate stabilization and repackaging facility to meet long term storage standard.

4 Stabilization and repackaging as required to meet the site storage requirements.

8 Stabilize and repackage to meet long term storage standard.

5 Transfer to "residue" category if standard cannot be met via themal stabilization.

9 Safe intermi stroage.

Figure 3.2-1 
- Priority thermal stabilization of reactive plutonium oxide.

- $\quad$ Priority repackaging of plutonium in close proximity to plastic (and other synthetic materials).

- Characterization required to select and prioritize items for treatment.

- Interim storage and emergency repackaging.

- Stabilization and repackaging to meet the metal and oxide storage standards (including the facilities required).

- $\quad$ Packaging and shipment for sites without storage, stabilization, or repackaging capabilities.

\section{Key Challenges}

- Improved material characterization, container design, surveillance, and handling techniques are needed to reduce operator exposure, minimize waste, control processes, and assure a safe long-term storage configuration.

- Integrated strategy to simultaneously support processing, storage, transportation, and disposition needs.

- Acceptable packaging and shipping capability that meets Department of Transportation (DOT) requirements.

- $\quad$ Stable long-term profile of the material.

In recognition to these challenges, activities will be initiated to focus on improving the efficiency, resource expenditure and time required to achieve the repackaging of containers holding plutonium metal and oxide ( $>50 \%$ assay) by:

- Developing standard requirements for the surveillance and maintenance activities associated with the inventory.

- Developing a technically adequate storage container for safe long-term storage.

- Developing a single strategy for transporting plutonium metal and oxides ( $>50 \%$ assay) within the Department. 


\section{Part III: Individual Site Activities}

\subsubsection{Implementation Approach for Rocky Flats Plutonium Metals and Oxides}

Several activities have been or are being implemented at Rocky Flats to reduce the risk associated with plutonium metals and oxides until they can be placed in a form suitable for safe interim storage. The material has been consolidated into vaults with access limited to essential personnel equipped with protective clothing and respirators. Movement of containers is strictly controlled. The vaults are constructed with air monitors, alarms, and ventilation systems that are designed to minimize the spread of contamination and protect the worker.

A monitoring and surveillance program detects degradation of storage conditions. Containers are periodically visually inspected as specified by site requirements (i.e., Health Safety Practices HSP 31.11; material control and accountability inventories, radiological surveys, etc.) to look for anomalies. A representative sampling of the repackaged material containers are weighed to determine if weight gain is within the allowable limits to prevent the container from breaching due to oxidation of the plutonium metal.

There are 1,858 items of plutonium metal that are not in compliance with on-site storage requirements. Compliance is necessary prior to placing these items in a form that can meet the metal and oxide storage standard. A representative sampling of plutonium metal (i.e. various forms, packaging configurations, alloys, etc.) is essentially complete, enabling prioritization for bringing these items into compliance. The highest priority has been placed on the metal that is packaged in direct contact with plastic. The 256 items in this storage configuration will be repackaged by October 1995. Repackaging operations are conducted in Building 707 and consist of opening the container, brushing the loose plutonium oxide from the metal, thermally stabilizing the oxide, and repackaging the metal without plastic. The remaining items requiring repackaging will be repackaged by October 1996 on a priority basis from the results of sampling. The oxides generated from brushing the plutonium will be thermally stabilized at a minimum of $500^{\circ} \mathrm{C}$ to eliminate the pyrophoric characteristics of the oxide; and then repackaged.

A new processing line is required to place the metal and oxide in a form that meets the metal and oxide storage standard for safe interim storage. This line is planned to be operational in FY98 upon installation in Building 371. The processing line will require a furnace to thermally stabilize the oxides to less than $0.5 \%$ loss on ignition and oxidize all plutonium metal with a surface area greater than $1.0 \mathrm{~cm}^{2} / \mathrm{g}$; the capability to brush loose oxide from metal; repackaging the material in the newly designed safe interim storage container; and, nondestructive assay capabilities. The conceptual design for this line has begun. 
Rocky Flats' metal inventory includes material in sealed weapon components (pits) and what is known as "scrub alloy sealed weapon components" that are not of weapons quality (i.e., "shelf-life" units, special order units, partially disassembled units, etc.) that have various tubulations or material configurations do not provide the packaging integrity required for long-term storage. All such pits are being considered for shipment to Los Alamos for disassembly with stabilization and repackaging of the plutonium to the metal and oxide storage standard. Scrub alloy, an alloyed button of plutonium and americium from the scrubbing of salts from the molten salt extraction process, will be considered for shipment to Savannah River for processing in FCanyon. Processing of scrub alloy at Savannah River allows the americium to be extracted to the high-level waste processing system, and the by-product metal to be packaged to the long-term storage standard.

\subsubsection{Implementation Approach for Savannah River Plutonium Metals and Oxides}

Savannah River has approximately 1,000 containers of high purity plutonium solids stored in F-Area vaults. Each container holds at least 100 grams of fissile material that is predominantly Pu-239 with minimal impurities. The stored material includes alloys, compounds, oxides, and large metal pieces. Savannah River had accumulated these high grade plutonium solids as a result of both F-Area facility operations and shipments received from other DOE sites. These materials were stored in a variety of containers within F-Area vaults and present extended storage concerns because of their physical condition. The degree of concern varies depending on the material form and packaging configuration. Additionally, approximately 200 containers of high quality metal and oxide will be produced from the stabilization of solutions, targets, and residues and will also require packaging and treatment to meet the metal and oxide storage standard. The objective is to ensure that all plutonium solids (metal and oxide) are in conformance with the DOE metal and oxide standard by May 2002.

Based on screening evaluations performed in support of the Interim Management of Nuclear Materials EIS, these materials will be identified as candidates for stabilization; primarily due to the presence of plastic in the packaging. The EIS will contain an evaluation of options for stabilizing these materials. Consequently, the plans outlined below to meet the standard are contingent upon the ROD, due in June 1995.

Based on available material and packaging information, there are 12 containers of metal turnings where plutonium metal is known to be in direct contact with plastic. These materials will either be processed to a safe storable form or directly repackaged by December 1995. Assuming the ROD on the Interim Management of Nuclear Materials EIS supports processing, the materials will be dissolved and processed to metal using the F-Canyon and the FB-Line facilities. If processing is not selected, the material will be repackaged to eliminate metal in direct contact with plastic.

Several activities are underway to reduce the risk until the remainder of the material can be repackaged. Design features of the vault (e.g., monitors, ventilation, limited access, etc.), and radiological controls and procedures are in place to minimize the 
worker risk in the event of a container failure. Surveillance and monitoring programs include statistical sampling to check for weight gain and visual checks for bulging. To select the required treatment and the priority for treatment, the containers will be nondestructively characterized using digital radiography equipment. Sampling of containers using existing gloveboxes will also be performed as warranted.

It is anticipated that a new or modified Actinide Repackaging Facility will be required to fully meet the metal and oxide storage standard. This facility will not be available until at least 2001 (assuming the approval of an FY98 Line Item Project) and would incorporate bagless transfer and high temperature calcination technology to ensure that plutonium materials could be treated and repackaged to meet the metal and oxide storage standard. This facility would be coupled with a new or modified vault to permit consolidation of plutonium materials into a facility suitable for extended interim storage and facilitate international inspections.

To demonstrate the technology and to provide an interim capability to meet the metal and oxide storage standard where practical, Savannah River is planning to install a bagless transfer system in the FB-Line facility. SRS has already completed proof-of principle testing for the bagless transfer system in a non-contaminated environment. The modifications are scheduled for completion by the end of FY97. If the demonstration is successful, some of SRS materials, particularly plutonium metal items, could be repackaged to the metal and oxide storage standard in this facility. Implementation of this system will be evaluated for use at other sites.

Savannah River is exploring the feasibility of modifying equipment within the FB-Line for thermal stabilization of oxides. However, technical evaluations have not been completed.

Key challenges include the demonstration of the bagless transfer system, digital radiography, and thermal stabilization by modified equipment; completion of the new actinide packaging capability; and the continued extended use of the FB-Line facility.

\subsubsection{Implementation Approach for Hanford Plutonium Metals and Oxides}

This material category includes the current inventory of plutonium metals and oxides at the Plutonium Finishing Plant (PFP) of approximately 2,850 items. These items are stored within the PFP vaults. All plutonium metal and oxide is packaged to meet Hanford's existing packaging and storage criteria of less than $1 \mathrm{wt} \%$ loss on ignition. Plastic is not in direct contact with the plutonium. Therefore, no immediate storage hazards exist and no urgent actions are required; although all metals and oxides require stabilization and/or repackaging to meet the metal and oxide storage standard.

In addition to the packaging criteria, PFP has an extensive monitoring and surveillance program that includes an engineered (automated temperature, pressure and safeguards) monitoring system. This program has proved successful at identifying suspect packages in sufficient time to allow for safe handling and repackaging of an item 
before container rupture. While PFP experiences 3 to 7 suspect containers that require repackaging each year, there has not been a vault-stored item rupture since the implementation of the packaging and storage criteria approximately 15 years ago.

The metal items currently stored at PFP can be repackaged without stabilization. Repackaging requires the development and installation of a new repackaging line to include a "Savannah River type" bagless transfer capability for containing the material. Engineering studies are scheduled for FY95-96 until funding can be secured in FY97 following issuance of the EIS. After completing detailed design, equipment procurement, and installation in 1998; the operations would commence in 1999 following staff training, procedure preparation, and operational readiness testing and reviews. Metal repackaging would be completed by the end of FY00.

Since the long-term storage goal for oxides requires stabilization to meet a loss on ignition of less than $0.5 \mathrm{wt} \%$; the items at PFP require restabilization. Restabilizing this material is expected to start upon completion of stabilization of two other categories of material: solutions and residues/low-assay, mixed oxides. PFP will, therefore, start restabilizing these high assay oxides in 1999 with completion anticipated in early 2002. To stabilize the oxide, a series of muffle furnaces will be used; the same furnaces for stabilizing the sludges and the reactive solids. Higher capacity and shorter cycle times are expected for this class of material because of its stable nature and lack of organic constituents. The through-put for the oxides would be approximately $2,200 \mathrm{~kg} / \mathrm{yr}$ using all 11 furnaces. After thermal stabilization, the oxide will be cooled in a controlled environment and then repackaged. Additional studies are planned to verify that the engineering design assumptions are consistent with exposure requirements for personnel.

\subsubsection{Implementation Approach for Los Alamos Plutonium Metals and Oxides}

Los Alamos National Laboratory (LANL) will design and qualify a suitable container for long-term storage of plutonium metals and oxides; conduct plutonium storage behavior studies and surveillance testing; and, establish quality-assured operations for processing and packaging of plutonium metal and oxide for long-term storage. Los Alamos has established operations for plutonium metal and oxide stabilization and repackaging for the PF-4 vault, and that meet the DOE-STD-3013-94.

Approximately 2.6 metric tons of plutonium will be stabilized for long-term storage through separation of oxide from metal, calcination of the oxide, and processing of residues to oxide. Repackaging prioritization has been established. Surveillance of the vault inventory will identify high risk items that will be promptly stabilized and packaged for safe near-term or long-term storage.

The schedule for repackaging of the inventory calls for initially processing and repackaging plutonium metal and oxides to long-term storage standards by 1997 , followed by completion of processing plutonium residues to stable oxide and repackaging by 2002 . 
The Los Alamos project will first repackage a group of items consisting of partially oxidized pure metal. A double encapsulation stainless steel containment system has been tested and is being qualified for long-term storage of plutonium metal and oxide. Testing data verify that the inner and outer containers are capable of maintaining their structural integrity and providing proper containment for the maximum theoretical pressure generated by radiolysis and chemical reaction in the stored material. Welding parameters are being refined. Container cleanliness criteria and a cleaning procedure have been developed. Inert gloveboxes to enable welding in helium atmospheres are in place and operable. Ambient helium surrounding special nuclear material provides leak-check capability, heat-transfer, and a nonreactive atmosphere in the container.

Los Alamos has established metal and oxide processing operations for long-term storage. Experimentation on the efforts of oxide calcination temperature on the basis of loss-on-ignition, particle size, and surface area is in process. The effects of relative humidity and time on water uptake of the calcined oxide are being studied. Research is continuing on nuclear material/container compatibility. Several surveillance diagnostic tools are being considered to determine pressure changes within the material container, such as resonance spectroscopy and aneroid bellows. An initial assessment of project quality assurance has been completed. After completion of a peer review in April 1995, packaging operations to the long-term storage standard will begin.

The TA-55 plutonium facility in Los Alamos has been in continuous operation since 1978. Residue and oxide processing, metal handling, and welding operations have been a normal part of continuing operations. As a result, repackaging at TA-55 has been reviewed for compliance with the National Environmental Protection Act by Los Alamos; and found to be within the current operation authorization basis. The repackaging operations are scheduled to be integrated and demonstrated in April 1995 with repackaging of plutonium metal and oxide to begin in May 1995. All metals and oxides are expected to be repackaged to the metal and oxide storage standard by May 2002. Included within this schedule is the stabilization and repackaging of excess metals and oxides from Lawrence Livermore.

\subsubsection{Implementation Approach for Lawrence Livermore Plutonium Metals and Oxides}

Lawrence Livermore National Laboratory (LLNL) has metal and oxide material in active programs in support of Defense Programs missions. The plutonium metal inventory includes about 250 containers that use the aluminum foil barrier system. The plutonium oxide inventory consists of 157 containers. These materials are located in Building 332, which is a fully functioning facility that meets federal, state, and local environmental regulations as outlined in the LLNL Environmental Impact Statement.

A project to identify, characterize, and non-destructively assay all plutonium items in inventory is identified in the Plutonium ES\&H Corrective Action Plan. This plan is in-process and scheduled for completion by January 1997. Lawrence Livermore does not believe there is any metal packaged in direct contact with plastic; however, any 
items found during this inventory process will be immediately repackaged with aluminum foil barrier. Excess plutonium metal items are scheduled to be repackaged in compliance with DOE-STD-3014-94 by 2002. Initial inspection of metal items will begin in April 1995.

LLNL has the means to repackage excess plutonium metal and oxide in compliance with the standard, however, we are considering improved methods for repackaging metal, and transferring and calcining oxide. These improved methods could reduce operator radiation exposure and potential worker contamination during decontamination of the storage cans. Repackaging of the material to meet the metal and oxide storage standard will be begin by May 1996.

LLNL is also investing a second option, namely, the possibility of shipping our excess plutonium to Los Alamos for processing, packaging or storage. This option is being discussed under the auspices of the Integrated Working Group (IWG). Successful shipment of the excess plutonium materials from the LLNL site may eliminate the need to process and package this material at LLNL. However, the combined cost to prepare the material to meet shipping requirements and the cost of reprocessing at LANL may be more then the cost of processing and packaging at LLNL.

\subsubsection{Implementation Approach for Other DOE Site Plutonium Metals and Oxides}

Many DOE sites that have small quantities of plutonium with a combined inventory less than $5 \mathrm{~kg}$; most in the form of sealed sources. Metal, oxide, and solutions make up the remainder. Under this implementation plan, all metals and oxides that are excess to programmatic need will be considered for consolidation at the larger sites that have; or will have; capabilities for processing and repackaging the materials to the metal and oxide storage standard.

\subsubsection{Key Milestones}

- $\quad$ Repackage all plutonium metals in direct contact with plastic:

RFETS . . . . . . . . . . . . . . . . . . . . October 1995

SRS (repackaging of metal turnings) . . . . . . . . December 1995

Mound ........................ September 1995

- Thermally stabilize all existing backlog reactive plutonium oxide:

RFETS . . . . . . . . . . . . . . . . October 1996.

- $\quad$ Conduct a sampling and inspection program to determine the relative risk and priority for repackaging plutonium metals and oxides in close proximity with plastic and other synthetic materials:

RFETS . . . . . . . . . . . . . . . . . . . . July 1995 
- $\quad$ Repackage plutonium metals and oxides in close proximity with plastic depending on risk:

RFETS . . . . . . . . . . . . . . . . October 1996

Stabilize all newly generated plutonium oxide . . . . . . . Ongoing

- Repackage all plutonium metals and oxides to the metal and oxide storage standard:

All Sites May 2002

\subsection{Plutonium Residues and Mixed Oxides (<50\% assay)}

\section{Part I: Stabilization Requirements}

\subsubsection{General Overview}

\section{Background}

The DOE currently manages a significant quantity of bulk materials contaminated with significant quantities of plutonium, defined as solid process residues. The residues represented feedstock and materials-in-process to nuclear weapon fabrication and nuclear material production until fabrication ceased in 1989. The residues are contaminated by materials such as impure oxides and metals, halide salts, combustibles, ash, dissolver heels, sludges, contaminated glass and metal, and other items. Since 1989 these residues have remained in packages in processing areas, vaults, and process lines awaiting disposition. They are not currently in a configuration suitable for long-term storage. Processing, treatment, stabilization, and/or repackaging are required to secure them in a safe, stable end-state. Table 3.3-1 indicates the quantities of solid residues at the various DOE facilities. 
Table 3.3-1: Summary of Plutonium Residue and Mixed Oxides (<50\% Assay)

\begin{tabular}{|l|l|l|l||}
\hline Site & SNM Inventory & Number of Items & Location \\
\hline Rocky Flats & 3,000 & 20,532 & $\begin{array}{l}371,559,776 / \\
777,779,707, \\
771,991\end{array}$ \\
\hline Hanford & 1,500 & 5,000 & PFP, Purex, PNL \\
\hline Los Alamos & 1,400 & 6,300 & TA-55, CMR \\
\hline Savannah River & Classified & 1,306 & $\begin{array}{l}\text { 235-F, FB-Line, } \\
\text { SRTC }\end{array}$ \\
\hline $\begin{array}{l}\text { Lawrence } \\
\text { Livermore }\end{array}$ & 35 & 182 & B332 \\
\hline Mound & 3 & 39 & T Building \\
\hline Argonne-East & $<1$ & 12 & \\
\hline New Brunswick & -- & --- & 3027,7930 \\
\hline Oak Ridge & 0.1 & 12 & \\
\hline Sandia & --- & -- & \\
\hline $\begin{array}{l}\text { Lawrence } \\
\text { Berkeley }\end{array}$ & $<1$ & 250 & \\
\hline
\end{tabular}

\section{Overview of Concem}

Within the solid residue inventory, many forms are corrosive, chemically reactive and difficult to contain, particularly when they are exposed to air and moisture. Hazards are generated as a result of either poor package design or packaging failure stemming from radiolysis and pressure buildup which contribute to the problem. Like other forms of plutonium, residues in contact with plastics cause radiolysis, hydrogen generation, and pressurization, making these packages susceptible to leaks or ruptures. Many packaging failures have occurred already. These failures have involved highly corrosive salts, fluoride-based reduction slags, plutonium oxide, and incinerator ash among others. Clearly, not all materials and packaging weaknesses within the inventory have been identified or characterized adequately. In fact, the long-term storage properties of materials are not well known. Action is needed both to respond to emerging hazards as well as to improve understanding of the long-term stability of these packaging materials. This effort is focused on arriving at the most desirable pathway to the acceptable end-state; using efficiency, cost, ALARA, waste, and facility constraints as elements of the acceptance criteria. 


\section{Applicable Sub-recommendations from DNFSB Recommendation 94-1}

Sub-recommendation 1a:

That an integrated program plan be formulated on a high priority basis, to convert within two to three years the materials addressed in the specific recommendations below, to forms or conditions suitable for safe interim storage. This plan should recognize that remediation will require a systems approach, involving integration of facilities and copabilities at a number of sites, and will require attention to limiting worker exposure and minimizing generation of additional waste and emission of effluents to the environment.

Sub-recommendation 2:

That a research program be established to fill any gaps in the information base needed for choosing among the alternate processes to be used in safe conversion of various types of fissile materials to optimal forms for safe interim storage and the longer term disposition. Development of this research program should be addressed in the program plan called for in (1) [Recommendation la] above.

Sub-recommendation 5:

That preparations be expedited to process the containers of possibly unstable residues at the Rocky Flats Plant [Rocky Flats Environmental Technology Site] and to convert constituent plutonium to a form suitable for safe interim storage.

\section{Acceptance and Objectives}

The DOE fully concurs with the DNFSB observations and recommendations on processing and stabilizing solid residues. Because of the complexity of the physical and chemical nature of the material forms and the storage configurations of the residues, the solid residue storage issue is similarly complex. The decision logic, as shown in Figure 3.3-1 for stabilizing the residues involved classifying them into one of three risk categories:

- High Risk: Condition likely to occur within 2-3 years and worker exposure consequence is unacceptable.

- Moderate Risk: Condition not likely to occur immediately but likely in 3-8 years and worker exposure consequence is above annual regulatory limit for routine operations.

- Low Risk: Condition not likely to occur in foreseeable future and worker exposure consequence is within operation limits.

By addressing the risks to workers, the risks to the public and environment are also mitigated. This assessment of risk is based on the results of the DOE Plutonium ES\&H Vulnerability Assessment (DOE/EH-0415). 


\section{PU RESIDUES AND MIXED OXIDES FLOW CHART}

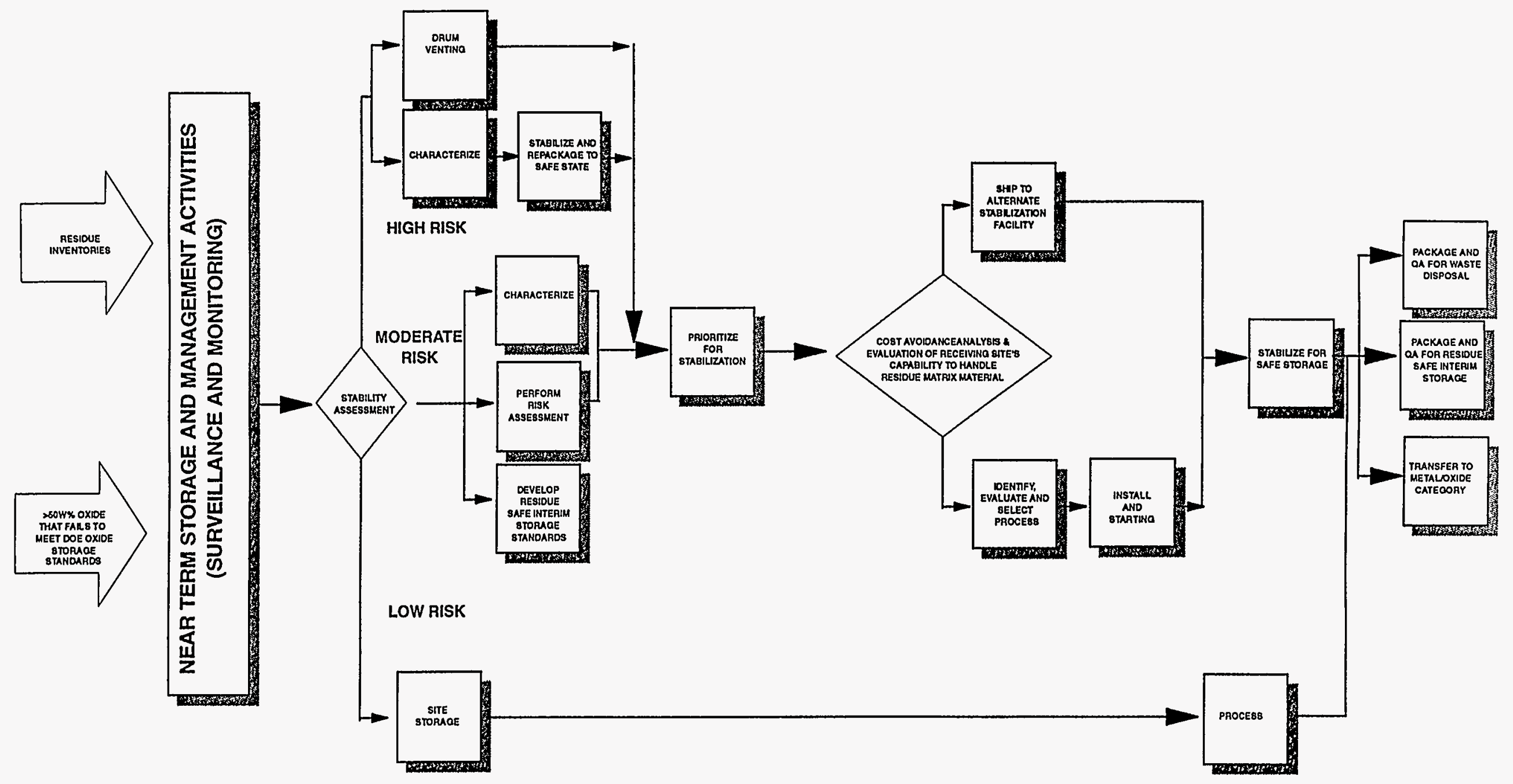

FIGURE 3.3-1 
The Department has split the action response for the stabilization of the three risk categories into two separate, albeit integrated, paths: 1) the stabilization and repackaging of high-risk residues, which has already begun and will be completed within 3 years, and 2) the establishment of a managed (planned, scheduled, and resource-loaded) program whereby all remaining residues will be prioritized, processed, stabilized, and packaged for long-term storage or a form suitable for disposal within an 8-year time frame. Characterization will continue in parallel along both paths where any uncertainties exist as to the contents of containers or the packaging configurations in an effort to better determine the proper stabilization path. This will include an aggressive research and development plan focused on more accurately understanding materials and packaging weaknesses, filling in gaps in technology and information needed in process selection and modification, as well as to gain a better understanding of long-term material and packaging stability.

In proceeding down the two paths, the general basis for achieving the objective of having a safe and stable inventory is as follows:

- Minimize the multiple handling of material in an effort to both reduce personnel radiation exposure and improve cost efficiency.

- Work across the DOE complex will be performed to a common set of residue category definitions and use a common risk-based approach to prioritization.

- $\quad$ Separate the hazards from the residue matrices, where appropriate from a cost benefit basis, so that the hazardous materials can be packaged according to the new DOE Metal and Oxide Packaging Standard, and the bulk residue can be discharged directly without further waste management cost.

- $\quad$ Avoid the use of RCRA listed hazardous materials and characteristics to preclude the generation of mixed waste.

- $\quad$ Adopt pollution prevention concepts such as reagent recycle systems where they are cost-effective.

- Define and use a DOE-approved set of safe interim storage standards for solid residues to use as an acceptable interim state until ultimate disposal can be achieved.

- Through risk/cost benefit analysis, identify and strive to use processes and produce end-states that minimize the life-cycle cost of long-term nuclear material management to include ultimate disposal.

- $\quad$ Minimize or eliminate waste generation from any processing path, meet all state and federal disposal regulations, avoid the introduction of additional reagents, and use existing residues as reagents. 


\section{Part III: Plutonium Residues and Mixed Oxides Integration Activities}

\section{Approach}

Functions Required to Accomplish Objectives: The key functions required to be in place for the implementation of the complex-wide approach to addressing the solid residue issues are as follows:

- Compensatory surveillance and monitoring activities that ensure that safe storage conditions be achieved until processing to the appropriate safe storage state occurs.

- Operational stabilization technologies that strive to achieve the above set of principles for all residues categorized as high risks to process (see Path 1 below).

- Common characterization approach to selection and prioritization of items for processing or stabilization (see Path 2 below).

- Safe interim storage capabilities and capacity.

- $\quad$ For all residues other than the high-risk category, processing technologies and capacity to convert those materials to meet the DOE standards for metals and oxides, criteria for available repositories, or a new standard to be developed for safe storage of specific residues.

- $\quad$ Packaging and shipment capabilities and facilities.

Path 1- High Risk Material Handling: This path strives to meet the 3-year target for mitigating risk associated with all high-risk residues. The materials in question exist in numerous facilities around the country. They have been generated via a number of different processing approaches. The sites individually have the knowledge of current material status and are best prepared to respond to the high-risk materials category rapidly. Each site has implemented a risk-based approach for evaluating the inventory and for identifying those items deemed high risks for stabilization. The residues will be dealt with in one of four ways:

- By processing to a form that complies with established standards for long-term storage or disposal. This is the preferred approach.

- $\quad$ By processing to a form that will be stable for an interim period (such as a few years).

- $\quad$ By repacking the residue to eliminate, at least for an interim period, the cause of the instability. (Ventilation is likely to be the most profitable type of repackaging). 
- By ascertaining through investigation and characterization that the residue is not possibly unstable.

For each site, the materials falling into the high-risk category include:

- $\quad$ RFETS: Selected pyrochemical salt reagents, sand slag, and crucible ( SS\&C), selected sludges, graphite fines, and selected combustibles.

- $\quad$ LANL: Single containment pressure vessels, solutions, selected pyrochemical salts, sand slag and crucible, gases, selected combustibles, selected Pu metal items, and selected sealed sources.

- $\quad$ SRS: SS\&C and reduction residues.

- Hanford: Sludges, selected incinerator ash, solutions, reactive solids such as SS\&C, and combustibles.

- LLNL: Ash.

- $\quad$ Other (Sites with small holdings): None.

The individual site reports found later in this section provide a detailed discussion of the specific materials, processing approaches, and schedules.

Path 2-Managed Material Handling: This path deals with all other remaining residue inventories. The target is to stabilize and package all of the remaining materials within 8 years in such a way that they 1) will meet the new DOE-approved safe interim storage standard for residues "as is"; 2) will be processed to partition the actinides from the residue matrix so that the actinides can be stabilized to meet the DOE standard criteria for safe storage of plutonium metals and oxides (DOE-STD3013-94); or 3) will be packaged to meet the criteria for waste repositories (see Figure 3.3-1). In the latter case, the resulting matrix waste will be sent to the appropriate storage repository. The necessary action associated with this path will be initiated immediately and will proceed in parallel with Path 1.

The Department will establish a formal, integrated management system for determining the order in which the material categories will be prioritized, processed, stabilized, and packaged for long-term storage. The first step is to arrange the materials into commonly defined groupings. Material holdings at each site are classified into at least one of nine major groupings as outlined below. These broad groupings are further subdivided at each site, as appropriate, according to the way the materials are to be processed.

- $\quad$ Mixed Oxides $<50 \%$ assay

- $\quad$ Alloys $<50 \%$ assay

- $\quad$ Chloride-based salts 
- $\quad$ Combustible materials (e.g., paper, rags, plastic, gloves)

- Ash, ash heel, and particulate residues

- $\quad$ Fluoride-based residues

- $\quad$ Sludges and wet residues

- $\quad$ Miscellaneous inorganic materials (e.g., glass, metal, ceramics)

- Other

Clearly Defined End-States: Acceptable end-states include material treated and packaged to a safe interim storage state for a residue grouping, material stored in compliance with the DOE Metal and Oxide Storage Standard, or material treated and packaged in compliance with criteria for acceptance by the waste repository to which the material is to be sent.

Characterization: All residues will be characterized by process knowledge, NonDestructive Assay (NDA), Non-Destructive Evaluation (NDE), selected monitoring of the material physical properties, or analytical chemistry methods to ensure that the properties of the residue materials are adequately known to understand safety implications. These data will be documented formally and become a part of each residue package's historical data base.

Risk Assignment: All residue material groups will be evaluated using a formalized risk-based approach (see Key Challenges section, below) based on their characterized properties and their packaging configurations. Each site will document the current risk-based assessment of their residue holdings that results in assignment of residue into one of the three defined stability categories outlined earlier.

The methodology will be to assign a risk category to each material group, based on consideration of the following factors:

- Known information about materials and packaging, which will be evaluated for the presence of potential hazards. Known hazards include, for example, the presence of flammable gas, shock-sensitive materials, ignitable or flammable materials, pressure build-ups, corrosives, incompatible chemicals or reactive metals, and significant container degradation.

- The likelihood of failure resulting in adverse radiological safety and health consequences.

- The severity of consequences to the worker, the public, and the environment, if a failure occurs.

In effect, this is a dynamic, risk-managed process because materials will constantly be moving into the residue management system and among categories within the system. Evaluation and prioritization must be continuous. 
Option Analysis: Selection of the end-state and stabilization pathway will be documented by trade studies.

- The functions required to accomplish each pathway will be defined along with all identified key issues and barriers.

- A standard set of decision criteria will be defined and used for comparison of alternatives. Criteria will be included for minimizing life-cycle cost, improving schedule, reducing technical risk, reducing environmental safety and health risk, minimizing waste generation, maximizing facility utilization, considering of other programmatic and site-specific objectives.

- Technical peer reviews will be conducted as appropriate to validate conclusions.

- Cross-cutting studies will be utilized to the extent practical to establish common factors and approaches.

- Inter-site shipment options will be explored where appropriate.

Plans: An overview of the base-case disposition approach currently planned at each site is outlined in the following site-specific sections. More detailed documentation of the baseline facility-use strategy and schedule will be developed as part of each site's Management Plan.

\section{Key Challenges}

Several challenges must be met to fulfill DOE's objectives for stabilization of residue. DOE needs:

- Establishment of a uniform approach to risk classification of plutonium inventories in order to prioritize stabilization activities.

- Development of a common approach to selecting the pathway for overall nuclear material management for items that are less than $50 \%$ assay.

- Development of a set of safe interim storage standards for materials that are less than $50 \%$ assay.

- $\quad$ RCRA requirements for storage, treatment, and disposal may have a significant impact on stabilization and packaging plans.

- $\quad$ Establishment of shipping and receiving agreements and residue shipping containers. 
- Development and implementation of a strategy for stabilizing and packaging residues at smaller sites for safe interim storage that optimizes use of complexwide capabilities.

- $\quad$ Allocation of space at the WIPP repository, which is oversubscribed and at sites that do not have space allocated. This lack of space precludes the option of sending their low concentrations of residues to waste rather than to partition and store. Waste is viewed as the best option for low assay items yet DOE does not have a final repository available, nor does the Department have space allocations or limitations assigned for the plutonium at each site.

\section{Part III: Individual Site Activities}

\subsubsection{Rocky Flats Plutonium Residues}

Rocky Flats has 100 metric tons of residues with low concentrations of plutonium stored in seven facilities. About 3 metric tons of plutonium are contained in 3,928 drums and 3,909 cans (for a total of over 20,000 packages) located in vaults and process areas. The plutonium in these drums and cans accounts for a large fraction of the 12.9 metric tons of plutonium and the vast majority of the over 27,000 packages of plutonium at the site. The classes of material, quantities, concerns, and 3- and 8-year actions are summarized in Table 3.3-2 below. Preliminary selections of the processes have been made for planning purposes. The material classes have been identified according to the logical stabilization process required to eliminate the concerns. Additionally, all residues were initially categorized into risk categories (1 through 5) to prioritize them for treatment. (Note: This was a unique risk categorization approach developed at RFETS in prioritizing the initial residue set.) Figure 3.3-2 provides a risk categorization for the Rocky Flats residues by Item Description Code (IDC). 
Table 3.3-2: Rocky Flats Residues

\begin{tabular}{|c|c|c|c|c|c|}
\hline Class & Description & Quantity & Concem & $\begin{array}{l}\text { Year } \\
\text { Action }\end{array}$ & $\begin{array}{l}8 \text { Year } \\
\text { Action }\end{array}$ \\
\hline Salts & $\begin{array}{l}\text { Pyro salt } \\
\text { reagents }\end{array}$ & $\begin{array}{l}15,980 \mathrm{~kg} \\
\text { in } 641 \\
\text { drums and } \\
2,954 \text { cans }\end{array}$ & $\begin{array}{l}\text { Reactive metals, } \\
\text { Plastic packaging }\end{array}$ & $\begin{array}{l}\text { Treat category } \\
1 \& 2 \text { and salts } \\
\text { in occupied } \\
\text { areas }\end{array}$ & $\begin{array}{l}\text { Treat } \\
\text { remaining salts }\end{array}$ \\
\hline Combustibles & $\begin{array}{l}\text { Paper, plastic, } \\
\text { grease, resin }\end{array}$ & $\begin{array}{l}17,495 \mathrm{~kg} \\
\text { in } \\
748 \text { drums } \\
\text { and } \\
4 \text { cans }\end{array}$ & $\begin{array}{l}\text { Hydrogenous } \\
\text { matrix; } \\
\text { nitrification; } \\
\text { spontaneous } \\
\text { combustion }\end{array}$ & & $\begin{array}{l}\text { Treat } \\
\text { remaining } \\
\text { combustibles } \\
\text { (within } 5 \\
\text { years) }\end{array}$ \\
\hline Ash & $\begin{array}{l}\text { Incinerator ash; } \\
\text { sand, slag \& } \\
\text { crucible; } \\
\text { graphite }\end{array}$ & $\begin{array}{l}27,433 \mathrm{~kg} \\
\text { in } \\
1,426 \text { drums } \\
\text { and } \\
456 \text { cans }\end{array}$ & $\begin{array}{l}\text { Reactivity of } \\
\text { metals; } \\
\text { Hydrogenous } \\
\text { matrix }\end{array}$ & $\begin{array}{l}\text { Treat SS\&C, } \\
\text { and graphite } \\
\text { fines; } \\
\text { vent others }\end{array}$ & $\begin{array}{l}\text { Treat } \\
\text { remaining ash }\end{array}$ \\
\hline Wet/Misc & $\begin{array}{l}\text { Acid- } \\
\text { contaminated } \\
\text { sludges, } \\
\text { classified } \\
\text { shapes }\end{array}$ & $\begin{array}{l}12,640 \mathrm{~kg} \\
\text { in } \\
448 \text { drums } \\
\text { and } \\
366 \text { cans }\end{array}$ & $\begin{array}{l}\text { Plastic packaging } \\
\text { causing } \\
\text { hydrogen } \\
\text { generation }\end{array}$ & $\begin{array}{l}\text { Vent all } \\
\text { containers }\end{array}$ & $\begin{array}{l}\text { Treat all } \\
\text { materials }\end{array}$ \\
\hline Inorganics & $\begin{array}{l}\text { LECOs, light } \\
\text { metal, glass, } \\
\text { Raschig rings }\end{array}$ & $\begin{array}{l}32,794 \mathrm{~kg} \\
\text { in } \\
665 \text { drums } \\
\text { and } \\
129 \text { cans }\end{array}$ & $\begin{array}{l}\text { Plastic packaging } \\
\text { causing } \\
\text { hydrogen } \\
\text { generation }\end{array}$ & $\begin{array}{l}\text { Vent categories } \\
1 \& 2\end{array}$ & $\begin{array}{l}\text { Repackage all } \\
\text { materials }\end{array}$ \\
\hline
\end{tabular}

Salts are of concern because they contain reactive metals, especially plutonium metal shot. They are also corrosive and can generate hydrogen gas from contact with plastic; and any absorbed water in the matrix. Pyrochemical oxidation will destroy the reactive metals and drive off water.

Combustibles consist of paper, plastics, rags, gloves, ion exchange resins, filters, and oil- and grease-contaminated residues. All combustibles generate hydrogen from the radiolysis of the matrix. However, the risk resulting from the pressure build-up has been mitigated at Rocky Flats in the short term by venting the drums. Ion exchange resins in nitrate form constitute a fuel and oxidizer in intimate contact. RFETS and LANL are exploring cementation of the resins to mitigate this safety issue. Some of the combustibles contain cellulosic materials, which are of concern due to the presence of nitric acid and nitrates or oil. The best long-term technical approach to address all of the above combustible safety issues is to destroy the matrix that involves incineration. However, permitting an incinerator can be a difficult and lengthy process. Consequently, RFETS is pursuing a parallel path approach, which includes the pilot fluidized bed incinerator (FBI) in Building 776 while at the same time exploring alternatives to incineration for short- and long-term mitigation of safety issues. 


\section{ROCKY FLATS RESIDUES}

\section{ITEM DESCRIPTION CODES (IDC) RISK BREAKOUT}

\begin{tabular}{|c|c|c|c|}
\hline & HIGH RISK & MODERATE RISK & LOW RISK \\
\hline SALTS & $\begin{array}{l}363,364,404,405,407,408 \\
409,410,411,412,413,414 \\
415,427,429,443,473,654 \\
655\end{array}$ & $\begin{array}{l}333,365,405,406,407,409 \\
410,411,413,414,415,418 \\
427,429,433,434.473,654 \\
655\end{array}$ & $044,416,426$ \\
\hline COMBUSTIBLES & NONE & 330,337 & NONE \\
\hline$\overline{\text { ASH }}$ & $\begin{array}{l}312,368,372,378,390, \\
391,392,393,394,398, \\
420,421,422,423\end{array}$ & $\begin{array}{l}089,368,378,390,391,392 \\
393,394,395,396,398,419 \\
420,421,428,601\end{array}$ & $310,374,387$ \\
\hline WET/MISC. & $\begin{array}{l}290,291,292,299,331,332, \\
335,336,339,340,341,342, \\
373,430,431,441,485,490\end{array}$ & $\begin{array}{l}\mathrm{H} 61,099,290,292,299, \\
340,441\end{array}$ & $\begin{array}{l}090,0901,092,093,097 \\
301,338,376,486,489\end{array}$ \\
\hline INORGANIC & $320,360,371,377,440,442$ & $\begin{array}{l}312,334,371,377,438,440, \\
442\end{array}$ & $\begin{array}{l}197,300,303,320,321,370 \\
479,480\end{array}$ \\
\hline OTHER & 050 & NONE & 080 \\
\hline
\end{tabular}


Ash generates gas from radiolysis of residual organic material. SS\&C and graphite contain reactive metals. Calcination of these materials is the process for removing these hazards. Wet/miscellaneous materials generate hydrogen from plastic packaging, residual water, and organic materials. A variety of methods will be used to eliminate these hazards. Inorganic materials, such as LECO crucibles, light metal, and glass, only require venting of current packaging and/or repackaging to eliminate plastic in contact with plutonium.

RFETS has committed to the following actions:

- $\quad$ The RFETS high risk residue groups will be mitigated/processed into a stable form within three years.

- The remaining residue groups will be processed into a stable form within eight years.

Specific actions to be taken with respect to the residue groups are as follows:

Salts: Category 1 and 2 risk groups and other residue groups in this class stored in occupied areas (i.e. outside of vaults) will be processed and repackaged for off-site shipment within $3 \frac{1}{2}$ years. Stabilization will be accomplished by pyrochemical oxidation using existing and newly installed furnaces in Building 779. Approximately $6,000 \mathrm{~kg}$ of salt can be processed by May 1997, with the remaining high hazard salts completed by December 1997.

- Combustibles: All high-risk combustibles will be processed and repackaged within four and a half years with the balance to be completed within eight years. As a compensatory measure, RFETS has mitigated many of the safety issues associated with combustibles through venting and surveillance. The potential for off-normal occurrences associated with fire scenarios involving combustibles is adequately mitigated until the planned combustible processing capability start-up. The installed fire detection and fire suppression systems minimize the probability of occurrence of large fires. The Conduct of Operations program provides training and qualification of operators in fire safety, which minimizes the human error occurrence rate. The Rocky Flats Fire Department fire and combustible loading ensure continued system operability and risk minimization. Combustible drums are inspected daily as well as every shift during rounds by Stationary Operating Engineers, Shift Managers, and Radiological Operations personnel. RFETS will continue to pursue short- and long-term mitigation and stabilization alternatives such as cementation of resins, washing and drying combustibles, pyrolysis, and non-thermal destruction technologies. 
- Ash: All residue groups represented by SS\&C IDCs, as well as all of IDC 310 (graphite fines), will be processed and repackaged in three years. All other IDCs will be vented in three years and processed and repacked within eight years. Stabilization will be accomplished using existing casting furnaces in building 707. All high hazard materials can be completed by May 1997.

- Inorganics: These residues will be vented within 3-years and will be repackaged for off-site shipment within 8-years. Repackaging operations will continue in building 707 .

- Wet/Miscellaneous: These residues will be vented within 3-years and will be processed and repackaged within 8-years.

The above "venting" commitments will be accomplished under the purview of the drum venting effort, which has committed to venting 2,045 drums in FY95, and the remaining unvented residue drums by the end of FY96. An analysis will be performed to determine if venting a drum in advance of its processing is warranted, or whether near-term (3-year) processing precludes the need to vent certain drums.

\subsubsection{Savannah Plutonium Residues}

The SRS has residues in four categories: 1) 212 containers of Metal and alloy residues $<50 \%$ assay; 2) 614 containers of oxide residues $<50 \%$ assay; 3) 413 containers of potentially reactive materials such as SS\&C, sweepings, turnings, alloys, and oxides; and 4) 67 containers of miscellaneous residues. These materials are stored in the FArea vaults, and are considered to be possibly unstable and thus unsuitable for longterm storage. The degree of concern varies depending on the isotopic content, chemical impurities, and packaging. A breakdown of these materials is shown in Table 3.3-3. 
Table 3.3-3: Savannah River Residues

\begin{tabular}{|c|c|c|c|c|c|}
\hline Cass & Description & Quantity & Concem & 3 Year Action & 8 Year Action \\
\hline $\begin{array}{l}\text { Metal and } \\
\text { alloy } \\
\text { residues } \\
<50 \% \\
\text { assay }\end{array}$ & $\begin{array}{l}\text { Mixed metals and } \\
\text { alloys (contain } \\
\text { EU, etc.) }\end{array}$ & $\begin{array}{l}39 \text { items } \\
\text { greater than } \\
100 \mathrm{~g} / \mathrm{can} .173 \\
\text { items less than } \\
100 \mathrm{~g} / \mathrm{can} .\end{array}$ & $\begin{array}{l}\text { Plastic in proximity, } \\
\text { high surface area, } \\
\text { possible reactives, un- } \\
\text { characterized }\end{array}$ & $\begin{array}{l}\text { Characterize and begin } \\
\text { processing items that } \\
\text { can- not meet new or } \\
\text { planned standards }\end{array}$ & $\begin{array}{l}\text { Stabilize and package to } \\
\text { new storage criteria or } \\
\text { residue criteria to be } \\
\text { developed }\end{array}$ \\
\hline $\begin{array}{l}\text { Oxide } \\
\text { residues } \\
<50 \% \text { assay }\end{array}$ & $\begin{array}{l}\text { Mixed oxides and } \\
\text { compounds }\end{array}$ & $\begin{array}{l}251 \text { items } \\
\text { greater than } \\
100 \text { g/can. } \\
363 \text { items less } \\
\text { than } 100 \\
\mathrm{~g} / \mathrm{can} .\end{array}$ & $\begin{array}{l}\text { Plastic in proximity, } \\
\text { uncharacterized }\end{array}$ & $\begin{array}{l}\text { Characterize and begin } \\
\text { processing items that } \\
\text { can- not meet new or } \\
\text { planned standards }\end{array}$ & $\begin{array}{l}\text { Stabilize and package to } \\
\text { new storage criteria or } \\
\text { residue criteria to be } \\
\text { developed }\end{array}$ \\
\hline $\begin{array}{l}\text { Reactive } \\
\text { solids }\end{array}$ & $\begin{array}{l}\text { Sand, Slag, } \\
\text { Crucible, and } \\
\text { reduction residues }\end{array}$ & $\begin{array}{l}413 \text { items } \\
\text { now. Over } \\
130 \text { more will } \\
\text { be generated } \\
\text { during } \\
\text { cleanout. }\end{array}$ & $\begin{array}{l}\text { May pressurize or } \\
\text { corrode over time }\end{array}$ & Process & $\begin{array}{l}\text { Package resultant } \\
\text { plutonium to meet storage } \\
\text { criteria }\end{array}$ \\
\hline Other & $\begin{array}{l}\text { Misc. items in } \\
\text { other residue } \\
\text { categories }\end{array}$ & $\begin{array}{l}67 \text { items less } \\
\text { than } 100 \mathrm{~g} / \mathrm{can}\end{array}$ & Poorly characterized & $\begin{array}{l}\text { Characterize and begin } \\
\text { processing items that } \\
\text { can- not meet new or } \\
\text { planned standards }\end{array}$ & $\begin{array}{l}\text { Stabilize and package to } \\
\text { new storage criteria or } \\
\text { residue criteria to be } \\
\text { developed }\end{array}$ \\
\hline
\end{tabular}

Note: Table excludes samples and standards, and shown actions are contingent upon EIS outcome.

These materials were classified as at-risk, or possibly unstable, as a result of the ES\&H Pu Vulnerability Assessment. They also have been identified as candidates for stabilization in the Interim Management of Nuclear Materials EIS. The ROD for the EIS is planned for June 1995 and is considering the following options:

- $\quad$ Mitigation of immediate vulnerabilities by repackaging in existing F-Area facilities, and continued storage of other plutonium scrap in existing packages.

- $\quad$ Continuation of active monitoring and management of the packages until the new Actinide Repackaging Facility is built and operational.

- $\quad$ Processing to oxide, dissolving material in F- or H-Canyon, purifying the plutonium, and transferring the solution to FB- or HB-Line for conversion to a metal or oxide.

- Vitrification of selected materials using the proposed MPPF or DWPF vitrification processes. 
Pending results of the ROD, the assumed stabilization pathway for these materials is to repackage the items that are greater than 100 grams to meet the residue safe interim storage standard (to be developed) and to stabilize the other materials via aqueous processing. Until the stabilization options can be exercised, the materials are under a surveillance and monitoring program that includes visual inspection and statistical sampling. The design features of the vault minimize worker risk in a packaging failure.

Where material and packaging properties are characterized incompletely, a program will be instituted to select the required stabilization process. Methods used will include NDA using digital radiography equipment, to be installed by late 1997 and selected sampling of containers using existing gloveboxes with modification.

Current plans call for the repackaging of all existing high-grade, mixed plutonium solids ( $>100 \mathrm{~g} / \mathrm{can}$ ) to meet the new residue safe interim storage standard. This would require the new Actinide Repacking Facility (ARF) to be available in 2001, provided it is approved as an FY98 line item. This new facility would be coupled with a new vault to permit consolidation of plutonium materials into a single facility. A new technology bagless transfer system will be demonstrated in the existing F-Area facility by September 1997.

The other possibly unstable residues are slated for processing in the canyons: the more reactive material, such as SS\&C, in FB-Line or F-Canyon; and the mixed, low-grade solids in the HB-Line. The material processed in FB-Line will be transformed to metal for storage, while the material processed in HB-Line will be transformed to oxide. Pending the results of the ROD, processing in the F-Area will begin in FY96. Processing existing inventories of SS\&C materials will be completed by December 1997. Other chemical processing activities will be completed by late 2001 .

Key assumptions in achieving the above include 1) IMNM ROD in June 1995 to support the plan; 2) start-up authorization obtained from DOE/HQ in FY95; 3) the development and installation of the bagless transfer system; 4) new packaging facilities to meet standards; and 5) the completion of modifications to the existing facilities to support container opening and repackaging.

\subsubsection{Hanford Plutonium Residues}

Hanford has several classes of materials at its Plutonium Finishing Plant (PFP), ranging from stabilized mixed oxides to unstable sludges stored in process gloveboxes. The PFP accounts for the majority of Hanford plutonium inventory, roughly 5,000 items with about 1.5 caps of plutonium. The classes of material, concern, and nearterm and long-term actions are summarized in Table 3.3-4. Processes for stabilization and cleanout of the PFP are being evaluated in ongoing PFP-related National Environmental Policy Act (NEPA) documentation. When NEPA documentation is complete, the selected stabilization processes will be installed and operated to place all of the material in a form suitable for vault storage. The highest priority will be to deal with unstable materials first. For example; the existing inventory of glovebox- 
stored reactive sludge is unstable and does not meet the current Hanford criteria for vault storage.

One special class of $<50 \% \mathrm{Pu}$ oxides is unirradiated encapsulated Fast Flux Test Facility (FFTF), which are presently stored both at PFP and at FFTF. All individual pins and fuel assemblies (217 pin configurations) are considered to be safe for longterm storage and that fuel is not being considered for further stabilization or repackaging. It is expected that all of the fuel rods an assemblies will eventually be stored at PFP until final disposition is determined.

Table 3.3-4: Hanford Plutonium Residues

\begin{tabular}{|c|c|c|c|c|c|}
\hline Class & Description & Quantity & Concem & $\begin{array}{l}\text { 3-Year } \\
\text { Action }\end{array}$ & $\begin{array}{l}\text { 8-Year } \\
\text { Plan }\end{array}$ \\
\hline $\begin{array}{l}\text { Interim stable } \\
\text { solids }<50 \\
\text { wt } \% \text { assay }\end{array}$ & $\begin{array}{l}\text { Lower grade } \\
\text { oxides, mixed } \\
\text { oxides, alloys }\end{array}$ & 2,850 items & $\begin{array}{l}\text { Material meets } \\
\text { current Hanford } \\
\text { criteria for } \\
\text { storage; does } \\
\text { not meet DOE } \\
\text { Standard }\end{array}$ & $\begin{array}{l}\text { None. } \\
\text { Material has } \\
\text { been stabilized } \\
\text { and packaged } \\
\text { to current } \\
\text { Hanford } \\
\text { criteria. }\end{array}$ & $\begin{array}{l}\text { After reactive } \\
\text { material and } \\
\text { sludges are treated; } \\
\text { stabilize and } \\
\text { package material to } \\
\text { new Hanford } \\
\text { criteria for interim } \\
\text { storage }\end{array}$ \\
\hline $\begin{array}{l}\text { Miscellaneous } \\
\text { solid residues }\end{array}$ & $\begin{array}{l}\text { Ash, slag and } \\
\text { crucible }\end{array}$ & $\begin{array}{l}1,625 \text { items, } \\
1,890 \mathrm{~kg} \text { bulk }\end{array}$ & $\begin{array}{l}\text { Material does } \\
\text { not meet } \\
\text { current Hanford } \\
\text { criteria for } \\
\text { storage; may } \\
\text { pressurize over } \\
\text { time }\end{array}$ & $\begin{array}{l}\text { The } 46 \text { items of } \\
\text { ash will be } \\
\text { stabilized and } \\
\text { repackaged. }\end{array}$ & $\begin{array}{l}\text { Add additional } \\
\text { furnace capability } \\
\text { to thermally } \\
\text { stabilize and } \\
\text { package material } \\
\text { for storage in } \\
\text { accordance with } \\
\text { new Hanford } \\
\text { criteria for interim } \\
\text { storage }\end{array}$ \\
\hline Sludges & $\begin{array}{l}\text { Wet, sludges, } \\
\text { future cleanout } \\
\text { residues }\end{array}$ & $\begin{array}{l}285 \text { items } \\
\text { Cleanout } \\
\text { residues TBD }\end{array}$ & $\begin{array}{l}\text { Wet, corrosive } \\
\text { material is } \\
\text { stored in } \\
\text { process } \\
\text { gloveboxes }\end{array}$ & $\begin{array}{l}\text { Currently, } \\
\text { sludges are } \\
\text { being processed } \\
\text { in two muffle } \\
\text { furnaces to } \\
\text { thermal- } \\
\text { stabilize and } \\
\text { package } \\
\text { material to } \\
\text { Hanford criteria } \\
\text { for vault } \\
\text { storage. }\end{array}$ & $\begin{array}{l}\text { Maintain thermal } \\
\text { stabilization } \\
\text { capability to } \\
\text { process future } \\
\text { cleanout material, } \\
\text { as needed }\end{array}$ \\
\hline Combustibles & $\begin{array}{l}\text { Polycubes, } \\
\text { plastic, rags }\end{array}$ & $\begin{array}{l}280 \text { items } 245 \\
\mathrm{~kg} \text { bulk }\end{array}$ & $\begin{array}{l}\text { Degrading } \\
\text { matrix; material } \\
\text { does not meet } \\
\text { Hanford storage } \\
\text { criteria and is } \\
\text { stored in vented } \\
\text { cans. }\end{array}$ & $\begin{array}{l}\text { None. Material } \\
\text { is stored in } \\
\text { vented cans, } \\
\text { subject to } \\
\text { surveillance. }\end{array}$ & $\begin{array}{l}\text { Develop pyrolysis } \\
\text { furnace to process } \\
\text { polycubes into } \\
\text { oxides suitable for } \\
\text { long-term storage }\end{array}$ \\
\hline
\end{tabular}


To ensure safe storage until the material can be processed, the PFP has an extensive monitoring and surveillance program. This program has proven successful in identifying suspect packages in sufficient time to allow safe handling and repackaging before a container rupture occurs.

A small amount of the miscellaneous solid residue category (46 items of Rocky Flats ash) has been identified in the plutonium vulnerability assessment and poses a risk due to the presence of unburned material that may pressurize during storage (See Table 3.3-5.). This material will be processed in the existing muffle furnaces after completion of sludge stabilization processing, scheduled to be completed by September 1995. Ash processing is scheduled to be complete by March 1996. Items not suitable for stabilization via the muffle furnaces, such as high-organic sludges, will be evaluated on a case-by-case basis for pretreatment and/or discard.

The remainder of the inventory is considered safe for continued storage until after the current PFP NEPA activity. Interim stable material has been processed to meet the current Hanford criteria for vault storage ( $<1.0 \mathrm{wt} \%$ loss on ignition) and is safe for continued storage. The slag and crucible containing reactive metals are packaged in accordance with current Hanford criteria and have not exhibited any problems during storage. The polycubes are packaged in a vented configuration in accordance with current Hanford criteria.

The residue materials in this group are not addressed by the current DOE standard for long-term storage of plutonium.

Processing of the remainder of the inventory to meet the long-term goal will depend on the ongoing PFP NEPA activities. Currently, additional muffle furnaces are anticipated to process the reactive solids and a pyrolysis furnace is planned to process combustibles. After the reactive material is processed, the interim stable material will be processed. Completion of stabilization of the reactive solids is projected to occur in January 2000. Subsequent stabilization and repackaging of the interim stable materials is projected for January 2002.

A polycube processing study will be performed to develop process design information after which a definitive design will be initiated. Stabilization is expected to start July 1999 and be completed in January 2001.

The following key assumptions apply to the development of the residues schedule:

- $\quad$ New process equipment (e.g., muffle furnaces, pyrolysis furnace, associated support equipment) will not require line item funding or extended funding approval (i.e., required funding will be provided on an expedited basis.)

- $\quad$ Operator dose rates associated with processing of this material will be acceptable without the need for extensive shielding or remote handling equipment. 
- The muffle furnace process will be adequate for stabilization.

- The pyrolysis furnace process will be acceptable; modifications to the off-gas treatment process may require development.

\subsubsection{Los Alamos Plutonium Residues}

The material that is considered within the scope of the DNFSB Recommendation 94-1 is shown in Table 3.3-5 below.

Table 3.3-5: Plutonium Inventory*

\begin{tabular}{||l|l|l|l||}
\hline MGatrix & SNM (kg) & Net $(\mathrm{kg})$ & Number of Items \\
\hline Compounds & 234 & 349 & 443 \\
\hline Gases & 0.2 & - & 2 \\
\hline Combustibles & 2 & 73 & 91 \\
\hline Glass & 1 & 16 & 37 \\
\hline Graphite & 4 & 134 & 94 \\
\hline MgO Crucibles & 39 & 565 & 269 \\
\hline Non-Pu Metal & 17 & 839 & 200 \\
\hline Non-Combustibles & 1 & 134 & 55 \\
\hline Ash & 26 & 159 & 142 \\
\hline Heels & 73 & 352 & 224 \\
\hline Hydroxides & 22 & 523 & 291 \\
\hline Sweepings & 26 & 310 & 192 \\
\hline Misc. residues & 27 & 335 & 139 \\
\hline Chloride salts & 307 & 6140 & 927 \\
\hline SS.\&C & 27 & 675 & 200 \\
\hline Other & - & - & 579 \\
\hline W & & & \\
\hline
\end{tabular}

*Np and $A m$ are additions to this inventory.

The overall priorities for stabilization are shown below:

- Items that present unusual radiation or release hazards:

- $\mathrm{Pu} / \mathrm{Be}$ neutron sources

- $\mathrm{PuF}_{6}$ gas

- Any item visually confirmed during a vault inspection to have a potentially failed container as indicated by discoloration, cracks or holes, improper tape seal, container swelling or other nonstandard condition

- Containers in the yard (single containment vessels) 
- Items that are corrosive and can breach their current containers:

- SSC (Iodine corrosion of the tin can)

- Moist hydroxide cakes from chloride processing (chloride corrosion)

- Moist pyrochemical salts (chloride corrosion)

- Items that are combustible or can easily form combustible mixtures:

- Nitrated rags

- Pu-238 rags

- Reactive/unstable mixtures such as organics in contact with radioactive material, calcium metal or solutions in interim containers:

- Analytical solutions

- Pyrochemical salts

Once prioritized, the items are being processed according to the approach shown in Table 3.3-6.

Table 3.3-6: Baseline Processing Approach by Residue Category*

\begin{tabular}{|c|c|}
\hline Residue Category & Remediation Approach \\
\hline Solutions & $\begin{array}{l}\text { Pu/U precipitation with hydroxide or oxalate. Cake to } \\
\text { calcination and sealed in long-term storage can when available, } \\
\text { filtrate to TA-50 Low Level Waste Treatment. }\end{array}$ \\
\hline Containers in the Yard & $\begin{array}{l}\text { Clean out material, discard low } \mathrm{Pu} \text { items, cement powder and } \\
\text { vermiculite, leach remainder. Weld clean container and store at } \\
\text { TA-54 Area G. }\end{array}$ \\
\hline Pyrochemical Salts/Reactive Metals & $\begin{array}{l}\text { Oxidize reactive metal }(\mathrm{Pu} / \mathrm{Ca}) \text { with carbonate and repackage in } \\
\text { slip top cans. Initially dissolve and recover Pu with } \\
\text { precipitation. Eventually, use salt distillation when appropriate. }\end{array}$ \\
\hline Sand, Slag, and Crucible & $\begin{array}{l}\text { Crush and pulverize to remove reactive metal. Dissolve to } \\
\text { remove plutonium with Ion Exchange. Iodine captured in } \\
\text { caustic scrubber and sent to TA-50 as caustic waste. Plutonium } \\
\text { to long-term storage, effluent to evaporation/cementation. }\end{array}$ \\
\hline $\begin{array}{l}\text { Oxides/Heels/Sweepings/Hydroxide } \\
\text { Cakes/Compounds. }\end{array}$ & $\begin{array}{l}<50 w t \% \text { to dissolution and Pu precipitation. }>50 w t \% \text { to } \\
\text { calcination }(950 \mathrm{C}) \text { and packaging for long-term storage. }\end{array}$ \\
\hline Resins and Graphite & Immobilize in cement. \\
\hline Gases & $\begin{array}{l}\text { Scrub/Calcination for PuF6. UF } 6 \text { gases sampled and shipped to } \\
\text { Portsmith for recycle. }\end{array}$ \\
\hline Non-Combustibles/Glass/Non-Pu Metal & $\begin{array}{l}\text { Discard low Pu items as TRU waste. Leaching for high Pu } \\
\text { items and package as TRU. Leaded gloves are wiped and } \\
\text { packaged as TRU. Particulates put into cement. }\end{array}$ \\
\hline Ash & $\begin{array}{l}\text { Calcination at } 600^{\circ} \mathrm{C} \text { to remove excess carbon. Leach to } \\
\text { remove Pu by Ion Exchange. Heels to cement. }\end{array}$ \\
\hline Sealed Sources & Dissolution in Ha, Pu removal by Ion Exchange. \\
\hline
\end{tabular}

"Mainly for Pu items, although generally true for U. 
To eliminate reactive and corrosive hazards, several existing technologies have been identified and will be implemented. To reduce the life-cycle cost of radioactive material management and the long-term liability of handling and storing energetic materials, the final form must be as stable as possible. The only proven method to achieve this stability is to separate the plutonium or other radioactive material from the bulk material, discard the bulk as a proper waste form, and store the radioactive material as an oxide.

The items known to be unstable are those that have failed or potentially failed containers. Residue containers in the vault are visually examined, according to a procedure, every time an item is removed from or replaced in the vault. Vault operators have been trained to look for certain abnormal conditions on the containers such as discoloration, inadequate tape seals, bulging containers, and other visual indicators. If such a condition is found, photographic and written evaluations are started and the item is removed for further examination. If a problem is discovered, a team of trained individuals determines its severity, and either repacks or processes the item into a stable form. For example, if such an item is metal, it will be oxidized and then re-canned. Current plans are to visually inspect $100 \%$ of vault items by May 1995.

Site-specific issues include:

- Obtaining RCRA and NESHAPS permits.

- Meeting the NPDES limits for activity and nitrate at the TA-50 liquid waste disposal out-fall.

- $\quad$ Obtaining adequate funding to meet the 8-year schedule.

- $\quad$ Meeting ALARA requirements given an eight year schedule.

- Maintaining support facilities such as CMR and TA-50.

- Installing adequate uranium stabilization facilities and capability.

\subsubsection{Lawrence Livermore Plutonium Residues}

Lawrence Livermore National Laboratory has residue material ( $<50$ wt.\%) supporting DOE missions and residue material that is excess to the DOE missions. The plutonium residue inventory includes about 130 containers. In 1994, 111 of the ash/residue containers were considered unstable, because 8 containers were found to be pressurized. LLNL has in process a remediation project for these cans of ash/residue.

A three phase plan has been formulated for residue materials.

- The first phase of this remediation project stabilized the pressure within the original cans, by venting and has been completed. 
- In phase two we are conducting a trade-off study to develop plans for the stabilization and packaging of ash/residues for long-term storage. The initial step is characterization of the materials. The next step is the development of a stabilization process that will allow this material to be packaged for long-term storage. Stabilization processes being considered are, thermal processing, washing for removal of halides, vitrification, and conversion to a greater than $50 \%$ oxide. We expect phase two to take one year. The "trade-off study" will be completed by April 1996.

- $\quad$ Phase three is the implementation of the stabilization and packaging methods developed in phase two. Stabilization and packaging will be complete by April 1998. Materials identified in the Pu ES\&H Vulnerability study requiring stabilization will be processed during the first year of the phase three operations. LLNL has the means to repackage these materials in compliance with the standard. Current capabilities could be improved to reduce operator radiation exposure and potential worker contamination during decontamination of the storage cans. LLNL will consider development of an advanced system for transferring and calcinating oxide.

LLNL is also investigating the secondary option of shipping excess plutonium to Los Alamos for processing, packaging or storage according to the metal and oxide storage standard. This option is being discussed under the auspices of the Integrated Working Group (IWG). Successful shipment of the excess plutonium metal from the LLNL site may preclude the need to process and package this material at LLNL. However, the cost to process to meet shipping requirements and then reprocess at LANL may be more than if processing and packaging were performed at LLNL.

\subsubsection{Other Plutonium Residues}

A large number of DOE sites have small quantities of plutonium with a low potential for environment, safety, and health vulnerabilities. Most is in the form of sealed packages. Metals, oxides, and solutions make up the remainder. The DOE complex maintains a variety of packaged standards, encapsulated sources, and process-support or archival samples. The DOE also retains responsibility for many standards and sources that are loaned or leased to universities, hospitals, and industry. These items do not constitute a major liability, as most are small, stable, sealed, and shippable. However, in aggregate, the future management of these technical materials constrains the few facilities that can receive the items and process them for disposal or reuse. DOE's Implementation Plan will ensure that small-quantity and unique items located at hundreds of sites do not interfere with those site's programs to reduce inventories of unneeded nuclear materials and comply with local radiological controls. One example of this integration is the recent consolidation of receipt and recovery activities for plutonium-beryllium sources to the Los Alamos National Laboratory. Within the last two years, sources from more than $240 \mathrm{DOE}$, university, and industrial sites have been returned, or scheduled to be returned, for treatment or safe disposal. 


\section{3-8 Key Milestones}

Table 3.3-8: Key Milestones and Commitments

\begin{tabular}{||l||l|l|l||}
\hline \hline & Commitment & Action & Date \\
\hline 1 & $\begin{array}{l}\text { Develop risk-based, complex-wide categorization } \\
\text { and prioritization decision criteria that all stored } \\
\text { residues will be required to meet }\end{array}$ & $\begin{array}{l}\text { LANL(lead), } \\
\text { RFETS, } \\
\text { SRS,Hanford } \\
\text { LLNL }\end{array}$ & Sept 95 \\
\hline 2 & $\begin{array}{l}\text { Vent 2,045 drums with a potential for hydrogen gas } \\
\text { generation due to residues packaged in plastic }\end{array}$ & RFETS & Oct 95 \\
\hline 3 & $\begin{array}{l}\text { Stabilize by pyrochemical oxidation, and repackage } \\
6,000 \text { kg of higher risk plutonium containing salts }\end{array}$ & RFETS & May 97 \\
\hline 4 & $\begin{array}{l}\text { Stabilize remaining higher risk salts (4,000 kg) via } \\
\text { chemical oxidation }\end{array}$ & RFETS & Dec 97 \\
\hline 5 & $\begin{array}{l}\text { Stabilize all sand, slag, and crucible and graphite } \\
\text { fines }\end{array}$ & RFETS & May 97 \\
\hline 6 & Vent all inorganic residues & RFETS & Oct 96 \\
\hline 7 & Vent all wet/miscellaneous residues & RFETS & Oct 96 \\
\hline 8 & Stabilize higher risk combustibles (11,000 kg) & RFETS & Nov 98 \\
\hline 9 & $\begin{array}{l}\text { Develop complex-wide secondary material storage } \\
\text { standard for materials that are less than 50\% assay }\end{array}$ & $\begin{array}{l}\text { DP } \\
\text { EM }\end{array}$ & Dec 95 \\
\hline 10 & $\begin{array}{l}\text { Identify, characterize, and non-destructively assay } \\
\text { all Pu items }\end{array}$ & LLNL & Jan 97 \\
\hline 11 & Ship all excess items to LANL & LLNL & May 02 \\
\hline 12 & $\begin{array}{l}\text { Pressure-stabilize cans containing ash/residue } \\
\text { materials }\end{array}$ & LLNL & Complete \\
\hline 13 & Conduct trade studies for ash/residue materials & LLNL & April 96 \\
\hline 14 & Stabilize and package all ash/residue materials & LLNL & April 98 \\
\hline 15 & $\begin{array}{l}\text { Stabilize 46 cans of selected sludge in muffle } \\
\text { furnaces }\end{array}$ & Hanford & Sept 95 \\
\hline 16 & Stabilize ash in muffle furnaces & Hanford & Mar 96 \\
\hline 17 & $\begin{array}{l}\text { Stabilize and package all remaining residues to safe } \\
\text { interim storage standards }\end{array}$ & Hanford & May 02 \\
\hline 18 & Stabilize Polycubes & Hanford & Jan 01 \\
\hline 19 & Perform 100\% visual inspection of vault inventory & LANL & May 95 \\
\hline
\end{tabular}




\begin{tabular}{||l||l|l|l||}
\hline \hline & Commitment & Action & Date \\
\hline 20 & Recover 100 neutron sources & LANL & Oct 95 \\
\hline 21 & Process $90 \%$ of analytical solutions & LANL & Oct 95 \\
\hline 22 & Process $100 \mathrm{~kg}$ sand, slag and crucible & LANL & Oct 95 \\
\hline 23 & Process $70 \mathrm{~kg}$ hydroxide solids & LANL & Oct 95 \\
\hline 24 & Oxidize $50 \mathrm{~kg}$ of corroded metal items & LANL & Oct 95 \\
\hline 25 & Stabilize existing inventories of SS\&C & SRS & Dec 97 \\
\hline 26 & Stabilize remaining residues & SRS & May 02 \\
\hline
\end{tabular}

\subsection{Special Isotopes}

\section{Part I : Stabilization Requirements}

\subsubsection{General Overview}

\section{Background}

The DOE manages inventories of a wide range of special transuranic isotopes, primarily derived as byproducts from previous defense reactor production and the chemical separation of large process streams of reactor targets. Many of the special radioisotopes have been widely used for medical, industrial, space exploration and other domestic and defense applications.

The primary "product" materials include Pu-238, used in compact power sources for NASA and terrestrial applications; Pu-242, a non-fissile isotope that is valuable for defense research; and Cf-252, used as a medical isotope and in a variety of specialized cases such as non-destructive assay equipment. Feedstocks for the future production of heavy isotopes include neptunium, americium, and curium. In small amounts, many heavy isotopes are also useful as "tracer" elements in defense and non-defense research. Holdings that are relevant to Recommendation 94-1 are listed in Table 3.4-1. 
Table 3.4-1: Special Isotopes Holdings

\begin{tabular}{||l|l|l||}
\hline Inventory & Location & Quantity \\
\hline \hline Americium-curium solution & Savannah River F-Canyon & 14,400 liters \\
\hline Pu-242 solution & Savannah River H-Canyon & 13,300 liters \\
\hline Np-237 solution & Savannah River H-Canyon & 6,000 liters \\
\hline Pu-238 solids with adverse packaging & Savannah River Building 235-F & 14 containers \\
\hline Pu-238 materials in active programs & Los Alamos, Mound, Savannah River & $\begin{array}{l}\text { A wide } \\
\text { variety of } \\
\text { container } \\
\text { types }\end{array}$ \\
\hline $\begin{array}{l}\text { Wide inventory of in-use and small-mass } \\
\text { items of other isotopes }\end{array}$ & $\begin{array}{l}\text { Large number of DOE, university, } \\
\text { medical, and industrial sites }\end{array}$ & $\begin{array}{l}\text { A wide } \\
\text { variety of } \\
\text { container } \\
\text { types }\end{array}$ \\
\hline \hline
\end{tabular}

Some or all of the inventories of each special isotope are judged to be "programmatic" materials that DOE wishes to retain for future use. As the defense reactor production mission has stopped, the potential source for significant quantities of byproduct isotopes has disappeared. Isotopes that will be retained must be stabilized in a safe, storable form for uses that may arise decades in the future.

\section{Overview of Concems}

The largest inventories of several key isotopes remain in aqueous solutions at the chemical treatment facilities that formerly supported the defense missions. The liquid form is unsuitable for long-term storage, as it allows for the potential release of radioactive and/or hazardous materials to the environment and exposure to workers. Many of the same concerns that govern DOE's management of Pu-239 solutions (see Section 3.1) exist for special isotopes, excluding only the risk of unplanned criticality. Programs to stabilize and safely store special isotopes will follow similar pathways and involve similar facilities. In some cases (e.g., Am/Cm stabilization), process development is necessary to demonstrate the large scale stabilization process and the stability of the proposed storage form.

Solids of special isotopes are generally part of active inventories or are stored in small quantities. Many are encapsulated or stored in sealed containers. However, one category of solids for which concern has been raised is Pu-238 oxides stored at Savannah River in configurations that were not intended for long-term management. Repackaging is required to ensure that these materials are not subject to failure stemming from helium ingrowth pressure buildup. 


\section{Applicable Sub-recommendations from DNFSB Recommendation 94-1:}

Sub-recommendation 1:

That an integrated program plan be formulated on a high priority basis, to convert within two to three years the materials addressed in the specific recommendations below, to forms or conditions suitable for safe interim storage. This plan should recognize that remediation will require a systems approach, involving integration of facilities and capabilities at a number of sites, and will require attention to limiting worker exposure and minimizing generation of additional waste and emission of effluents to the environment.

Sub-recommendation 2:

That a research program be established to fill any gaps in the information base needed for choosing among the altemate processes to be used in safe conversion of various types of fissile materials to optimal forms for safe interim storage and the longer term disposition. Development of this reseanch program should be addressed in the program plan called for in (1) [Subrecommendation 1] above.

Sub-recommendation 3:

That preparations be expedited to process the dissolved plutonium and transplutonium isotopes in tanks in the F-Canyon at the Savannah River Site into forms safer for interim storage. The Board considers this problem to be especially urgent.

\section{Acceptance and Objectives}

The DOE fully concurs with the Board's observations and recommendations relative to the stabilization of trans-plutonium isotopes in Savannah River's F-Canyon, and extends the program to include $\mathrm{Pu}-242$ and neptunium solutions in Savannah River's $\mathrm{H}-$ Canyon. Concerns about the packaging of Pu-238 materials, identified during the Plutonium Vulnerability Assessment, will also be dealt with in concert with the program for the management of $\mathrm{Pu}-239$ materials. Components of this program include:

- Improving surveillance and monitoring for actinide solutions stored at Savannah River, and implementing measures to manage risk until long term storage forms can be produced.

- $\quad$ Establishing firm criteria for product forms and storage containers for solids resulting from solution stabilization and implementing necessary research and testing.

- $\quad$ Accelerating repackaging Pu-238 solids currently in inadequate storage configurations. 
- Establishing an integrated program to define long term storage and utilization goals for byproduct isotopes; identifying amounts that will be retained or discarded; and establishing programmatic ownership for long term management.

Inventory-specific objectives include:

- Immediately discontinuing active water cooling for americium-curium solutions in Savannah River's F-Canyon, eliminating the greatest environmental exposure pathway risk for continued storage [completed].

- $\quad$ Completing process development, conceptual design, construction and startup for americium-curium solidification facility at Savannah River, and completing stabilization of the Am/Cm solution by September 1998.

- Implementing effective surveillance and monitoring programs to reduce the risk extended storage of special isotope solutions.

- $\quad$ Stabilizing Pu-242 solutions at Savannah River's HB-Line Phase III following Pu-238 campaign, with completion by November 1997.

- Completing neptunium processing to final storage form for storage in new shielded vault array by the end of 2002 .

- Accommodating special isotopes that will be separated or recovered from the plutonium bearing materials and fuel processing activities outlined in other sections of this plan.

- Venting Pu-238 solids that are stored under adverse conditions in Savannah River's Building 235-F by April 1995 in preparation for repackaging.

\section{Key Assumptions}

- $\quad$ Special isotopes may have future programmatic use, thus these materials should be prepared for long term storage, pending future use.

- The ROD for the Interim Management of Nuclear Materials (IMNM) EIS will support implementation of the options presented in this plan for Savannah River materials.

- Storage, shipment, and specification issues associated with these materials will be resolved. 


\section{Part II: Special Isotopes Integration Activities}

\section{Approach}

Most of the identified materials are stored at Savannah River, where interim stabilization measures must be performed. The Department will integrate the program through the development of long-term storage and use requirements with programmatic customers and the designated long-term storage sites, including Los Alamos (Pu-238 and $\mathrm{Pu}-242)$ and Oak Ridge (Am/ $\mathrm{Cm}$ and isotopes controlled by the Isotope Production and Distribution Office).

The key functions required to be in place to adequately address the special isotope issues are shown in Figure 3.4-1: Management of Special Isotopes and are summarized as follows:

- Continue, improve, and formalize compensatory surveillance and monitoring activities to assure safe storage conditions are maintained.

- Stabilize actinide solutions on a priority basis. If solutions must be treated in sequence, develop treatment schedules that recognize the relative risks of existing conditions and the availability of storage facilities for stabilized solids.

- Establish criteria (form and packaging) for long-term storage of solid special isotopes that will be retained for future use.

- Develop and demonstrate solidification technologies, as required, to meet long term storage criteria.

Timing for isotope solidification and storage improvements will be prioritized with a risk-based approach, recognizing that many of the facilities that are required to mitigate concerns with Pu-239 and uranium materials must also be used to deal with special isotopes.

Reserve Requirements: Strategic goals will be refined for which parts of current inventories must be retained for future use. The Department Defense Programs will define isotope quantities and forms that will be reserved for national security needs. Non-defense users will define requirements for programmatic and National Asset reserves, in concert with DOE representatives (including the Office of Nuclear Energy). Inventories in excess of these requirements will be considered for long-term storage or disposal, depending on the best mixture of technology, risk factors, and costs. Under current guidance, all of the $\mathrm{Am} / \mathrm{Cm}, \mathrm{Pu}-242$, and Pu-238, and Np-237 stored at Savannah River would be retained. 


\section{MANAGEMENT OF SPECIAL ISOTOPES}

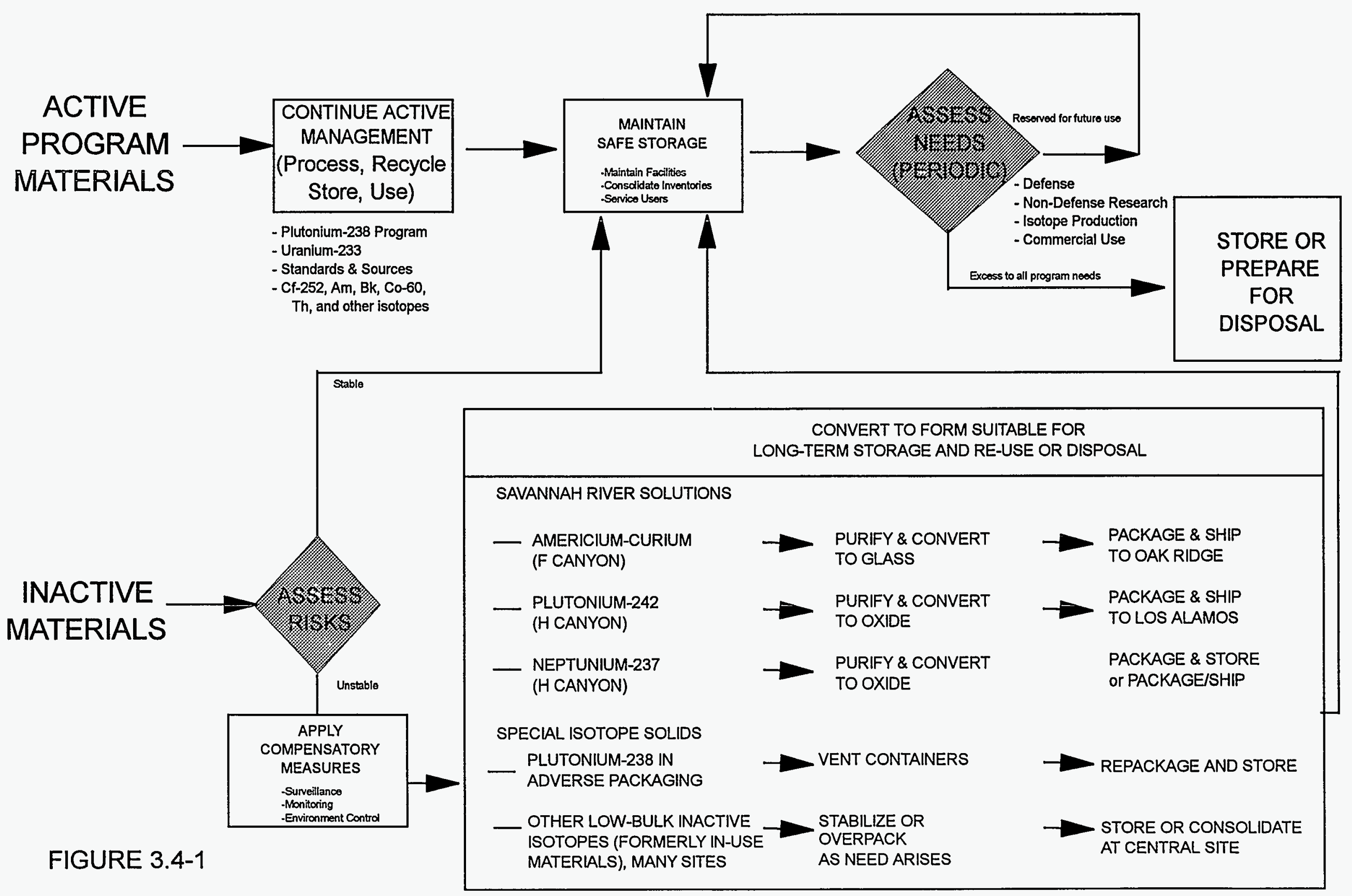


Storage Requirements: Storage form will be determined based on long-term safety and isotopic accessibility to user programs. Stable oxides are considered suitable for all major isotopes, although alternative forms (like glass for americium-curium) may be preferable. Special containers and shielded storage arrays must be developed and procured for high-radiation isotopes (e.g., neptunium).

\section{Key Challenges}

- $\quad$ Acceptable end-states for long term storage of isotopes that will be retained must be fully developed.

- Inventories that are excess to program needs must be defined, with prioritization of stabilization-versus-disposal decisions.

- $\quad$ Acceptable storage space must be established, and shipping and storage containers developed for neptunium oxide.

- Development and demonstration of vitrification technology for americium/curium stabilization must continue to be successful.

- A strategy for dispositioning special isotopes from smaller government, industrial, and university sites is needed in order to optimize use of complexwide capabilities while treatment capabilities are still available.

In recognition of the challenges, activities will be initiated to:

- $\quad$ Clarify end-states and disposition pathways

- $\quad$ Establish storage standards and/or criteria for unique material forms as required

- Resolve transportation, storage space, and consolidation issues related to special isotopes.

\section{Part III: Individual Site Activities}

\subsubsection{Savannah River Americium-Curium Solution}

Special Isotopes at Savannah River includes 14,400 liters of aqueous solution in a single tank in F-Canyon. The americium-curium solutions cannot be stabilized within the STET year period recommended by the Board because of the lack of capability and the need for process development. However, to address the urgency of the storage conditions, DOE has implemented compensatory measures that have reduced risks to workers and the environment to acceptable levels, pending completion of the program to convert the solutions to a stable solid. The Department judges the americium and curium to be programmatically important, and plans to retain stabilized solids for use in the DOE's National Heavy Element and Advanced Neutron Source programs. 
The radioactivity levels associated with the americium-curium make it necessary that this material be stabilized to a solid form within the heavily shielded F-Canyon building. The $\mathrm{Am} / \mathrm{Cm}$ represents about $90 \%$ of the potential radiological hazard of solutions currently stored in F-Canyon. A process in F-Canyon was used previously (in the early 1980s) to convert small quantities of Am-241 to an oxide. However, this process equipment has not been maintained and would require extensive modification to produce either a borosilicate glass or oxide.

The IMNM EIS will evaluate options for stabilization of the F-Canyon americiumcurium solutions to a storage form suitable for future use. The EIS ROD is expected by June 1995. In addition to "no action", options being considered include continued storage under active management until new facilities and processes are installed in FCanyon to vitrify, or solidify as an oxide. The vitrification alternative is to produce a glass form to be shipped to Oak Ridge for storage and eventual recovery of the americium and curium. The task includes a process development and test program to develop information on the flowsheets for solidification and the stability of the solid product. Concurrently, facilities in F-Canyon must be renovated to allow the stabilization equipment to be installed, requiring several years to complete. If this option is selected, solutions would be stabilized by September 1998 .

Other alternatives, including in situ solidification of the actinides, or disposal by transfer of the solution to high-level waste tanks are less desirable because of the material's programmatic use and technical uncertainties associated with these alternatives.

The site has implemented measures that will reduce the hazard until full stabilization is achieved. The major vulnerability is related to a potential for tank cooling coil failure coupled with detection delay errors, resulting in significant release of radioactivity. Savannah River has determined that the solutions no longer require active water cooling and has thus mitigated this potential source of risk by disconnecting the cooling coils. A monitoring and surveillance program continues, including tank sampling and evaluation of the potential for actinide precipitation.

The stabilization program includes: restarting and operating F-Canyon; completing bench process development work and conceptual design for solidification facility by December 1995; installing equipment in the renovated Multi-Purpose Processing Facility at F-Canyon; testing equipment in the cold facility and installing a new process line; and developing procedures for remote handling, canning, decontamination, and cask loading of product canisters for offsite shipment.

\subsubsection{Savannah River H-Canyon Plutonium-242 Solution}

Savannah River holds approximately 13,300 liters of aqueous solution of Pu-242 in a single tank in the $\mathrm{H}$-Canyon chemical treatment facility. The site also stores 3 containers, with small quantities of oxide, in the F-Area Laboratory (Building 772-F). Plans are being developed to stabilize this small quantity of $\mathrm{Pu}-242$ oxide. 
Plutonium-242 has a programmatic customer, and the goal is to convert it to a form suitable for shipment to that customer and for interim storage. The options for converting this material are to process the solution in H-Canyon to remove impurities, then to concentrate the solution and transfer it to Savannah River's HB-Line Phase III for conversion to an oxide; or to continue storage under active management (no action). The vehicle for deciding the course of action is the IMNM EIS, with the ROD expected June 1995. Converting this solution to an oxide would be the quickest way to stabilize this material while meeting the programmatic need. Assuming this alternative is selected, stabilization would proceed no later than May 1997 and would be completed within six months, by November 1997. The stabilized oxide will then be shipped to Los Alamos National Laboratory.

The continued storage of this material in solution form would result in safety concerns similar to those for other highly radioactive solutions, however, to a lesser degree. The Pu-242 solutions have been in storage longer than originally envisioned. Preventing deterioration in solution chemistry requires mitigating actions, including increased sampling and surveillance, to reduce the potential for equipment failure and radioactive release. Undesirable events could result from the inherent vulnerabilities associated with extended storage, such as releases from spills or leaks and transfer errors that could occur while maintaining these solutions.

\subsubsection{Savannah River H-Canyon Neptunium Solution}

As with the Pu-242, Np-237 has a potential programmatic need, in this case as a target material for production of $\mathrm{Pu}-238$ for use as a fuel for radioisotope thermo-electric generators in spacecraft as well as terrestrial applications. Savannah River Site holds 6000 liters of neptunium nitrate solution in H-Canyon. The options for material stabilization are as discussed above for Pu-242, except that Phase II of HB-Line would be used rather than Phase III. Again, the course of action will be governed by the IMNM EIS, and the plan outlined here assumes that the processing alternative is selected. Other alternatives under consideration include continued storage under active monitoring (no action), disposal to the Savannah River Site high-level waste systems, or vitrification.

HB-Line Phase II was constructed in the mid-1980s but never operaied, and several years would be required to prepare the facility for start-up in accordance with current requirements (e.g., DOE Order compliance, safety documentation, training, etc.). Phase II will be used to solidify Pu-239 solutions that also are stored in H-Canyon (see Section 3.1) and for stabilization of mixed oxides and residues, and the facility is not expected to be available for neptunium solution until late 2001. This delay may not affect the "critical path" schedule, however, because special provisions for storage of the resultant neptunium oxide, including new storage containers and shielded storage space, are also required due to radiation levels associated with the in-growth of protactinium. Feasibility studies are underway to determine the most cost-effective 
method of storage. These studies are evaluating acceleration of HB-Line Phase II restart; new storage facilities; and upgrades of existing storage facilities beyond the year 2000 .

Other storage options including consolidation of neptunium oxide storage at a single site are being evaluated under the Fissile Materials Disposition Programmatic EIS. No firm criteria have been developed for long term storage of neptunium oxide; however, development of a configuration that provides protection equivalent to the DOE standard for long term storage of Pu-239 metals and oxides should be straightforward.

While the neptunium solutions await disposition, activities to reduce the potential for release to the environment include: an expanded and formalized sampling and monitoring program; pressurization and monitoring of the cooling water supplied to the solution storage vessels; and physical isolation of the cooling system to ensure no radioactivity is released to external systems. Restart of support facilities in adjacent parts of H-Canyon will also greatly reduce the risks of continued, monitored solution storage. Expanded treatment, chemical adjustment, agitation, and solution movement options will be available in case deficiencies are noted in current storage conditions.

During the neptunium solution stabilization, Savannah River also plans to solidify any neptunium recovered during treatments of mixed plutonium-neptunium solids and irradiated fuels, four containers of neptunium oxide scrap, and (if treatment is required for programmatic users) unirradiated neptunium-aluminum reactor targets that are currently stored at the site.

\subsubsection{Plutonium-238 Solids}

The DOE is managing a program to recover, purify, solidify, and fabricate Pu-238 for use in radioisotope thermo-electric generators. The largest application for these generators is as power sources for NASA deep space missions.

The main inventories are effectively managed with active processing and production programs at Los Alamos, Mound, and Savannah River. However, one category of inventories was shown to be stored under significantly adverse conditions during the Plutonium Vulnerability Assessment performed by DOE's Office of the Environment, Safety, and Health. This category includes certain materials stored in Building 235-F at Savannah River where the primary containment vessel was found to be potentially susceptible to pressurization due to helium buildup from alpha decay. The Department has taken immediate steps to mitigate this vulnerability. All such Pu-238 materials will be transferred to the Savannah River HB-Line facility by April 1995, where the primary containment vessel will be vented into a protected glovebox line, and the containers will be repackaged. 


\subsubsection{Other Special Isotope Concems}

The Department manages many items that hold special isotopes, including a wide array of standards and sources. These items are not major safety drivers for the DOE Implementation Plan related to Recommendation 94-1. However, DOE expects that demand will continue for DOE to supply these materials and to accept items that are no longer needed by user programs. Many of the facilities and processes that traditionally serviced non-defense isotope requirements are located at former defense nuclear facilities. Future demands on those facilities are not completely defined.

Los Alamos is operating a program to receive and treat Pu-239-beryllium sources that are no longer needed, and programs are also being developed to deal with more than 10,000 excess americium and Pu-238 sources.

The Department commitments may be achievable using small, bench-scale and glovebox operations to support the reduced support missions for isotopes. Besides the isotopes listed above, DOE has also supported research involving curium, berkelium, californium, neptunium, thorium, and U-233. Any demands on the facilities used to treat the materials identified in Recommendation 94-1, will also be factored into the schedule and funding requirements for the complete program to deal with nuclear materials that are excess to national security needs. No major impacts would be expected on the DOE's support for the utilization of non-actinide materials, which have included Co-60, Ni-63, Sr-90, Cs-137, and a wide range of medical and research isotopes.

\subsubsection{Key Milestone Schedule}

The following schedule milestones are contingent upon the outcome of the Savannah River IMNM EIS.

- Start vitrification of $\mathrm{Am} / \mathrm{Cm}$ solutions at Savannah River in April 1998 and complete in September 1998.

- $\quad$ Pending completion of Pu-238 campaign, begin stabilization of Pu-242 solutions at Savannah River's HB-Line Phase III in May 1997, with all solutions stabilized by November 1997.

- Begin stabilization of Np-237 solutions at Savannah River's HB-Line Phase II in July 2001, with all solutions stabilized and stored in new packaging by the end of 2002.

- Transport Savannah River's Pu-238 solids currently in inadequate storage to the HB-Line by April 1995 for venting and repackaging. 


\subsection{Uranium}

\section{Part I: Stabilization Requirements}

\subsubsection{General Overview}

\section{Background}

The Department currently manages significant quantities of enriched uranium. This material exists in a number of configurations including weapons to be dismantled, excess weapon components, and materials left in the production cycle. Although highly enriched uranium (HEU) was not specifically identified in DNFSB Recommendation 94-1, this section provides a description of the required stabilization activities.

Table 3.5-1: Materials Requiring Stabilization or Conversion for Shipment

\begin{tabular}{|c|c|c|c|}
\hline Site & Material Group & Location & Quantity \\
\hline $\begin{array}{l}\text { Savannah } \\
\text { River }\end{array}$ & HEU Solution & Building $221-\mathrm{H}$ & 230,000 liters \\
\hline $\begin{array}{l}\text { Rocky } \\
\text { Flats }\end{array}$ & HEU Solutions & Building 886 & $\begin{array}{l}569 \mathrm{kgs} \text { of U-235 } \\
\text { contained in } \\
2,700 \text { liters }\end{array}$ \\
\hline $\begin{array}{l}\text { Rocky } \\
\text { Flats }\end{array}$ & HEU Solids & $\begin{array}{l}\text { Buildings } 371,707 \text {, } \\
777,779,991\end{array}$ & $6,100 \mathrm{kgs}$ \\
\hline Oak Ridge & HEU Solids & K-25 Building & $\begin{array}{l}\text { Less than } 100 \text { items } \\
\text { each with }>500 \mathrm{~g} \\
\text { HEU located in an } \\
\text { unfavorable } \\
\text { geometry }\end{array}$ \\
\hline Oak Ridge & HEU Solids & $\begin{array}{l}\text { Molten Salt Reactor } \\
\text { Experiment }\end{array}$ & $\begin{array}{l}\text { Bulk salt inventory } \\
\text { of } 4,650 \mathrm{kgs} \\
\text { (containing } 31 \mathrm{kgs} \\
\mathrm{U}-233,1 \mathrm{~kg} \mathrm{U}-235 \text {, } \\
1 \mathrm{kgs} \mathrm{Pu} \text { ) }\end{array}$ \\
\hline Idaho & HEU Solids & $\begin{array}{l}\text { Buildings CPP-602, } \\
\text { CPP-603, CPP-651 }\end{array}$ & $2,500 \mathrm{kgs}$ \\
\hline $\begin{array}{l}\text { Los } \\
\text { Alamos }\end{array}$ & HEU Solids & CMR Building & $1,200 \mathrm{kgs}$ \\
\hline
\end{tabular}


The Y-12 Plant in Oak Ridge has been assigned custodianship for enriched uranium (EU). Excess EU used to be shipped to Y-12 for reuse in weapons production. With the virtual cease in weapons production, the EU is now shipped to Y-12 for processing into a safe, storable form to be placed in interim storage until final dispositioning is determined through the Nuclear Material Disposition PEIS.

In March 1993, an "Environmental Assessment (EA) for the proposed interim storage of Enriched Uranium Above the Maximum Historical Storage Level at the Y-12 Plant, Oak Ridge Tennessee" was initiated. An integrated plan for potential EU receipts at the Y-12 Plant was developed that would set the boundaries to be used in transportation analyses for the EA and simultaneously promote an effective transfer of $\mathrm{EU}$ to a single site. Responses from multiple sites indicated that a quantity greater than 98 metric tons of enriched uranium, excluding classified shipments from the Pantex site, could be shipped to the Y-12 Plant during the next 10 years. In addition, approximately 7,100 metric tons of low enriched uranium (LEU) could possibly be shipped to Y-12, depending on material disposition scenarios that involve large quantities of LEU for blending down HEU material. As a result of stakeholder and State of Tennessee responses, the draft Finding of No Significant Impact (FONSI) limits the LEU shipments to Y-12 to approximately 3 metric tons.

\section{Overview of Concems}

The Department manages significant quantities of HEU in solution at Rocky Flats and Savannah River. The liquid form is not suitable for long-term storage, as it allows for the possibility of releases to the environment, exposure to workers, or unplanned criticality. Storage arrays must be controlled or solution dilution must be maintained to preclude the formation of critical configurations. The extended storage of these solutions also precludes the timely deactivation of these facilities, thus requiring the continued high cost for surveillance and maintenance activities to maintain facility safety envelopes. In addition to reducing the safety risk, the stabilization of these solutions would reduce the proliferation risk because the HEU content would likely be blended to a low-enrichment level.

Several DOE programs that supported reactor fuels cycles and defense research generated solid residues. Such residues remain at Oak Ridge facilities, INEL, Los Alamos, and various smaller sites. Some of these residues are reactive, and could possibly generate toxic or hazardous conditions, and in some cases pose an unnecessary risk for unplanned nuclear criticality. Additional details associated with these concerns are addressed in the individual site sections. The Department has not formally assessed the vulnerability of uranium materials; however, the risk posed by these materials is substantially less than that from the plutonium materials and spent nuclear fuels. As additional vulnerabilities are identified during these upcoming assessments, appropriate action will be taken. 


\section{Applicable Sub-recommendations from DNFSB Recommendation 94-1}

\section{Sub-Recommendation 1:}

That an integrated program plan be formulated on a high priority basis, to convert within two or three years the materials to forms or conditions suitable for safe interim storage.

\section{Acceptance and Objectives}

The DOE concurs with the DNFSB recommendations and has established the following objectives:

- $\quad$ All HEU uranyl nitrate solutions will be removed from Building 886 at Rocky Flats by September 1996 and shipped off-site for commercial sale.

- $\quad$ All existing HEU solutions at Savannah River will be blended down to a low enrichment and then converted to an oxide form by December 1997, or sold commercially in a solution form.

- Mechanical removal of HEU deposits will be completed at the Oak Ridge K-25 site, which includes about $66 \%$ of total items containing deposits greater than $500 \mathrm{~kg} \mathrm{HEU}$ located in an unfavorable geometry, by September 1997. Chemical removal of remaining HEU deposits will be pursued aggressively and completed in April 1999.

- $\quad$ Uranium deposits from Oak Ridge National Laboratory (ORNL) Molten Salt Reactor Experiment (MSRE) project will be removed by February 1998. Compensatory measures were put in place November 1994 to mitigate a potential accidental criticality caused from water entering the auxiliary charcoal bed (see Section 3.5.4.)

\section{Key Assumptions}

- The preferred alternatives from the NEPA process will be consistent with the options used to develop the schedules for uranium stabilization and transfer.

- The preferred form for interim and long-term storage of uranium metal and oxide will be accepted and implemented as stated in the draft criteria currently being developed.

- The HEU solutions are excess to national defense requirements.

- $\quad$ Y-12 will resume receipt of off-site Uranium shipments by September 1996. 


\section{Part II: Uranium Integration Activities}

\section{Approach}

- An integrated, complex-wide approach will be used to determine schedules, costs, and ultimate conversion of the uranium materials. Uranium solutions will receive priority for aggressive disposition to safe, storable forms. The inter-site team approach has proven successful, and will be accelerated. Typical material flows and projected transfer times are noted in Figure 3.5-1.

\section{Key Challenges}

- Issue a DOE Standard for safe storage for uranium.

- Improve material characterization, consolidation, inventory techniques, and handling techniques to reduce exposure to operators, minimize waste, and reduce overall costs.

- Develop innovative packaging and shipping techniques to optimize material dispositioning to long-term storage facilities.

In recognition of these challenges, activities will be initiated to:

- Develop a summary of specific facilities and worker talents needed to achieve the stabilization and storage of Uranium containing materials.

- Develop and issue a Department Standard for the safe interim storage for Uranium.

- Develop a single complex-wide strategy for transporting and storing Uranium.

- Develop a complex-wide strategy for commercial sale of excess Uranium through the United States Enrichment Corporation. 


\section{HEU DISPOSITION LOGIC}

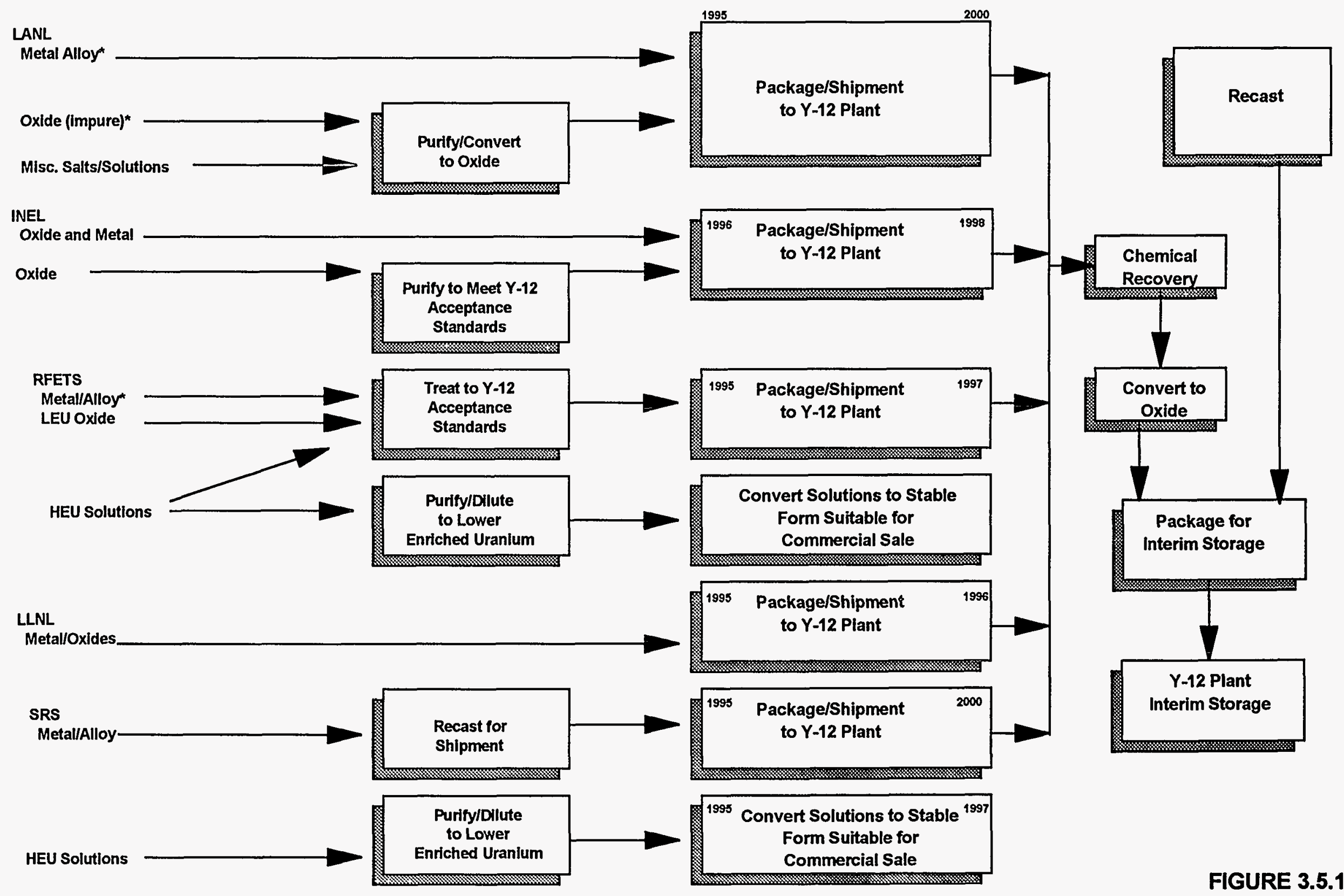




\section{Part III: Individual Site Activities}

\subsubsection{Uranium Solutions at Rocky Flats}

Rocky Flats is currently storing approximately 2,700 liters of highly enriched uranyl nitrate solution (HEUN), containing $569 \mathrm{~kg}$ of U-235 in eight Raschig ring tanks in Building 886. In its present storage configuration, these solutions present a potential criticality safety hazard based on continued long term storage and various postulated accident scenarios. The objective is to convert these solutions to low enriched solids suitable for storage and potential commercial sale.

Rocky Flats expects to use the services of a contractor with a specialized uranium processing expertise to prepare and remove the HEUN from Building 886, converting the solution to a form acceptable to the U.S. Enrichment Corporation. The contractor would provide portable skid-mounted blending equipment that would be connected to the existing HEUN storage tanks. This equipment has been licensed for blending of HEU solutions. Once isotopically diluted, the solutions would be shipped to the contractor's facility in trucks licensed by the Nuclear Regulatory Commission and Department of Transportation. Approximately six shipments would be required. The contractor would convert the low-enriched solution to a stable oxide and then deliver the material to an approved storage location.

Prior to initiating draining and blending activities in Building 886, extensive corrective maintenance, safety analysis, personnel training, and facility readiness review activities must be completed. Blending and shipment work will begin in May 1996 and include blending of the material, shipment to the contractor's facility, conversion, and final delivery to the storage location. Completion of all shipments to the final storage location will occur prior to September 30, 1996.

\subsubsection{Uranium Solutions at Savannah River}

\section{Highly Enniched Uranium}

Savannah River holds 230,000 liters of highly enriched uranium in dilute nitrate solutions in the site's H-Canyon processing facility. This inventory consists of active, "in-process" solutions that remained after chemical processing and separation of spent nuclear fuel were suspended. The solutions posed a minor hazard while connected processes were operating, but solutions are not suitable for long-term storage of excess uranium. Continued storage would raise the risks of unplanned releases of radioactive materials to the environment, increased exposure to facility workers, or exposure to the public. An active monitoring and surveillance program is expected to maintain solutions under safe conditions until they can be treated for long term disposition. Options for stabilizing these solutions are being considered in the Interim Management of Nuclear Materials (IMNM) EIS. The Record of Decision is expected to be issued in June 1995. 
One stabilization method cited in the IMNM EIS is to process solutions through HCanyon to separate the enriched uranium from impurities and fission/decay products and transport depleted uranium solutions from F-Canyon (either existing solutions or additional solutions made by dissolving depleted uranium oxide in FA-Line). The resulting stream would then be blended to less than $1 \%$ U-235 before transporting it to FA-Line for conversion into oxide for on-site storage. If this option is selected, treatment is straightforward, and the schedule depends largely on construction time for the blending facilities and transportation interfaces, restart activities, readiness reviews, and the availability of funding and technical resources. Construction completion is projected for January 1996, with blending and processing into oxide to be completed by December 1997.

The Department also is evaluating a stabilization method in which the solutions would be diluted to less than $20 \%$ U-235 and shipped off-site to commercial fuel fabricators, which would produce power-reactor or research-reactor fuel from the stream. The EIS is also evaluating the completion of the Uranium Solidification Facility, continued storage of the solutions under active management, and disposal by discharge to highlevel waste tanks as well as options for stabilizing existing depleted uranium solution.

Major challenges include the allocation of key skilled personnel between restart efforts and operations at both F- and H-Canyons at Savannah River. The proposed plan would use existing facilities and processing technology. In the interim, increased and formalized monitoring and sampling programs are expected to reduce the risk of continued storage to an acceptable level, pending completion of the stabilization program.

\subsubsection{Uranium Residues Needing Stabilization at Oak Ridge}

\section{Molten Salt Reactor Experiment (MSRE)}

The Molten Salt Reactor Experiment operated from 1965 through 1969 to investigate molten salt reactors for commercial power applications. The reactor used a fluoride salt mixture of lithium, beryllium, and zirconium fluorides, with uranium tetrafluoride as the fuel component. Initially, the reactor was fueled with U-235, which was later replaced with U-233 in 1968. Less than $1 \mathrm{~kg}$ of plutonium trifluoride was added in 1969. When the reactor was shut down, the fuel salt was drained into two fuel drain tanks in the drain tank cell, where it cooled and solidified. Following a post-operation examination, the facility was placed under a program of surveillance and maintenance (S\&M) awaiting eventual decontamination and decommissioning (D\&D). Radiolysis of the fuel salt was expected to slowly produce fluorine $\left(\mathrm{F}_{2}\right)$ gas after a latent period. A procedure to anneal the salt annually was developed as part of the S\&M program. In the late 1980s, radiological surveillance at the facility indicated elevated radiation in the North Electric Service Area (NESA) on piping connected to the drain tanks.

A visible release of an unidentified gas also was observed from the off-gas system piping in the vent house during a maintenance operation. This indicated that 
contamination associated with the stored fuel salt may have migrated from the drain tanks. Plans were developed and initiated to investigate the migration problem and to determine appropriate mitigative measures. Gas samples taken from the vent house indicated significant concentrations of uranium hexafluoride $\left(\mathrm{UF}_{6}\right)$ and $\mathrm{F}_{2}$. Radiation readings in the adjacent charcoal cell also determined a significant deposit of solid uranium in the inlet section of the auxiliary charcoal bed (ACB). The ACB section containing the uranium deposit was under water originating from the designed shutdown. If water were to have entered the ACB and migrated to the deposit, the potential for an accidental criticality could not be eliminated.

As a result of these discoveries, a comprehensive plan was established and put into place to initiate interim corrective measures (drain water from the ACB cell, partition the off-gas system, and eliminate water sources); remove the uranium deposits; and dispose of the fuel salt. The interim measures will be completed by November 1995 . The uranium deposits will be removed by February 1998, and the fuel salts by May 2000.

\section{Deposit Removal Project at the K-25 Site}

During the operating life of the K-25 facilities, isotopically highly enriched uranium accumulated inside equipment and piping as a result of wet air in-leakage. The K-25 Building was initially shut down in 1964. In 1985 it was determined that the gaseous diffusion facilities were in excess of uranium enrichment needs, and they were placed on standby. The decision was made to permanently shut them down in 1987.

Deposits of enriched uranium remain in the piping and equipment. Based on field nondestructive assay (NDA) measurements, it was determined that some of the HEU deposits present an unacceptable criticality risk based on requirements currently defined in DOE Order 5480.24, Nuclear Criticality Safety. In 1989, steps were taken in the field to reduce the likelihood of a criticality event by welding openings in the process piping that could have allowed water in-leakage, and by isolating specific piping and equipment of concern.

The Deposit Removal Project was initiated to remove the HEU deposits from piping and equipment in the K-25 Building. The project's scope includes removal of deposits containing greater than $500 \mathrm{~g}$ quantities of U-235 (unsafe mass) in an unfavorable geometry from target items such as pipes, compressors, cold traps, chemical traps, surge tanks, and convertors (Whitehead and Type II). Completion of this project should bring the building into compliance with the DOE Order 5480.24 requirement that the probability of a criticality be less than $10^{6}$. Subsequent actions are planned for removal of smaller quantities of HEU, which present a criticality risk of less than $10^{-6}$. Removal of deposits began in FY95 and will be accomplished by using mechanical and chemical methods. Mechanical removal of HEU deposits will be completed by the September 1997 date that DNFSB recommended. This removal will include about $66 \%$ of the items containing deposits greater than $500 \mathrm{~kg} \mathrm{HEU}$ located in unfavorable geometry. Chemical removal of the remaining HEU will be completed by April 1999. 


\subsubsection{Los Alamos Uranium Residues}

The Los Alamos National Laboratory (LANL) enriched uranium inventory contains approximately 3.3 metric tons. Los Alamos and the Oak Ridge Y-12 Plant have held planning sessions over the past year to identify items in the Los Alamos uranium inventory that could be shipped to the Y-12 Plant for interim storage. This led to the successful transfer of the first shipment in August 1994. However, much of the Los Alamos inventory is not in a shippable form and will need some conversion or repackaging.

For several years, Los Alamos has been planning a lab-scale pilot facility for uranium processing research and development similar to the Advanced Testing for Actinide Separation (ATLAS) developed for plutonium process chemistry research. This labscale facility ULISSES line was intended to allow Los Alamos to stabilize enriched uranium residue as well as to provide a location for demonstration of advanced uranium process chemistry methods. The Los Alamos stabilization and repackaging capabilities installed to meet the requirements of DNFSB 94-1 will not duplicate the process capabilities available at the Y-12 site.

Once the repackaging line is available, several hundred kilograms of $\mathrm{UO}_{3}$ powder can be repackaged and shipped to the Y-12 site. Y-12 would then process and package these materials into a form suitable to meet the interim storage standard for enriched uranium.

\subsubsection{Idaho Enriched Uranium Materials}

The Idaho National Engineering Laboratory (INEL) has accumulated a significant quantity of uranium and other nuclear materials that should be returned to sites capable of safe interim storage. The material discussed in this section includes unirradiated spent fuel material created for the Rover program, the Light Water Breeder Reactor, and the Naval Propulsion Program. Other than the Rover material, cited as a potential combustion threat in the Spent Fuel Working Group Report, no safety concerns have been identified regarding the materials discussed here. These materials will be included in the overall plans to consolidate the HEU at a central location.

Secure uranium storage capacity exists at INEL. However, additional planning is necessary for the disposition the entire INEL enriched uranium inventory. In future planning, clear direction must be provided to establish shipment and storage criteria, procure appropriate shipping containers, develop appropriate documentation, and ship the material to sites capable of safe interim storage. 


\subsubsection{Key Milestones}

\section{Rocky Flats}

- Begin shipping HEU solutions off-site for stabilization . . . . . . . . May 1996

- Remove HEU solutions from Rocky Flats . . . . . . . . . . September 1996

- Ship 6.1 metric tons of HEU to Y-12 . . . . . . . . . . . December 1997

\section{Savannah River}

- $\quad$ Record of Decision for Interim Management of Nuclear Materials . . June 1995

- Convert 230,000 liters of HEU solutions to a stable oxide . . . December 1997

- Ship HEU solids to Y-12 . . . . . . . . . . . . . December 2000

\section{Oak Ridge}

Molten Salt Reactor Experiment

- Complete corrective interim measures . . . . . . . November 1995

- Remove uranium deposits . . . . . . . . . . . . . . February 1998

- Remove fuel salt ................... May 2000

\section{$\underline{\mathrm{K}-25 \text { Site }}$}

- Complete mechanical removal of uranium deposits . . September 1997

- Complete chemical removal of uranium deposits . . . . . . A April 1999

\section{Los Alamos}

- Ship 1.2 metric tons of HEU to Y-12 . . . . . . . . December 2000

\section{$\underline{\text { Idaho }}$}

- Ship 2.5 metric tons of HEU to Y-12 . . . . . . . . . December 1998 


\subsection{Spent Nuclear Fuel}

\section{Part I: Stabilization Requirements}

\subsubsection{General Overview}

\section{Background}

This section addresses only specific concerns highlighted by the Board involving spent fuel located in the K-East Basin at the Hanford Site, the CPP-603 Basin at the Idaho National Engineering Laboratory (INEL), and the processing canyons and reactor basins at the Savannah River Site (SRS). This material represents a significant subset of the total inventory of spent nuclear fuel (SNF) managed under the DOE SNF Program. However, major elements of the SNF Program are briefly described in order to place the concerns of the Board in context of the overall program.

SNF is nuclear fuel or targets containing uranium, plutonium, or thorium withdrawn from a nuclear reactor or other neutron irradiation facility following irradiation, the constituent elements of which have not been separated by chemical reprocessing. These materials include essentially intact fuel and disassembled or damaged units and pieces; irradiated reactor fuel, production targets, slugs, and blankets presently in storage or that will be accepted for storage at DOE facilities; debris, small pieces of fuel, and cut up irradiated fuel assemblies subject to evaluation of their waste classification.

The inventory of DOE-owned SNF is composed of approximately 2,700 metric tons of initial heavy metal as shown in Table 3.6-1. Planned additions to existing inventories will come from naval reactors, U.S. research reactors, and other government reactors. DOE may accept responsibility for some spent fuel resulting from the operation of research reactors located overseas that operated using fuel of U.S. origin. This Foreign Research Reactor SNF represents a potential addition to existing DOE inventories and may impact existing storage capacity. The combination of these additions to SNF inventories through the year 2035 is estimated to be 97 metric tons, which represents less than 4 percent of the existing inventories.

\section{Overview of Concems}

The vast majority of DOE-owned SNF was designed to be reprocessed and is therefore susceptible to dissolution in aqueous solutions. Long-term storage in the underwater fuel storage facilities was not intended for the majority of the spent fuel. The storage facility engineering design and the monitoring requirements were not adequate to compensate for the various underwater corrosion mechanisms experienced. Severe unintended consequences have resulted including the loss of configuration control of the storage equipment; the failure of cladding, which affects criticality safety, sludge 
generation, and fuel handling; and radionuclide leakage into the basin water, which affects personnel exposure and increases potential environmental impacts.

Because these facilities were designed between 30 and 50 years ago, most do not meet all current standards for seismic resistance to prevent potential fuel reconfiguration or current standards for leak protection and detection. A design basis seismic event may result in reconfiguration of fissile material and potential criticality, worker overexposure, and leakage to the environment. Failure to provide accurate leak detection and adequate barriers to leakage could result in unmonitored releases of radioactive material to the environment.

Generally, DOE failed to ensure that adequate characterization of the spent fuel, targets, and storage equipment was performed so that facility conditions continued to meet the authorization basis. Additionally, DOE did not update the authorization basis to address long-term storage of the degrading material. Upon the decision to phaseout reprocessing in April 1992, the Department lacked an integrated approach for transitioning from short-term to long-term storage. The lack of characterization for the spent fuel and targets and the lack of a path forward for ultimate disposition resulted in delays in establishing methods for future safe handling, transport, and storage.

In its May 26, 1994, letter to the Secretary of Energy, the DNFSB forwarded its Recommendation 94-1 for consideration. The Board was "especially concerned about specific liquids and solids containing fissile materials and other radioactive substances in spent fuel storage pools, reactor basins, reprocessing canyons, processing lines, and various buildings once used for processing and weapons manufacture." The Board highlighted specific concerns with irradiated reactor fuel located in the K-East Basin at Hanford, the CPP-603 Basin at Idaho, and the processing canyons and reactor basins at Savannah River. The Board was "concerned about the slow pace of remediation" and provided several recommendations to expedite the remediation of their concerns.

\section{Applicable Sub-recommendations}

The following specific recommendations relate to spent nuclear fuel:

Sub-recommendation 6:

That preparations be expedited to process the deteriorating irradiated reactor fuel stored in basins at the Savannah River Site into a form suitable for safe interim storage until an option for ultimate disposition is selected.

Sub-recommendation 7:

That the program be accelerated to place the deteriorating reactor fuel in the $K$ East Basin at the Hanford Site in a stable configuration for interim storage until an option for ultimate disposition is chosen. This program needs to be directed toward storage methods that will minimize further deterioration. 
In August 1993, the Secretary requested that the Spent Nuclear Fuel Working Groupmade up of site personnel and participants from the cognizant Secretarial Offices, Operations Offices; the National Laboratories, and the Office of Environment, Safety, and Health - assess the conditions of DOE SNF storage facilities. After studying the conditions at 66 facilities at 11 sites, the Working Group published the Spent Fuel Working Group Report on Inventory and Storage of the Department's Spent Nuclear Fuel and other Reactor Irradiated Nuclear Materials and their Environmental, Safety and Health Vulnerabilities (Volume I, November 1993, and Volumes II and III, December 1993). The Working Group Report identified a total of 106 vulnerabilities associated with the Department's spent nuclear fuel storage facilities. Although the Working Group found no conditions that required immediate action to prevent harm to the workers or the public, it did identify five DOE facilities and three burial grounds that warranted priority attention to avoid unnecessary increases in worker radiation exposure and cost during cleanup. In addition to the specific site vulnerabilities, the Working Group identified five generic issues that are common to many DOE spent fuel storage facilities. They are (1) the lack of approved and current authorization bases, (2) seismic design inadequacies, (3) the lack of programmatic ownership, (4) the lack of complete material characterization, and (5) the lack of a specified path forward. These generic issues were taken into consideration when developing individual action plans and will require careful consideration by all facilities during future planning and decision making activities.

Table 3.6-1: DOE Spent Nuclear Fuel Inventory Summary

\begin{tabular}{||l|c|c|c|c|c|c||}
\hline \multicolumn{1}{|c|}{ Site } & MTIHM & $\begin{array}{c}\% \text { of } \\
\text { Total } \\
\text { MTIHM }\end{array}$ & $\begin{array}{c}\text { Total } \\
\text { Mass } \\
\text { (Metric } \\
\text { Tons) }\end{array}$ & $\begin{array}{c}\% \text { of } \\
\text { Total } \\
\text { Mass }\end{array}$ & $\begin{array}{c}\text { Volume } \\
\text { (Cubic } \\
\text { Meters) }\end{array}$ & $\begin{array}{c}\% \text { of } \\
\text { Total } \\
\text { Volume }\end{array}$ \\
\hline Hanford & 2,132 & 80 & 2,367 & 53 & 261 & 19 \\
\hline Idaho & 269 & 10 & 1,046 & 23 & 679 & 49 \\
\hline Savannah River & 201 & 8 & 543 & 12 & 164 & 12 \\
\hline West Valley & 27 & 1 & 42 & 1 & 5 & $<1$ \\
\hline Ft. Saint Vrain & 16 & $<1$ & 190 & 4 & 160 & 12 \\
\hline $\begin{array}{l}\text { Other (LANL, BNL, ANL } \\
\text { and SNL) }\end{array}$ & 10 & $<1$ & 292 & 6 & 86 & 6 \\
\hline Oak Ridge & 3 & $<1$ & 25 & $<1$ & 21 & 1 \\
\hline Total & 2,659 & 100 & 4,507 & 100 & 1,376 & 100 \\
\hline
\end{tabular}




\section{Acceptance and Objectives}

The Department agrees that the materials addressed by the Board should be converted into a form suitable for safe interim storage on a high-priority basis. The Department has committed to resolving all vulnerabilities identified in the SNF Working Group Report.

Recommendation 94-1 essentially demands the acceleration of the resolution of safety issues identified in the SNF Working Group Report for selected SNF at Hanford, Savannah River, and Idaho National Engineering Laboratory. This represents a significant portion of the DOE-owned SNF inventory and is acknowledged as the fuel at highest risk. Resolving these SNF issues is the single highest priority within the Department's SNF Program. Changes to existing vulnerability action plans will be necessary, including shortening the schedules for mitigating these issues when practical and ensuring the reallocation and reprioritization of sufficient funding to perform the work. The program has set the following objectives:

- $\quad$ Place all DOE-owned SNF in secure, safe interim storage.

- Remove all fuel from the Hanford K-Basins by December 1999.

- $\quad$ Complete stabilization of the Savannah River Mk31 targets by September 1996 and dissolution of Mk16 and Mk22 SNF by November 1999. Complete conversion of the resultant uranium solutions by April 2000.

- $\quad$ Remove all fuel from the Idaho CPP-603 Fuel Storage Facility by December 2000.

\section{Key Assumptions}

- DOE-owned SNF that is not processed will be disposed of in the first geologic repository as part of the 7,000 metric tons allocated for DOE High-Level Waste.

- An integrated $R \& D$ program will be continued as a means to overcoming the following technical shortcomings:

a) Corrosion mechanisms of DOE-owned spent nuclear fuels

b) Hanford Path Forward Stabilization Process for hydrided and corroded $\mathrm{N}$-Reactor fuels from K-Basins

c) Dry interim storage of DOE-owned SNF. 


\section{Part II: Spent Nuclear Fuell Integration Activities}

\section{Approach}

DOE's Spent Nuclear Fuel Program began in 1992, when the Secretary of Energy directed the Assistant Secretary for Environmental Management (EM) to develop an integrated long term SNF management program. This would consolidate under EM the management of DOE-owned SNF and associated facilities not addressed by the Office of Civilian Radioactive Waste Management (OCRWM). The EM Office of Waste Management is responsible for program direction for all DOE-owned SNF including SNF generated by DOE production, research, and development reactors; naval reactors; university and foreign research reactors (FRRs); other miscellaneous generators; and special-case commercial reactors. Within the Office of Waste Management, the Office of Spent Fuel Management provides strategic planning and policy for management of DOE-owned SNF. This overall guidance and policy is implemented through the line management operations organizations of the Offices of Waste Management and Nuclear Materials and Facilities Stabilization.

The strategies for achieving the mission of the SNF Program-to safely, reliably, and efficiently manage DOE-owned SNF and prepare it for disposal -are contained in several key Environmental Impact Statements (EISs)currently in preparation and through the SNF Program Strategic Plan, which was issued December 1994. The EISs will provide the framework within which the SNF Program must operate. Details of the EISs are provided below. The SNF Strategic Plan is not intended to prejudice decisions on National Environmental Policy Act (NEPA) alternatives under consideration; rather, it sets out the broad objectives and strategies for achieving the program's mission within the framework established through the NEPA process.

A significant aspect of the Strategic Plan is the commitment to using a systems engineering process to provide sound program definition, management, and implementation. This process has been used to define the top-level functions and requirements needed to accomplish the SNF mission. The functions are shown in Figure 3.6-1. The Spent Nuclear Fuel Systems Engineering Technical Functions (Levels 0, 1, \& 2), published in December 1994, provides a more in-depth presentation of these functions and their interrelationships and their interfaces with the SNF Program. The Spent Nuclear Fuel Program Requirements Document, October 1994, delineates the top-level requirements for the SNF Program. The SNF Program Plan implements the SNF Strategic Plan and will be a combined Program Plan, Program Management Plan, and Systems Engineering Management Plan that defines the SNF program management process and technical approach, including implementation of the system requirements. It will specify and authorize a subset of implementing documents required to fulfill the SNF program strategic objectives, including the Stakeholder Involvement, Technology Integration, and Interim Storage Plans. The Technology Integration Plan was issued December 1994. The SNF Program Plan will detail the disposition of all DOE-owned SNF, including those fuels 


\section{SNF Program Systems Engineering Technical Functions}

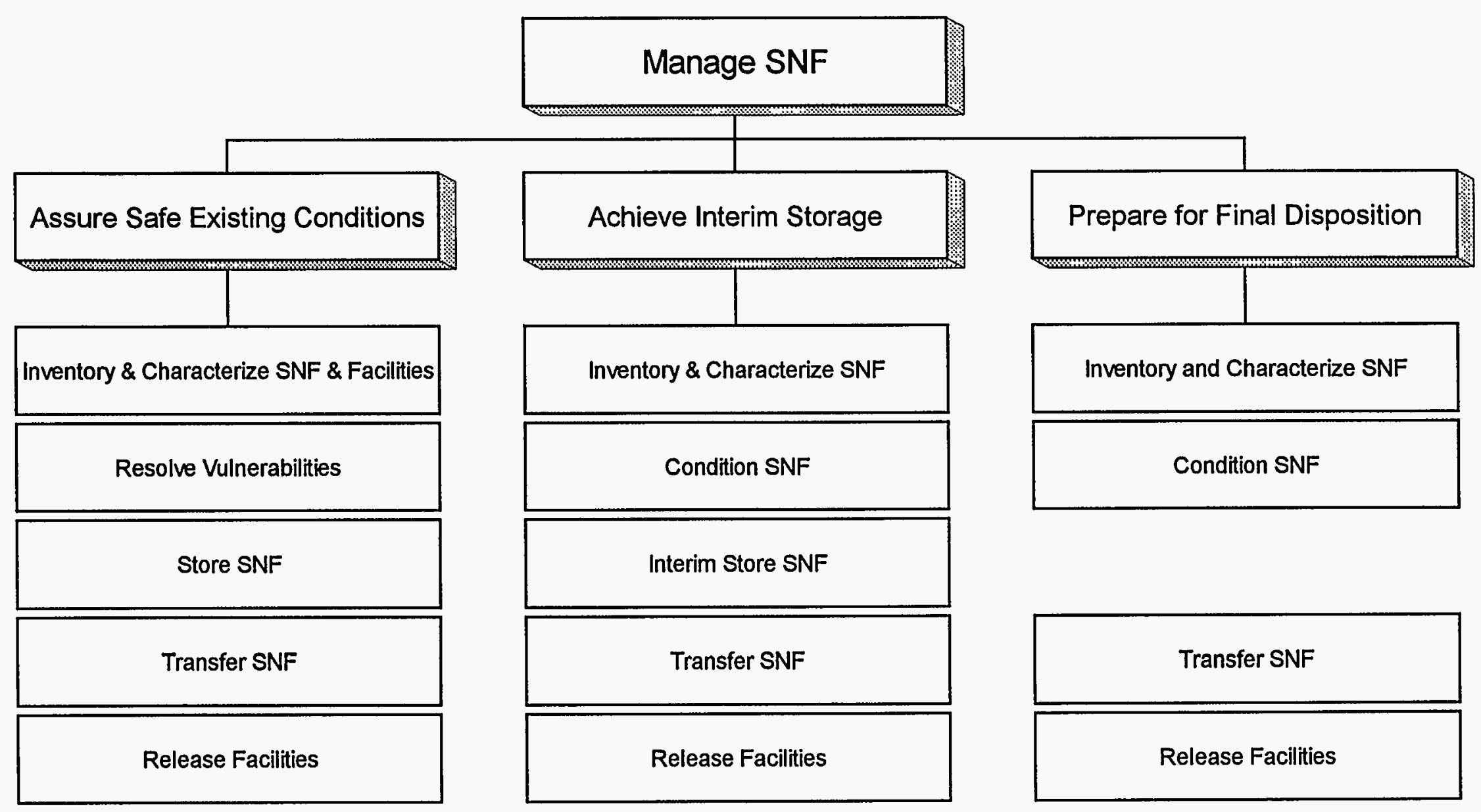

Figure 3.6-1 
addressed in Recommendation 94-1 and the Spent Fuel Working Group Report. As previously noted, the Program Plan will serve as the SNF Material Integration Plan and incorporate schedules and milestones delineated by the Integrated Program Plan through the Site Implementation Stabilization Management Plans. The SNF Program Plan is scheduled for release in November 1995.

The Plan of Action to Resolve Spent Nuclear Fuel Vulnerabilities (Phase III, October 1994) addresses the resolution of the vulnerabilities addressed by the Spent Nuclear Fuel Working Group. It addresses all 106 vulnerabilities and provides the Department's baseline for corrective actions. The Phase III Plan of Action responds to the vulnerabilities identified in the SNF Working Group Report, and represents the completion of the Secretary's initiative to assess the Department's SNF facilities. The SNF Commitment Tracking System was developed to monitor commitments detailed in the Phase III Plan of Action and manage any new SNF issues which emerge. It is through these plans, functions and requirements that the resolution of vulnerabilities, as described in the SNF Working Group Report and Recommendation 94-1, is integrated and managed in concert with the interim and long-term objectives of the SNF Program.

DOE currently is making key policy decisions under a process established by NEPA and is committed to a comprehensive NEPA review process in making decisions on the storage, disposition, and, if appropriate, transportation of DOE-owned SNF. These decisions apply to:

- The interim management period pending ultimate disposition.

- $\quad$ Foreign Research Reactor SNF program-wide.

- Specific interim management of nuclear materials at the DOE sites.

The first set of decisions involves programmatic (DOE-wide) decisions regarding the appropriate means of managing existing and projected quantities of SNF for an interim storage period that could last until the year 2035. This 40-year time frame was chosen to allow enough time to make and implement a decision on the ultimate disposition of all DOE-owned SNF. Accordingly, Volume 1 of the Programmatic SNF EIS addresses the potential environmental impacts associated with alternative approaches for managing DOE-owned SNF for 40 years on a national level.

The alternative approaches include:

- $\quad$ No Action - take the minimum actions required for safe and secure management of $\mathrm{SNF}$ at or close to the generation site or current storage location.

- Decentralization - store most SNF at or close to the generation site or current storage location with limited shipments to DOE facilities. 
- $\quad$ 1992/93 Planning Basis - transport and store newly generated SNF at Idaho National Engineering Laboratory (INEL) or SRS.

- $\quad$ Regionalization - distribute existing and projected SNF among DOE sites based primarily on fuel type or geographic location.

- $\quad$ Centralization - manage all existing and projected SNF inventories from DOE and the Navy at one site until ultimate disposition.

Volume 2 of this EIS addresses the alternative approaches for management of DOE's SNF activities over the next ten years at INEL and includes fuel receipt, transportation, characterization, stabilization, storage, and technology development for ultimate disposition.

The final Programmatic SNF EIS is scheduled for issuance by April 1995, following review and revision based on stakeholder comments with a Record of Decision planned for June 1995. Site-specific NEPA reviews will tier from the Programmatic SNF EIS and be guided by and consistent with it.

The second set of decisions involves SNF from foreign research reactors. The SNF Program is preparing the "Proposed Policy for Management of U.S. Foreign Research Reactor SNF EIS" as part of the decision making process, which will provide the Administration's decision regarding the implementation of a nuclear nonproliferation policy for FRR spent fuel containing uranium of U.S. origin. (To facilitate discussion, this EIS will be designated the FRR SNF EIS.) This document will evaluate the potential environmental effects of establishing and implementing a policy to manage spent fuel from foreign research reactors over the next 10 to 13 years. The FRR SNF EIS will defer to the Programmatic SNF EIS for siting alternatives but identifies the environmental consequences for a stand-alone, site-specific FRR SNF management approach. The selection of a site or sites to manage FRR SNF would be based on the Programmatic SNF EIS, and no decisions on the proposed policy would be made until both EISs are completed. The Record of Decision (ROD) for the FRR SNF EIS is scheduled to be issued by December 1995.

The third set of decisions involves the interim management of nuclear materials at specific DOE sites. At SRS, DOE needs to decide what materials can safely remain in their current form for an interim period (approximately 10 years) until disposition decisions can be made. DOE must also decide which materials are at risk and therefore require near-term stabilization to assure continued safe management. DOE will also determine appropriate stabilization methods and decide whether it has a need for certain nuclear materials and, if so, how to convert the materials to a useful form. Accordingly, DOE is preparing an EIS, titled "Interim Management of Nuclear Materials (IMNM) at the Savannah River Site." This document is scheduled for release in final form in May 1995, with an ROD scheduled for June 1995. Subsequent to the RODs for the IMNM EIS and the Programmatic EIS, a SRS SNF Management EIS will be developed for fuels at SRS which are not considered to be at risk. 
At Hanford, an EIS is being prepared to allow implementation of the K-Basins Path Forward (see section 3.6.2). The Record of Decision is scheduled for March 1996. Consideration is being given to obtaining Council for Environmental Quality approval for performing engineering and construction in parallel with the finalization of the NEPA process.

\section{Key Challenges}

- Formal authorization to place DOE-owned SNF into the first geologic repository.

- Obtaining stakeholder acceptance of planned activities.

- Development and demonstration of the technologies for mitigating corrosion mechanisms of DOE-owned spent fuels, stabilizing of hydrided and corroded $\mathrm{N}$-Reactor fuels, and placing of DOE-owned SNF into dry interim storage.

The Office of Spent Fuel Management has been performing complex-wide integration of spent fuel management activities. They will continue to perform this function in the future but will communicate with the Task Group to ensure the coordination of potentially interrelated actions. An example of an action that would require coordination is the stabilization of spent fuel through a Canyon at Savannah River because of its potential impact on stabilization actions for Plutonium solutions or special isotope solutions.

The following initiatives are underway to address the key challenges identified:

- $\quad$ The Office of Environmental Management has developed a strategy for the ultimate disposition of DOE-owned SNF and has been coordinating with other Secretarial Offices in order to confirm this as the Department-wide position. An action memorandum for the Secretary of Energy that articulates the ultimate disposition strategy for DOE-owned spent fuel is undergoing senior management review. Once approved, a systems analysis will be required to identify the specific allocation of the repository allotment.

- To improve the involvement of stakeholders, the Office of Spent Fuel Management has developed a Stakeholder Involvement Plan that tiers off the Environmental Management Public Participation Program Plan. Significant stakeholder involvement actions were a key element of the development of the Programmatic Spent Nuclear Fuel and the Foreign Research Reactor Environmental Impact Statements. Continued efforts are necessary to ensure stakeholder acceptance of future spent fuel management actions.

- $\quad \mathrm{R} \& D$ efforts are in progress to support the placement of spent nuclear fuel into safe, secure interim storage. The coordination of these efforts is achieved through the Technology Integration Technical Working Group established by 
the Office of Spent Fuel Management in June 1993. A Technology Integration Plan was issued in December 1994. The plan's purpose is to establish all the planned and proposed technologies envisioned as necessary to support the spent nuclear fuel program. Specifically, efforts are underway using the Pacific Northwest Laboratory to support the characterization and stabilization of spent fuel and sludge at the Hanford K-Basins. Efforts to determine the behavior of hydrided N-Reactor fuel will be initiated by April 1995 to support the Hanford K-Basins Path Forward. Other efforts include the study of spent fuel corrosion mechanisms associated with wet and dry storage and the study of heat transfer mechanisms associated with dry storage.

\section{Part III: Individual Site Activity Plans}

\subsubsection{Hanford Spent Nuclear Fuel}

\section{Hanford Facility Description}

The K-East and K-West Storage Basins were constructed in the early 1950s to provide temporary storage of Single Pass Reactor fuel discharged from the K Reactors until the K Reactors were shutdown in 1970. Subsequently, the basins were used for storage of $\mathrm{N}$ Reactor spent fuel. The basins are located approximately 1,000 feet from the Columbia River. They are unlined, concrete, 1.3-million-gallon water pools with an asphaltic membrane beneath each basin. The K-East Basin presently stores approximately 1,152 metric tons of initial heavy metal (MTIHM). The spent fuel has been stored under water in open-top canisters for periods ranging from 6 to 23 years. The fuel is corroding and an estimated 50 cubic meters of sludge has accumulated in the basin containing radionuclides, corrosion products, and miscellaneous materials. The K-West Basin presently stores approximately 953 MTIHM. Prior to storage in the $\mathrm{K}$-West Basin, the spent fuel was placed in closed canisters and thus there is no appreciable sludge buildup in the basin. Leakage to the environment from K-East Basin has occurred, most likely at the basin discharge chute construction joint. The asphaltic membrane does not extend beneath this area. The K-West Storage Basin is not believed to be leaking. The discharge chute construction joints between the foundations of the Basins and the K-Reactors are not adequately reinforced, and a seismic event could trigger considerable leakage due to displacement.

\section{Hanford Issures}

To address the urgent $\mathrm{K}$-Basin issues, the Department and Westinghouse Hanford Company have developed a K-Basins Path Forward that greatly accelerates fuel removal from the basins, stabilizes it, and places it in safe, secure interim storage. The K-Basins Path Forward was approved by DOE on November 2, 1994, and it is currently being implemented. Concurrent with this action, several near-term actions are being taken to minimize safety and environmental risks for the short remaining 
time that the fuel remains in storage at the basins. These actions include the installation of cofferdams to isolate the basin water from the suspected leakage site, several dose reduction measures to minimize worker exposure, essential facility services upgrades, conduct of operations improvements, and fuel/sludge characterization.

A full description of the K-Basin Path Forward including alternative descriptions, important assumptions, and comparative evaluations is provided in Westinghouse Hanford Company report WHC-EP-0830, "Hanford Spent Nuclear Fuel Recommended Path Forward," Volumes I, II, and III, October 1994. To arrive at the K-Basins Path Forward, systems engineering and risk-based decision techniques were utilized, in conjunction with a variety of technical and programmatic reviews that included independent assessments by senior experts from outside Hanford. The evaluation process included analysis of cost, schedule, regulatory and stakeholder drivers, and affected Indian nation values to develop a comprehensive, balanced treatment of the various alternatives. Results from these reviews and analyses were used to formulate a technical and regulatory strategy. The key elements of the K-Basins Path Forward are described below:

- The first step would place fuel and sludge in damp inerted Multi-Canister Overpacks and transfer the overpacked fuel to a Canister Storage Building (CSB) prior to fuel drying and passivation. This step would remove fuel from the deteriorating safety and environmental conditions at the K-East Basin at the earliest possible date.

- The second step would transfer the fuel in the Multi-Canister Overpacks to a Conditioning Facility where it would be dried and passivated. The fuel would then be returned to the CSB in dry, inerted Multi-Canister Overpacks for longterm interim storage. This would achieve a storage condition that satisfies criteria for interim storage and stages the fuel for final disposition activities. Using the same Multi-Canister Overpacks for both storage conditions and the conditioning process minimizes the total amount of waste to be generated. Simultaneous initiation and performance of the two steps will enable expeditious implementation of dry interim storage.

This dry storage configuration will result in a stable passive system designed to arrest further fuel corrosion, the fuel remaining in its metallic form protected by an unreactive oxide coating and an inert gas environment. This condition maximizes stability and safety while maintaining the flexibility to further process the SNF into a waste form suitable for disposition if this proves to be necessary. The CSB will be designed and constructed to modern design standards and seismic criteria suitable for the 40-year storage requirement. It would also use a double containment (sealed Multi-Canister Overpack in a storage tube with inspectable seals) and a highefficiency-particulate-air (HEPA) filtered confinement system. 


\section{$\underline{\text { K-Basins Path Forward Near-Term Objectives }}$}

In the near term, major acquisitions will be initiated to support the $\mathrm{K}$-Basins Path Forward. These include the CSB, the Fuel Transportation System, the Multi-Canister Overpacks and the Conditioning Facility. These acquisitions, except for the Conditioning Facility, will be necessary for completion of the expedited response phase of the path forward. Other activities are also proceeding in parallel with the major acquisitions to improve the near-term safety and environmental posture at the $\mathrm{K}$ Basins. These actions include:

- Installation of cofferdams between the basin and the discharge chute to mitigate the consequences of a seismic event by isolating the basin from the anticipated leak site located in the unreinforced construction joint in the discharge chute. This action is being taken to minimize the potential for environmental release of contaminated sludge either directly through the leak into the ground or by airborne release, should the basin be drained and the sludge dry to a powder. This action also addresses concerns about fuel dryout and possible pyrophoric ignition leading to radioactive material releases. Maintaining the fuel under water prohibits pyrophoric ignitions.

- Performance of fuel and sludge characterization to assess fuel condition, the degree of hydriding, and the makeup of the sludge. The fuel data will be used to support safety analyses for transport of the fuel and development of a fuel conditioning process to eliminate reactivity and pyrophoricity concerns in the stabilized condition. Sludge characterization will be used in determining the path forward for the sludge.

- Establishment of a path forward for basin sludge that considers the probable differences between sludge in the fuel canisters and sludge lying on the basin floor. While the sludge contained in the fuel canisters is primarily the result of fuel corrosion, the vast majority of the sludge on the basin floor is believed to consist of blow sand, structural material oxides, and concrete spallation products. While the canister sludge will remain with the fuel and be considered SNF, it may be possible to disposition the basin sludge through existing waste disposal systems.

- Establishment and maintenance of a formal Conduct of Operations program at the K-Basins to improve safety of ongoing operations.

- Completion of essential facility systems recovery actions necessary for continued safe operations and personnel protection, such as electrical, potable water, fire protection, and maintenance systems. 
- $\quad$ Reduction of personnel exposure in keeping with as-low-as-reasonablyachievable (ALARA) practices by improving dose reduction measures and reducing the radioactive source term from cesium-contaminated concrete basin walls and pipe runs.

- $\quad$ Removal of debris from the K-East Basin such as unused canisters and discarded tools in preparation for fuel and sludge removal. This waste will be cleaned and compacted prior to shipment to the solid waste management area to minimize the waste volume.

- Improvement of water clean-up including minimizing TRU loading of the ion exchange modules and providing redundant systems to insure that adequate ion exchange capability is always available.

- $\quad$ Performance of basin modifications and preparations for operational readiness to support fuel removal activities.

\section{K-Basins Path Forward Schedule}

Depending on the alternative selected in the K-Basins EIS Record of Decision and the acquisition strategy, the schedule will be limited by the design, construction, and operational readiness of the new CSB. The K-Basins Path Forward preliminary schedule indicated that fuel and sludge removal from the K-Basins would begin in December 1998 and be completed in November 2000, an acceleration of two years over the previous schedule for fuel encapsulation that supported the Tri-Party Agreement (TPA) target milestone of December 2002. Additional acceleration of the K-Basins Path Forward schedule was recently evaluated, and DOE is now committed to having the fuel removed from the K-Basins by December 1999.

Key schedule dates supporting the K-Basins Path Forward between now and December 31, 1995, are:

- $\quad$ Finalize and implement the major systems acquisition strategy by February 1995.

- $\quad$ Issue Notice of Intent for K-Basins EIS by February 1995.

- Complete cofferdam installation in K-West Basin by February 1995 and in KEast Basin by April 1995. (K-West installation is being performed first to qualify materials, processes, and procedures before installation in the more adverse conditions in K-East Basin.)

- $\quad$ Start fuel characterization in hot cells by April 1995.

- $\quad$ Issue K-Basins EIS Record of Decision by March 1996. 
- Initiate sludge retrieval demonstration in conjunction with cofferdam installation by April 1995.

Additional dates will be included in the K-Basins integrated schedule that will be issued by May 1995. This schedule will provide details of major system acquisitions and material movements. The following milestones will be included:

- $\quad$ Submit project validation package.

- Initiate development for $\mathrm{N}$ Reactor fuel stabilization process.

- $\quad$ Finalize site identification and initiate site characterization for facilities.

- $\quad$ Place contract(s) for necessary equipment and facilities.

- Begin fuel removal from K-Basins.

- Design Multi-Canister Overpack.

- Begin Multi-Canister Overpack manufacture.

- $\quad$ Start and complete construction of Canister Storage Building.

- Start and complete construction of Conditioning Facility.

- Start and complete fuel stabilization.

- $\quad \mathrm{K}-\mathrm{Basin}$ fuel in dry storage.

Related issues also exist at the PUREX facility where some single-pass reactor fuel is stored in baskets in the receiving basin and some $\mathrm{N}$ Reactor fuel lies on dissolver cell floors. These issues are related to the K-Basins issues because of the fuel type. The fuel currently in PUREX is scheduled to be moved to K-East Basin and dispositioned as part of the K-Basins Path Forward.

\subsubsection{Savannah River Spent Nuclear Fuel}

\section{Savannah River Facility Description}

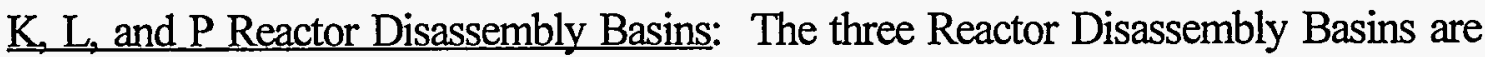
unlined, concrete water pools and have been used for up to 5 years for storage of spent fuel, target assemblies, and other radioactive material. The basins have been in operation since 1954 and hold 3.5 to 4.5 million gallons each. The total inventory in the three basins consists of approximately $13,700 \mathrm{Mk} 31 \mathrm{U}-238 / \mathrm{Pu}-239$ targets containing approximately 138 metric tons of heavy metal and approximately 1,870 Mk16 and Mk22 spent fuel elements containing 7.2 metric tons of heavy metal. The 
extended duration of storage, poor water chemistry control, galvanic coupling, damaged cladding due to handling, and lack of appropriate water filtration systems have all contributed to accelerated corrosion of the spent nuclear fuel and target materials and increased radioactivity levels in the water of the Basins. Additionally, the facilities were not designed to meet current seismic standards and the current leak detection method is not sufficiently sensitive to detect small leaks.

Receiving Basin for Off-Site Fuels: The Receiving Basin for Off-Site Fuels (RBOF) Facility stores reactor fuel elements from off-site reactors and occasionally from onsite reactors. The RBOF is a concrete pool with a volume of approximately 500,000 gallons placed into operation in 1963, it has a stainless steel bottom and Phenoline resin-coated walls. The original design incorporated a basin water chemistry control system consisting of a filter and mixed ion-exchange resin deionizer system. The fuel elements in the RBOF, some of which have been in the basin for 30 years, show no visible signs of corrosion. The fuel assemblies and canisters of fuel, which contain 60.6 metric tons of heavy metal, and targets, which contain 17.4 metric tons heavy metal, are stored at RBOF in storage racks that provide the spacing required to preclude nuclear criticality. The roof over the cask basin and the transite walls provide inadequate protection to prevent penetration of tornado-generated missiles. RBOF was not designed to meet current seismic standards and the storage racks, although anchored to the floor and walls of the basin, are not seismically qualified.

F- and H-Canyons: The F- and H-Canyons have two dissolvers each that provide the capability to process spent fuel and target material to recover special nuclear material. They include small water basins, with volumes of approximately 4,000 to 12,000 gallons, for spent fuel and target assemblies that are awaiting processing. The facilities have been in operation since the mid-1950s, although the basins were not designed for long-term storage. The inventory in F-Canyon is comprised of 1,224 Mk-31A targets containing 22.6 metric tons of heavy metal. The inventory in HCanyon is comprised of $13 \mathrm{Mk} 16 / \mathrm{Mk} 22$ spent fuel assemblies, which contain a total of 68 kilograms of heavy metal. Because the Canyons were designed and constructed with no special provisions for seismic resistance, a criticality could potentially occur as a result of seismically-induced damage to the storage racks. The Canyons lack means to maintain water chemistry and corrosion of fuel and targets is occurring.

\section{Savannah River Issues}

\section{Processing Enriched Uranium in H-Canyon (Baseline Planning Case)}

Savannah River has traditionally processed highly enriched uranium (HEU) SNF in the $\mathrm{H}$-Canyon and plutonium production targets, which are irradiated depleted uranium (less than $0.2 \%$ U-235), through the F-Canyon. The separated enriched uranium produced in H-Canyon was transported to Oak Ridge as enriched uranyl nitrate solution for recycling into new fuels for SRS reactors. The depleted uranium produced in the F-Canyon as a by-product of the plutonium separations process was traditionally converted to oxide in the F-Area A-Line facility. 
Assuming the processing option is selected in the IMNM EIS ROD stabilization operations would be similar to traditional operations, outlined above. Based upon this assumed selection, Mk31 target stabilization is expected to begin in F-Area in November 1995, and stabilization of SRS Mk16 and Mk22 HEU SNF is expected to begin in H-Area in November 1996. The HEU SNF would be dissolved in the HCanyon as per past practice. The resulting enriched uranium solutions would then be transferred to the enriched uranium storage tank in the H-Area A-Line facility for temporary storage. At the same time, depleted uranium oxide currently stored in drums would be dissolved in the F-Area A-Line facility, placed into a transfer truck (equivalent to the HM trailers used for transfer of enriched uranium solutions to Oak Ridge in the past), and transferred to the H-Area A-Line facility. This depleted uranium solution would be mixed with the enriched uranium solution in the enriched uranium storage tank, diluting it to approximately 0.9 at \% U-235. The dilution is necessary to control criticality during processing in the F-Area A-Line facility, as it was designed to handle only depleted uranium solutions resulting from processing of Mk31 targets. This newly diluted solution would then be pumped back into the transfer trailer and returned to the F-Area A-Line facility where it would be converted to oxide for storage. Assuming a canyon dissolver capacity of approximately 2,000 elements per dissolver per year, and that F- and H-Canyons have two dissolvers available, the dissolution of Mk31 targets and Mk16 and Mk22 SNF will be completed in September 1996 and November 1999, respectively. When processing is completed, miscellaneous aluminum-clad targets and fuels containing unusable isotopes will be dissolved for disposal to the Waste Tank Farm. Then eventual vitrification of radioactive material will occur in the Defense Waste Processing Facility (DWPF). Sufficient tank volume exists to handle the projected waste steams.

While this processing scenario requires trucking uranium solutions be'ween the $\mathrm{F}$ - and H-Areas, no new technology would be required and the trucking is already planned to occur as part of the disposition of existing $\mathrm{H}$-Canyon uranium solutions. Past processing practices produced enriched uranium solutions for storage in H-Area ALine, transferred uranium solutions in trailers (enriched solutions to Oak Ridge rather than depleted solutions F- to H-Areas), and produced depleted uranium oxide in the FArea A-Line. The only change required to complete the HEU SNF processing using this technique would be the installation of a trailer loading and unloading port in the F-Area A-Line for the transfer of depleted uranium solution and the receipt of isotopically diluted $\mathrm{H}$-Canyon solutions. This scenario also offers the opportunity to transfer the enriched uranium produced in $\mathrm{H}-\mathrm{Canyon}$, perhaps at some reduced enrichment, to a commercial facility for production of commercial fuels, if desired.

In response to Recommendation 94-1, SRS has evaluated acceleration of this schedule using various combinations of canyon capabilities. None of these alternatives has yet been approved by the Department but are presented below as options by which the intent of the Recommendation could also be achieved. 


\section{Processing Enriched Uranium in F-Canyon}

In this scenario, the Mk16 and Mk22 SNF would be processed through the F-Canyon concurrent with the Mk-31 targets. The F-Canyon has traditionally been used to process only depleted uranium solutions. The equipment and criticality control procedures were not designed for processing enriched uranium. To address this, one of the two dissolvers in F-Canyon would be dedicated for the dissolution of existing Mk31 depleted uranium targets and the other for dissolution of the enriched uranium SNF. After appropriate accountability sampling of the two dissolver tanks, the dissolved solutions would be mixed in appropriate proportions to produce a 0.9 at \% solution of U-235. The resultant solution would then be processed through the existing F-Canyon and F-Area A-Line facilities using established procedures. Once the Mk31 stocks were exhausted, depleted uranium oxide would be dissolved in FArea A-Line, transferred into the F-Canyon, and similarly mixed with the dissolved enriched solutions.

This scenario has the advantage of containing all uranium solutions generated by SNF processing within F-Canyon and F-Area A-Line with no need for inter-area trucking of these solutions. Processing using this technique can begin as early as November 1995, versus November 1996 as proposed for H-Canyon. The rate at which the inventory of SNF could be processed is essentially the same through either canyon, allowing completion of processing approximately one year earlier than the baseline case.

\section{Processing Enriched Uranium in Both F- and H-Canyons}

Here, processing is commenced as soon as possible in the F-Canyon, as discussed above, while concurrently preparing and operating the H-Canyon for remaining Mk16 and Mk22 SNF. Enriched uranium SNF processing in F-Canyon could begin as early as November 1995. Additional capacity for SNF processing could be achieved by initiating SNF processing in H-Canyon in November 1996 while continuing SNF processing in F-Canyon. This additional capacity could be used to accelerate completion of SRS SNF processing by as much as two years (i.e., 1997) from the baseline completion of late 1999, or to accelerate processing of other aluminum-clad SNF if desired. F-Area A-Line capacity is more than sufficient to support two-canyon SNF processing.

Another option under this scenario is to discontinue SNF processing in F-Canyon when H-Canyon SNF processing begins. This option would accelerate completion of SNF processing by 12 months from the base case and would allow excess F-Canyon dissolving capacity to be dedicated to stabilization of suitable materials from other sites.

For all of the alternative process schemes, DOE is pursuing a sub-option that would make use of the uranium's enrichment and avoid long-term storage of slightly enriched uranium. Solutions would be diluted to less than 20 at U-235, instead of 0.9at U-235, and shipped to commercial fuel fabricators in certified containers. 


\section{Savannah River Near-Term Objectives}

A recent structural assessment for the K-Reactor Disassembly Basin exterior walls and foundations determined that they could withstand a $0.2 \mathrm{~g}$ earthquake, the current $\mathrm{DOE}$ design basis seismic criteria. For such an occurrence, minor leakage could occur through an expansion joint or cracks in the retaining walls; however, the leakage would be very slow. The consequences of an earthquake for the L- and P-Reactor Disassembly Basins are less than those for the K-Reactor Disassembly Basin because the K-Reactor Disassembly Basin has the highest radionuclide inventory. A detailed structural assessments for design basis hazards is being performed for RBOF in order to upgrade the safety analysis reports Also a seismic assessment of the H-Canyon and its components is also underway as part of the effort to upgrade its safety analysis report.

To reduce the corrosion rate of fuels and storage equipment, the L-Reactor Disassembly Basin will undergo a cleaning and conductivity reduction campaign. Sludge has been vacuumed from approximately $70 \%$ of the basin floor and conductivity has been substantially lowered. Additionally, a one-time batch deionization will be conducted; that along with other upgrades, will maintain conductivity below critical levels. Corrosion surveillance indicates progress in slowing the corrosion rates of aluminum in the basin. Coupons were immersed in the L-Reactor Disassembly Basin in late 1993 and were examined in March 1994 revealing no signs of pitting after 180 days of exposure. These coupons will be reexamined in late February 1995.

Upgrades, necessary to permit extended storage of aluminum-clad SNF in L-Reactor Disassembly Basin, are in progress and funded for implementation. Similar activities are planned for K-Reactor Disassembly Basin, with completion for both areas scheduled for May 1996. These changes are expected to improve the Reactor Disassembly Basins water chemistry to levels approaching RBOF. The upgrades include:

- $\quad$ One-time vendor "shock" deionization of the basin.

- Installation of continuous deionization system sized to treat the basin proper. The existing system was originally designed to treat only basin discharge water.

- Operation of a zeolite deionization system designed to remove Cesium-137.

- Installation of a deionized make-up water system. Current make-up water is filtered river water.

- Additional groundwater monitoring wells. 
Additionally, vertically stored fuel in K- and L-Reactor Disassembly Basins is being reoriented to eliminate galvanic coupling and associated storage equipment corrosion.

The current SRS schedule is as follows:

- $\quad$ Complete RBOF criticality "re-baselining" evaluation (acceptability of existing spacing) by April 1995.

- Complete vacuum consolidation of L-Reactor Disassembly Basin sludge (currently more than 70\% complete) in September 1995.

- $\quad$ Reorient fuel in L- and K-Reactor Disassembly Basins to horizontal configuration by September 1995 and February 1997, respectively.

- Begin stabilization of Mk31 target inventory in F-Area in November 1995.

- Complete fuel consolidation to free approximately 1,250 additional storage spaces in RBOF by December 1995.

- $\quad$ Complete K- and L-Reactor Disassembly Basins water chemistry upgrades by May 1996.

- Complete processing of Mk31 targets in F-Canyon by September 1996.

- $\quad$ Complete vacuum consolidation of K-Reactor Disassembly Basin sludge in FY 1996.

- $\quad$ Begin processing of Mk16 and Mk22 SNF in November 1996.

- $\quad$ Remove consolidated basin sludge from K- and L-Reactor Disassembly Basins by September 1997.

- $\quad$ Complete dissolution of Mk16 and Mk22 SNF by November 1999 and stabilization of resultant uranium solutions by April 2000.

\subsubsection{Idaho Spent Nuclear Fuel}

\section{Idaho Facility Description}

The CPP-603 Fuel Storage Facility is an underwater fuel storage facility that was built in two phases (1951 and 1959) for storage of metal-clad spent nuclear fuel elements pending reprocessing. It consists of three unlined concrete storage basins, two cask handling areas, a fuel element cutting facility, a structural steel/transite superstructure, and assorted basin water treatment areas that were added individually in the 1960s and 1970s. The two basins built in 1951 used a monorail and yoke storage system for fuel storage, and the basin built in 1959 used an open basin filled with free-standing 
underwater storage racks. The total volume of the three basins is approximately 1.5 million gallons. There are 1,141 units of spent fuel stored in the facility comprised of 2.7 metric tons of initial heavy metal. This fuel is predominantly zirconium-, aluminum-, and stainless-steel-clad, and some fuels are canned because of cladding breaches or for fuel handling economy.

\section{Idaho Issues}

A federal court order specifies a schedule for fuel movement from CPP-603. This includes 189 fuel units moved by September 1994, an additional 189 units by December 1995, all fuel moved from the North and Middle basins by December 1996, and all remaining fuel removed by December 2000. The plan first calls for fuel whose cladding is intact to be moved to the CPP- 666 wet storage facility in available transport casks. Fuel with suspect cladding integrity will be packaged in a dry overpacking station in the CPP-603 Irradiated Fuel Storage Facility (IFSF) fuel handling cave for safe transfer and short-term interim storage. Following the overpacking, this fuel will be stored in the CPP-666 underwater fuel storage area unless an agreement with the State of Idaho can be reached to store it in appropriate dry storage areas. To date, the first 189 fuel units were expedited to complete movement by July 1994, and 10 additional units were removed by September 1994 . Means are being pursued to expedite removal of the spent nuclear fuel from the CPP603 basin in advance of the date specified in the court order, December 2000.

Installation of accurate level-monitoring instrumentation for the basin water and an accurate basin water balance program will partially compensate for the absence of leak detection systems. Several actions have been completed to improve criticality safety including storage yoke rerigging, repackaging of some corroded canister, and fuel spacing. The EBR-II uranium metal fuels, which also contain metallic sodium for bonding, are canned because they are potentially reactive with water. Complete underwater video inspections of all spent fuel and storage equipment have been completed. Canisters will be nondestructively examined to determine the condition of the canisters and their contained fuel. Corrective actions taken to address corrosion include storage yoke rerigging, fuel repackaging, and full implementation of a corrosion monitoring program. Moreover, ion exchange resin replacement/regeneration has significantly reduced radioactivity levels in the basin water and improved overall basin water chemistry. Recently completed structural analyses have determined that the storage basins will meet the design basis seismic events. A system analysis found that only two of the noncompliances concerning the steel superstructure warranted correction. Corrective actions are in progress.

The key milestones for accomplishing removal of CPP-603 from service are provided below.

- Establishment of the Facility Safety Authorization Basis-Currently complete (included rerigging, of storage equipment, SNAP fuel recanning, video inspection of all spent fuel and storage equipment, and seismic evaluation). 
- Movement of first 189 units from North and Middle Basins to CPP666-Completed in July 1994. Moved 10 additional units in September 1994.

- Movement of South Basin Fuels—begin by July 1995 .

- $\quad$ Movement of second 189 units from North and Middle Basins to CPP-666 by December 1995.

- $\quad$ Removal of all fuel from the North and Middle Basins by December 1996.

- Removal of all fuel not requiring canning by December 1998 .

- $\quad$ Dry Storage Canning Station construction and startup by December 1998.

- $\quad$ Fuel Removal from the CPP-603 South Basin by December 2000.

An INEL Spent Nuclear Fuel Management Plan is currently under development to direct the placement of spent fuel currently in existing INEL facilities into interim storage. The plan will also address the coordination of intrasite fuel movements with new fuel receipts and intersite transfers that may be required in accordance with the upcoming DOE SNF Programmatic EIS ROD. The plan assumes that all spent fuel at INEL will be placed into dry storage facilities or shipped offsite until it can be prepared for final disposition. The CPP-666 underwater storage facility will be maintained to provide temporary storage for spent fuel requiring decay cooling before it can be moved to dry storage.

\subsubsection{Key Milestones}

\section{SNF Program Activities}

Phase III Plan of Action Issued . . . . . . . . . . . . . . . . . October 1994

Strategic Plan Issued . . . . . . . . . . . . . . . . . . . . . December 1994

Programmatic SNF EIS Record of Decision . . . . . . . . . . . June 1995

Environmental Management Programmatic

EIS Record of Decision . . . . . . . . . . . . . . . . . September 1995

SNF Program Plan . . . . . . . . . . . . . . . . . . . . . . November 1995

Foreign Research Reactor EIS Record of Decision . . . . . . . . December 1995

Repository EIS Record of Decision . . . . . . . . . . S September 2000

Hanford Milestones

Notice of Intent for K-Basins EIS . . . . . . . . . . . . . February 1995

Fuel Characterization Begin . . . . . . . . . . . . . . . . . . . . A April 1995

Integrated Path Forward Schedule . . . . . . . . . . . . . . May 1995

K-Basins EIS Record of Decision . . . . . . . . . . . . . March 1996

Fuel Removal Begin . . . . . . . . . . . . . . . . . . . . . . December 1997

Fuel Removal Complete . . . . . . . . . . . . . . . . . . December 1999 


\section{Savannah River Milestones}

Interim Nuclear Materials Management

EIS Record of Decision . . . . . . . . . . . . . . . . . . . . June 1995

Processing of Mk31 Targets in F-Canyon Begin . . . . . . . November 1995

RBOF Fuel Consolidations . . . . . . . . . . . . . . . December 1995

K- and L-Basin Water Chemistry Upgrades . . . . . . . . . . . . . . . May 1996

Processing of Mk31 Targets in F-Canyon . . . . . . . . . . S September 1996

Dissolution Mk16/Mk22 Spent Fuel Begin . . . . . . . . . . November 1996

Dissolution of Mk16/Mk22 Spent Fuel . . . . . . . . . . . . November 1999

Stabilization of resultant uranium solutions . . . . . . . . . April 2000

Idaho Milestones

189 Fuel Units from North/Middle Basins Removed . . . . . . . . . July 1994

Removal of next 189 Fuel Units from North/Middle Basins . . December 1995

Removal of All Fuel from North/Middle Basins . . . . . . . December 1996

Removal of All Fuel Not Requiring Canning . . . . . . . . . . December 1998

Startup of Dry Storage Canning Station . . . . . . . . . . . December 1998

Removal of All Fuel from CPP-603 . . . . . . . . . . . . . December 2000 


\section{IIST OF ACRONYMS AND ABBREVIATIONS}

\begin{tabular}{ll} 
at \% & Atom Percent \\
ACB & Auxiliary Charcoal Bed \\
ACRR & Annular Core Research Reactor \\
Al & Aluminum \\
ALARA & As Low As Reasonably Achievable \\
ANL & Argonne National Laboratory \\
Am & Americium \\
Am-Cm & Americium-Curium \\
ARF & Actinide Repackaging Facility \\
ATLAS & Advanced Testing Line for Actinide Separation \\
Be & Beryllium \\
BNL & Brookhaven National Laboratory \\
C & Celsius (degrees) \\
Cf & Californium \\
Co & Cobalt \\
Cm & Curium \\
CMR & Chemical and Metallurgical Research [Building] (at Los Alamos) \\
CPP & Chemical Processing Plant (at Idaho) \\
Cs & Cesium \\
CSB & Canister Storage Building (at Hanford) \\
CFR & Code of Federal Regulations \\
D\&D & Decontamination and Decommissioning \\
DNFSB & Defense Nuclear Facilities Safety Board \\
DOE & Department of Energy \\
DOE/HQ & DOE Headquarters \\
DOT & Department of Transportation \\
DP & Defense Programs \\
DWPF & Defense Waste Processing Facility (at Savannah River) \\
EA & Environmental Assessment \\
EBR-II & Experimental Breeder Reactor II \\
EIS & Environmental Impact Statement \\
EM & (DOE Ooffice of Environmental Management \\
EM-60 & Office of Facility Transition and Management \\
ES\&H & Environment, Safety and Health \\
EU & Enriched Uranium \\
F & Fahrenheit (degrees) \\
F & Flourine Gas \\
FFTF & Fast-Flux Text Facility \\
FMF & Fuel Manufacturing Facility \\
FONSI & Finding of No Significant Impact \\
FRR & Foreign Research Reactor \\
& \\
& \\
\hline &
\end{tabular}




\begin{tabular}{|c|c|}
\hline FSF & Fuel Storage Facility \\
\hline FY & Fiscal Year \\
\hline g & Gram \\
\hline $\mathrm{HCF}$ & Hot Cell Facility \\
\hline $\mathrm{HCL}$ & Hydrochloric acid \\
\hline HEPA & High-efficiency Particulate Air \\
\hline HEU & Highly Enriched Uranium \\
\hline HEUN & Highly Enriched Uranyl Nitrate \\
\hline IAEA & International Atomic Energy Agency \\
\hline $\mathrm{IDC}$ & Item Description Code \\
\hline IFSF & Irradiated Fuel Storage Facility (at Idaho) \\
\hline IMNM & Interim Management of Nuclear Materials \\
\hline INEL & Idaho National Engineering Laboratory \\
\hline IPP & Integrated Program Plan \\
\hline ISMP & Integrated Stabilization Management Plan \\
\hline IWG & Integration Working Group \\
\hline $\mathrm{kg}$ & Kilograms \\
\hline LANL & Los Alamos National Laboratory \\
\hline LEU & Low Enriched Uranium \\
\hline LLNL & Lawrence Livermore National Laboratory \\
\hline $\mathrm{MD}$ & Office of Material Disposition \\
\hline $\mathrm{MgO}$ & Magnesium oxide \\
\hline $\mathrm{MIP}$ & Material Integration Plan \\
\hline MOA & Memorandum of Agreement \\
\hline MPC & Multi-purpose Canisters \\
\hline MPPF & Multi-Purpose Processing Facility \\
\hline MSRE & Molten Salt Reactor Experiment (at Oak Ridge) \\
\hline MT & Metric Ton \\
\hline MTIHM & Metric Ton of Initial Heavy Metal \\
\hline NASA & National Aeronautics and Space Administration \\
\hline NDA & Non-destructive Analysis (or assay) \\
\hline $\mathrm{NDE}$ & Non-destructive-Evaluation \\
\hline $\mathrm{NE}$ & DOE Office of Nuclear Energy \\
\hline NEPA & National Environmental Policy Act \\
\hline NESHAPS & National Emission Standards for Hazardous Air Pollutants \\
\hline NFS & Nuclear Fuel Services, Inc. \\
\hline NMSF & Nuclear Material Storage Facility \\
\hline NMSTG & Nuclear Materials Stabilization Task Group \\
\hline $\mathrm{Ni}$ & Nickel \\
\hline $\mathrm{Np}$ & Neptunium \\
\hline NPDES & National Pollutant Discharge Elimination System \\
\hline $\mathrm{NRC}$ & Nuclear Regulatory Commission \\
\hline OAK & (DOE) Oakland Operations Office \\
\hline OCRWM & Office of Civilian Radioactive Waste Management \\
\hline ORNL & Oak Ridge National Laboratory \\
\hline ORO & (DOE) Oak Ridge Operations Office \\
\hline
\end{tabular}


ORR

PEIS

PFP

PNL

PO

$\mathrm{Pu}$

PUREX

R\&D

R\&TD

RBOF

RCRA

RFETS

ROD

RWMC

S\&M

SARP

SIPP

SISMP

SNF

SNL

SNM

$\mathrm{Sr}$

SRS

SRTC

SS\&C

SST

STD

TBD

TPA

TREAT

TRU

U

$\mathrm{U}_{3} \mathrm{O}_{8}, \mathrm{UO}_{3}$

$\mathrm{UF}_{6}$

WHC

WIPP

wt \%

ZPPR
Operational Readiness Review

Programmatic Environmental Impact Statement

Plutonium Finishing Plant (at Harford)

Pacific Northwest Laboratory

DOE Policy Office

Plutonium

Plutonium and Uranium Extraction Process

Research and Development

Research and Technology Development

Receiving Basin for Offside Fuels

Resource Conservation and Recovery Act

Rocky Flats Environmental Technology Site

Record of Decision

Radioactive Waste Management Complex

Surveillance and Maintenance

Safety Analysis Report for Packaging

Site Integrated Program Plan

Site Integrated Stabilization Management Plan

Spent Nuclear Fuel

Sandia National Laboratories

Special Nuclear Material

Strontium

Savannah River Site

Savannah River Technology Center

Sand, Slag, and Crucible

Safe, Secure Transport

Standard

To be determined

Tri-Party Agreement

Transient Reactor Test facility (at Idaho)

Transuranic

Uranium

Uranium Oxide

Uranium Hexaflouride

Westinghouse Hanford Company

Waste Isolation Pilot Plant

Weight percent

Zero Power Physics Reactor 


\section{APPENDIX B}

\section{GLOSSARY}

Actinide - Any element in a series of elements of increasing atomic numbers beginning with actinium (89) or thorium (90) and ending with element of atomic number 103.

Canning - The process of placing spent nuclear fuel in canisters to retard corrosion, contain radioactive releases, or control geometry.

Covered materials - Bulk liquids and solids containing fissile materials and other radioactive substances in spent fuel storage pools, reactor basins, reprocessing canyons, processing lines and various other facilities which require treatment for conversion to forms or conditions more suitable for safe interim storage. Wastes in a recognized treatment system and lowlevel wastes, most uranium and uranium compounds and weapons usable plutonium already suitable for safe interim storage are not included.

End State: The goal for packaged physical form of a nuclear material at the conclusion of the stabilization project.

Facility condition vulnerabilities - Potential for failures of physical barriers such as equipment, buildings, or safety systems; and holdup of plutonium in a facility.

Gloveboxes - Filtered and ventilated enclosures that allow handling of hazardous materials without direct worker contact with the material.

Institutional vulnerabilities - An administrative or management weaknesses that are underlying causes or significant contributors to material/packaging and facility condition vulnerabilities.

Interim storage - Acquisition, management, and operatation of storage facilities in compliance with approved safety basis pending preparation for final disposition. Long-term interim storage could last for up to 40 years.

Material/packaging vulnerabilities - Potential for releases related to design deficiencies and degradation of materials and packaging due to corrosion, radiolytic damage, or changes in material form.

Passivation - The process of making metals inactive or less reactive. For example, to passivate the surface of steel by chemical treatment.

Processing - Changing the chemical or physical characteristics of nuclear material and/or their packaging configurations.

Processing (of spent nuclear fuel) - Applying a chemical or physical process designed to alter the characteristic of the spent nuclear fuel matrix. 
Proximity to Plastic - Where direct communication between the plutonium and the plastic is possible.

Pynophoric - The capability for spontaneous ignition in air at or below room temperature in the absence of added heat, shock, or friction.

Radiolysis - Chemical decomposition by the action of radiation.

Residues - Scrap and compounds generated in the processing, fabrication, or recycling of nuclear materials (particularly plutonium).

Safe interim storage - A safe, controlled, inspectable storage under conditions where minimum surveillance and maintenance is required for the period (potentially decades) prior to ultimate long-term storage and/or disposition. This is the "end state" for purposes of the Integrated Program Plan.

Skulls - Low-density residues from plutonium metal casting operations that have a high surface area, making them pyrophoric.

Spent nuclear fuel - Fuel or targets containing uranium, plutonium, or thorium withdrawn from a nuclear reactor or other neutron irradiation facility following irradiation, the constituent elements of which have not been separated by chemical reprocessing.

Stabilization (of spent nuclear fuel) - Actions taken to further confine or reduce the hazards associated with spent nuclear fuel, as necessary for safe management and environmentally responsible storage for extended periods of time. Activities which may be necessary to stabilize spent nuclear fuel include canning, processing, and passivation.

Task Group - The Nuclear Materials Stabilization Task Group responsible for ensuring the Department achieves commitments detailed in Implementation Plan.

Thermal stabilization - A process of converting potentially reactive plutonium into a stable form which is more safe for storage and transportation.

Transuranic materials - Elements having atomic numbers greater than that of uranium.

Uranium or Plutonium solutions - Processed to oxide or metal; or processed and solidified. If plutonium oxide or metal, end state to be in accordance with requirements of the DOE plutonium storage standard. If uranium, stored in accordance with DOE requirements or National Consensus Standards, and dispositioned as, e.g., low enriched uranium.

Working Group - the Plutonium Working Group, made up of over 150 DOE staff, site contractors, consultants, and stakeholders, who planned and directed the plutonium vulnerability assessment. 